\title{
AGE-INCLUSIVE CITY \\ Reconsidering Toronto's neighbourhoods for an aging population
}

by

Deanna Coates

A thesis submitted to the Faculty of Graduate and Postdoctoral Affairs

in partial fulfillment of the requirements for the degree of

Master of Architecture

Carleton University

Ottawa, Ontario

(C) 2021

Deanna Coates 


\section{AGE-INCLUSIVE CITY}

Reconsidering Toronto's neighbourhoods for an aging population
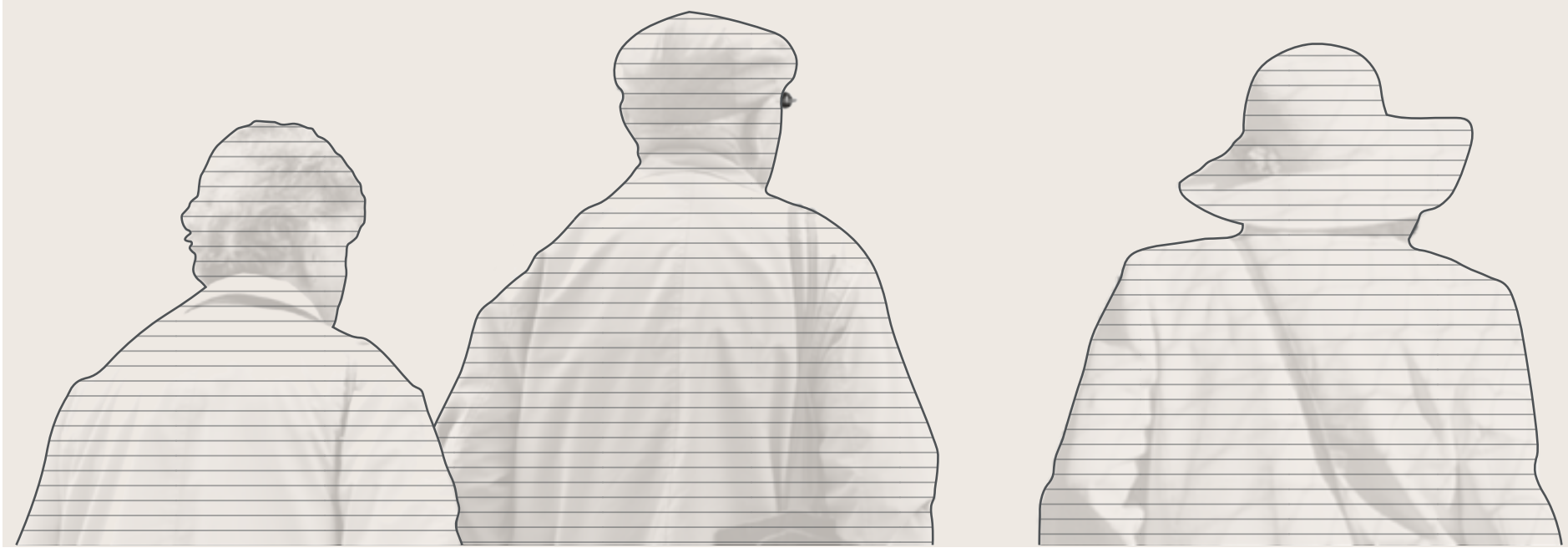
"The measure of a society can often be taken by the fate of its elderly." Dr. Francine Ducharme, Université de Montréal 


\section{Abstract}

Sites of eldercare and seniors housing can often be identified as places of age segregation and isolation for their lack of integration with their surrounding context and society. These sites take two primary forms on opposing ends of the spectrum: institutional settings and 'aging in place,' neither of which are adequate solutions for an aging population. Today, the increasingly imbalanced population of seniors to youth is making alternative living arrangements increasingly important.

Seniors are valuable members of society, contributing to both their families and communities, however, their needs are both under-acknowledged and under-represented in urban spaces. The response to this has resulted in several population-based and placebased strategies to enrich communities at the scale of the dwelling and the neighbourhood. This thesis engages with these strategies and their role to foster age-inclusive communities - to engage the spectrum in between institutional settings and 'aging in place' in the context of Toronto's existing neighbourhoods. 


\section{Acknowledgments}

To my advisor, Federica Goffi - thank you for your support and kindness throughout this process. Your guidance and feedback has been invaluable, and it was a pleasure to be your student.

To my peers and all the friends made along the way, especially to Jake Nogy - you are an inspiration, and I am grateful to have gone through architecture school with you.

To my family, especially my parents - thank you for your endless support and encouragement, and for always making me smile when I needed it most. I could not have done this without you. 


\section{Table of Contents}

Abstract 4

Acknowledgments $\quad 5$

Table of Contents 6

$\begin{array}{ll}\text { List of Figures } & 7\end{array}$

$\begin{array}{ll}\text { Preamble } & 10\end{array}$

Introduction 11

$\begin{array}{lll}\text { Chapter One } & \text { Seniors and Cities } & 16\end{array}$

Urban Sprawl 17

Aging and Urbanization 18

Investing in Seniors 19

$\begin{array}{lll}\text { Chapter Two } & \text { Present-day Toronto }\end{array}$

Approaching 2030 and Beyond 24

Existing Seniors' Living Conditions 29

Idealizing 'Aging in Place' 38

Chapter Three $\quad$ Planning for Improvement 44

Strategies and Guidelines $\quad 45$

Neighbourhood Improvement Areas 54

Innovations in Seniors Living $\quad 58$

$\begin{array}{lll}\text { Chapter Four } \quad \text { Design Proposal } & 77\end{array}$

The Focus Area $\quad 79$

The Age-Inclusive Neighbourhood 86

Towards an Age-Inclusive City 110

$\begin{array}{ll}\text { Conclusion } & 111\end{array}$

Bibliography 114

$\begin{array}{ll}\text { Figures } & 120\end{array}$

Appendices 124 


\section{List of Figures}

Fig. 01 Average Assets, Debts and Net Worth 20

Fig. 02 Average Income and Expenses 20

Fig. 03 Average Community Contributions 20

Fig. 04 Toronto, Ontario - Location Map. 21

Fig. 05 Sites of long-term care in Toronto, Ontario. 25

Fig. 06 COVID-19 Impact: Most affected neighbourhoods in Toronto, 26 Ontario

Fig. 07 Moving from the single-family home to an institutionalized setting.

Fig. 08 Seven Oaks Long-Term Care Home, Toronto, Ontario. 30

Fig. 09 The Village of Humber Heights, Toronto, Ontario. 31

Fig. 10 Hellenic Home for the Aged, Toronto, Ontario. 32

Fig. 11 Long-term Care vs. Retirement Homes vs. Home Care. 41

Fig. 12 Determinants of Active Aging. 46

Fig. 13 A compilation of the guidelines and recommendations from the 53 Toronto Seniors Strategy 2.0, the Global Age-Friendly Cities: A Guide.

Fig. 14 Neighbourhood Improvement Areas (NIAs), Toronto, Ontario. 55

Fig. 15 Aerial image of Victoria Village, Toronto, Ontario. 57

Fig. 16 A spectrum of seniors' living arrangements and innovations 59 across the neighbourhood and dwelling scale. 1/2.

Fig. 17 A spectrum of seniors' living arrangements and innovations $\quad 60$ across the neighbourhood and dwelling scale. $2 / 2$

Fig. 18 Site plan of The Alcabideche Social Complex. 68

Fig. 19 Ground floor plan of De Hogeweyk in Weesp, Netherlands 70

Fig. 20 A collection of images of The Villages, Florida. 75

Fig. 21 Golf cart infrastructure in The Villages, Florida. 76 
Fig. 22 Design Proposal: Focus Area, and Victoria Village surrounding 78 context. Figure ground diagram.

Fig. 23 Design Proposal: Focus Area (as highlighted in Figure 23).

Fig. 24 Existing conditions, Victoria Village, Toronto, Ontario.

Fig. 25 Existing conditions, Victoria Village, Toronto, Ontario.

Fig. 26 Existing conditions, Victoria Village, Toronto, Ontario.

Fig. 27 Existing conditions, Victoria Village, Toronto, Ontario.

Fig. 28 Existing conditions, Victoria Village, Toronto, Ontario.

Fig. 29 Existing conditions, Victoria Village, Toronto, Ontario.

Fig. 30 Existing conditions, Victoria Village, Toronto, Ontario.

Fig. 31 Existing conditions, Victoria Village, Toronto, Ontario.

Fig. 32 Existing conditions, Victoria Village, Toronto, Ontario.

Fig. 33 Existing conditions, Victoria Village, Toronto, Ontario.

Fig. 34 Location map of 104-110 Bartley Drive. Excerpt from 104-110

Bartley Drive - Zoning By-law Amendment Application - Final Report.

Fig. 35 Final site plan of 104-110 Bartley Drive. Excerpt from 104-110

Bartley Drive - Zoning By-law Amendment Application - Final Report.

Fig. 36 Part 1: The Housing Site - Site Plan.

Fig. 37 Final site plan of 104-110 Bartley Drive. Excerpt from 104-110 Bartley Drive - Zoning By-law Amendment Application - Final Report.

Fig. 38 Part 1: The Housing Site - Site Plan.

Fig. 39 Final site plan of 104-110 Bartley Drive. Excerpt from 104-110 Bartley Drive - Zoning By-law Amendment Application - Final Report.

Fig. 40 Part 1: The Housing Site.

Fig. 41 Part 1: The Housing Site. 
Fig. 42 Part 1: The Housing Site. 96

Fig. 43 Part 1: The Housing Site. 97

Fig. 44 Part 1: The Housing Site: Key components and their relation to 98 key recommendations from the Toronto Seniors Strategy 2.0.

Fig. 45 Part 1: The Housing Site. Cutaway view. 99

Fig. 46 Part 1: The Housing Site. Key floor plans. 100

Fig. 47 Part 1: The Housing Site. Key floor plans. 100

Fig. 48 Part 1: The Housing Site. Key floor plans. 100

Fig. 49 Part 1: The Housing Site. 3D view between townhouse block 101 (T) and serviced housing $(\mathrm{SH})$

Fig. 50 Part 1: The Housing Site. 3D view between serviced housing 102 $(\mathrm{SH})$ and "downsizer" homes (DH).

Fig. 51 Design Proposal: Focus Area. Part 2: Neighbourhood Connectivity.

Fig. 52 Part 2: Neighbourhood Connectivity - Defined neighbourhood routes.

Fig. 53 Part 2: Neighbourhood Connectivity. 3D view of defined neighbourhood route.

Fig. 54 Part 2: Neighbourhood Connectivity. 3D view of defined neighbourhood route.

Fig. 55 A compilation of the guidelines and recommendations from the Toronto Seniors Strategy 2.0, and the Global Age-Friendly Cities: A Guide, and how The Age-Inclusive Neighbourhood Model performed.

Fig. 56 Toward an Age-Inclusive City: applying The Age-Inclusive Neighbourhood Model to neighbourhoods across Toronto.

Fig. 57 Toward an Age-Inclusive City: applying The Age-Inclusive Neighbourhood Model to neighbourhoods across Toronto. 


\section{Preamble}

In 2018, I pursued a design studio regarding designing healthy places, and focused specifically on 'housing for aging' and the search for alternative living arrangements. Now, in 2021, faced with the reality of a global pandemic, the concern surrounding housing for our senior citizens has become even more glaring.

When Ontario entered a quarantine state in March of 2020, our front-line workers, like many around the world, risked their own lives to show up and care for those most in need. This cohort of modern-day heroes is especially not exclusive of the staff of our long-term

1 Canadian Institute for Health Information. Pandemic Experience in the Long-Term Care Sector: How Does Canada Compare With Other Countries? (2020): 1 care homes. As of May 2020, over 80\% of COVID-19 related deaths in Canada were linked to long-term care facilities and retirement homes, ${ }^{1}$ and senior citizens were placed under especially isolating circumstances to mitigate their vulnerability.

This unprecedented time took the world by storm, disrupting our way of life. This thesis seeks to engage with the disruption of the old "normal" in search of a new normal that is inclusive of our senior citizens. 
2 Alice Bucknell, "Aging in Place: For America's Older Adults, Access to Housing Is a Question of Race and Class." Harvard Graduate School of Design. October 24, 2019. https://www.gsd.harvard. edu/2019/10/aging-in-placefor-americas-older-adults-access-to-hous-ing-is-a-questionof-race-and-class/. (accessed March 21, 2021)

3 Janice M. Blanchard, "Aging in Community: The Communitarian Alternative to Aging in Place, Alone," Generations 37 No. 4 (2013).

4 Federation of Canadian Municipalities. Seniors and Housing: The Challenge Ahead. (2015): 12.
With an increasing senior population, the demand for new seniors housing is growing faster than the supply and in the next decade, as Alice Bucknell of Harvard University's Graduate School of Design affirms, "caring for our aging population will be a formidable challenge.”2 By $\mathbf{2 0 3 0}$, upwards of 80 million baby boomers will have turned 65 , with more than $85 \%$ facing living conditions that do not support their needs. ${ }^{3}$ Not only does this crisis raise concern regarding access to safe and secure housing, but concern of loneliness and mental health. As many individuals may face inadequate housing situations and circumstances, seniors housing will be encouraged to take on alternative arrangements.

As the aging population continues to grow, and as the life expectancy of Canadians continues to increase, there is a strong desire among seniors to age in place. Contrary to popular belief, this concept is not restricted to one's residence, but includes moving to "suitable housing within the same community or region or some alternative to a long-term care facility." ${ }^{4}$ However, there are several barriers in place that restrict seniors from safely doing so. Over the past three decades, significant gaps have occurred in the areas of social housing, 
Introduction

5 Federation of Canadian Municipalities. Seniors and Housing: The Challenge Ahead. (2015): 11.

6 Janice M. Blanchard and William H. Thomas, "Moving Beyond Place: Aging in Com munity," Generations 33, No. 2 (2009).

7 Charles Shafaieh, "A radical transformation in building and designing for health is underway - but not everyone will benefit equally." Harvard Graduate School of Design. April 27, 2020. https://www. gsd. harvard.edu/2020/04/ the-pandemic-may-instigate-a-radical-transfor- mationin-building-and-designing-forhealth-but-not-everyone-willbenefit-equally/. (accessed March 21, 2021)
8 City of Toronto. Toronto Seniors Strategy 2.0, 2018: 9 . supportive services, and home care. ${ }^{5}$ The lack of public sector investment in these areas has made it increasingly difficult to access these services in an affordable way if at all. In the absence of affordable systems, many seniors rely on support from friends, family, and even neighbours. Under such circumstances, many seniors face the reality of entering care facilities due to support shortages rather than medical needs. It is at this juncture that William H. Thomas, geriatrician, and Janice M. Blanchard, gerontologist, raise the discussion about a 'Third Way': a means of living that does not result in an institutional setting or an over-idealized vision of aging in place. ${ }^{6}$

In discussing design for health, Charles Shafaieh of Harvard University's Graduate School of Design illuminates that the contemporary focus on "invisible solutions with inherent surveillance qualities $[. .$.$] may limit the healthier, more visible changes that should$ be made to improve the qualities of both our interior and exterior environments, particularly those occupied by the most marginalized and oppressed communities."7 Now during a time of a global pandemic, the inadequacies of our built environment have only become increasingly apparent not only in our healthcare system and care homes, but communities and cities at large. As with many healthcare environments, the built environment presents the opportunity for reformation and adaptation to become truly humanized, inclusive space.

Large cities account for a substantial number of senior residents, and as the most populous metropolitan area in Canada (2019 Census), Toronto is no exception with the senior population projected to increase to $21.2 \%$ by $2041 .{ }^{8}$ According to the World Health 
Introduction

9 World Health Organization, Global Age-Friendly Cities Project (2020)
10 City of Toronto. Toronto Seniors Strategy 2.0, 2018: 4
Organization, making cities age-friendly is one of the "most effective policy approaches" for responding to this increasing demographic. ${ }^{9}$ The Global Age-Friendly Cities Project, a policy framework released by the World Health Organization (WHO), seeks to encourage "active-aging" - that is, to enable seniors to participate fully, and safely in society for as long as possible. Unfortunately, the current living arrangements and their physical placements in cities such as Toronto, often work against the intent of this framework. Toronto's urban fabric has situated seniors housing facilities as heterotopic places, often separated and isolated from existing services. A question is thus presented:

How can Canadian cities, such as Toronto, truly integrate housing for seniors in a safe way without living separate from society?

To begin to answer this question, this thesis goes beyond the scale of the individual building to reveal how the composition of a neighbourhood impacts the ability to support seniors. Between international policy frameworks such as the Global Age-Friendly Cities Project by the WHO, and more localized frameworks such as the Toronto Seniors Strategy 2.0 (TSS 2.0), and Toronto Strong Neighbourhoods Strategy 2020 (TSNS 2020), there are several principles and priorities enacted to enrich neighbourhoods, and to provide collective services, but few are radical enough to promote a visible and impactful change. The Toronto Seniors Strategy 2.0 asks: "What does an age-friendly city look like against the backdrop of a fast-moving, growing, and technologically-charged metropolis?" 10 This thesis en- 

encourage inclusivity in current and future neighbourhood design.

As a further means of guidance, this thesis engages with a variety of precedents and innovations across the neighbourhood and dwelling scale. In contrast to more conventional arrangements such as long-term care facilities, retirement homes, and home care, innovations to enrich neighbourhoods are fostering a sense of community through engaging seniors with not only each other, but other generations, as well as their greater surrounding context. Toronto is a city of 140 neighbourhoods, including several suburban neighbourhoods established with the rise of the automobile and urban sprawl. Much of neighbourhood developments and redevelopments are driven by socio-economic factors and gentrification, and today, Canada is seeing trends toward urbanization and an aging population in its cities. The 'Age-Inclusive Neighbourhood Model' proposed in Chapter 4, is a response to these trends and the associated concerns as they relate to senior residents. 


\section{CHAPTER ONE}

\section{Seniors and Cities}

1.1 Urban Sprawl

1.2 Aging and Urbanization

1.3 Investing in Seniors 
At first, cities may not seem like the most suitable environments for seniors to live in, especially in comparison to more idealized rural settings, suburbs, and small towns. Cities are often thought of as busy and expensive concrete jungles with little green space, while rural settings are idealized for their charm and peaceful lifestyle. Now in 2021, the COVID-19 pandemic has only intensified this narrative with many city dwellers relocating to more rural settings, driven by shifting lifestyles and capabilities such as working from home. However, there is still an argument to be made for cities, especially for our seniors. While the COVID-19 pandemic has forced the effects of isolation upon many with confinement to our homes and restricted movement beyond certain boundaries, this was already the experience for many seniors, having only been heightened by the pandemic's existence. Even in a pre-pandemic world, many seniors faced a level of confinement due to reduced mobility and an inability to drive. This reality of the COVID-19 pandemic has now re-sparked conversations around the concept of the "15-minute city": a concept in urban design that aims to place everything a resident may need within fifteen minutes of travel by foot or bicycle. 
11 Statistics Canada. 2019. Population growth in Canada's urban areas fuelled by permanent and temporary immigration. The Daily. Ottawa. Version updated: March 2019. Ottawa. https://www150.statcan.gc.ca/ n1/daily-quotidien/190328/ dq190328b-eng.htm (accessed

March 21, 2021)

12 Alex Bozikovic, Joe Castaldo, and Danielle Webb, "The 15-minute city aims to build more livable neighbourhoods. In Canada, only 23 per cent of urban dwellers live in this type of area," The Globe and Mail, November 23, 2020, https:// www.theglobeandmail.com/ canada/article-when-it-comesto-liveable-neighbourhoodstheres-a-wide-divide-in/. (accessed March 21, 2021).
13 City of Toronto. Toronto Seniors Strategy 2.0, 2018: 8.
With the invention of the automobile, came the consequences of urban sprawl: low-density city planning and auto-dependency. Not only has urban sprawl been linked to increased energy demands, pollution, congestion, and the ongoing climate crisis, but to socio-economic factors including a lack of social support and decreased accessibility. As cities become more spread out, with greater distances between residences and amenities/services, the disconnect between residential and commercial areas becomes increasingly debilitating, especially for those without access to a car. These factors strongly influence the ability for residents, especially seniors, to thrive in their environments. Reversing these consequences of urban sprawl and transforming cities into densely populated, amenity rich areas where a car is not necessary, is in summary the intent of the "15-minute city."

Over the last several decades, Canada has seen significant trends toward urbanization, with a population of 26.5 million living in census metropolitan areas as of 2018. ${ }^{11}$ However, as census data shows today: "[O]nly 23.2 per cent of urban dwellers live in [amenity-rich neighbourhoods]. This suggests that creating a country of 15-minute cities will be challenging: it would likely mean bringing even more people into central Vancouver and Toronto and parts of Montreal and making changes to the suburbs." ${ }^{12}$ Today's world however, faces a secondary trend of a growing population, specifically of an aging population that as of the 2016 Census, outnumbered children under 15 in Toronto for the first time, posing "significant, long-term implications for the City."13 Of particular concern, is that 
Chapter One

14 Alex Bozikovic, "Yes, in my backyard: How urban planning must shift to meet our postpandemic challenges," The Globe and Mail, March 6, 2021 https://www.theglobeandmail. com/opinion/article-yes-inmy-backyard-how-urban-planning-must-shift-to-meet-our/. (accessed March 21, 2021).
15 Alex Bozikovic, Joe Castaldo, and Danielle Webb, "The 15-minute city aims to build more livable neighbourhoods In Canada, only 23 per cent of urban dwellers live in this type of area," The Globe and Mail, November 23, 2020, https:// www.theglobeandmail.com/ canada/article-when-it-comesto-liveable-neighbourhoodstheres-a-wide-divide-in/. (accessed March 21, 2021). as the demand for eldercare continues to increase, service providers will be faced with added pressures to keep up.

\subsection{Aging and Urbanization}

Alex Bozikovic, architecture critic at The Globe and Mail, argues: "Cities are places of opportunity and cohesion, and people want to live there. Yet our city planning, and urban politics make this far too difficult. The COVID-19 pandemic is the moment to change that." ${ }^{14}$ COVID-19 shed a light on the inadequacies of our built environment, and how our systems have especially failed our senior residents, low-income neighbourhoods, and racialized areas, with a particular link to areas considered as non-amenity dense. While Toronto's downtown areas and urban centres are considerably amenity-dense, neighbourhoods toward the edges of the city are not. These are the same areas of the city that lack adequate access to affordable housing and residents who are less likely to own vehicles, thus further contributing to a sense of isolation and exclusion within the city. Today, Toronto is considered a "divided city" with $55.8 \%$ of its population living in amenity-dense neighbourhoods, compared to Vancouver's $72.4 \%$ : the "poster child for regeneration" where the concept of the 15 -minute city has been discussed for decades. ${ }^{15}$

In comparison to rural settings, cities offer access - access to amenities, public transportation, and health services - services that are especially important to an aging population. Now more than ever, it is imperative to improve accessibility within our cities, especially for the most marginalized of senior residents to thrive. In summary, the benefits of the "15-minute city" parallel the needs of city dwellers, 


\subsection{Investing in Seniors}

16 Canada Mortgage and Housing Corporation, Housing a Senior Population: The Economic and Social Benefits, March 31, 2018, https: www.cmhc-schl.gc.ca/en/ developing-and-renovating/ accessible-adaptable-housing/ aging-in-place/economic-social-benefits-of-seniors-your-community. (accessed March 21, 2021).

18 Statistics Canada. 2020 Survey of Financial Security, 2019. The Daily. Version updated: December 2020. Ottawa. https://www150.statcan.gc.ca/ n1/daily-quotidien/201222/ dq201222b-eng.htm. (accessed March 21, 2021)
19 Canada Mortgage and Housing Corporation, Housing a Senior Population: The Economic and Social Benefits, March 31, 2018, https:/ www.cmhc-schl.gc.ca/en/ developing-and-renovating/ accessible-adaptable-housing/ aging-in-place/economic-social-benefits-of-seniors-your-community. (accessed March 21, 2021).
Seniors are valuable members of society, contributing to both their families and communities in various ways. According to the Canadian Mortgage and Housing Corporation (CMHC), “[b]uilding a population with a diverse age mix is an investment, not a cost." ${ }^{16}$ In short, senior residents are more inclined to invest locally, meaning they support community members and services through spending, working, and volunteering. Data from a Statistics Canada Survey of Financial Security (2012) reflects this ability as senior residents tend to have more assets, less debt, and a greater net worth than the average population. ${ }^{17}$ (See Figures 01, 02 and 03). However, senior residents are now reporting more financial vulnerability in their retirement than in the last two decades (2019), ${ }^{18}$ making the demand for accessible and affordable housing and services even more critical in maintaining older residents in city neighbourhoods especially.

Financials aside, older residents provide a great deal of support to their families and communities through volunteering their time. Younger generations tend to turn toward their parents or other family members for childcare and household support. This not only strengthens a sense of belonging and purpose for older residents, but a sense of relief for younger generations. Ultimately, diverse communities are stronger and more vibrant, ${ }^{19}$ and it is up to urban design to foster environments where residents can coexist and mutually support one another. 


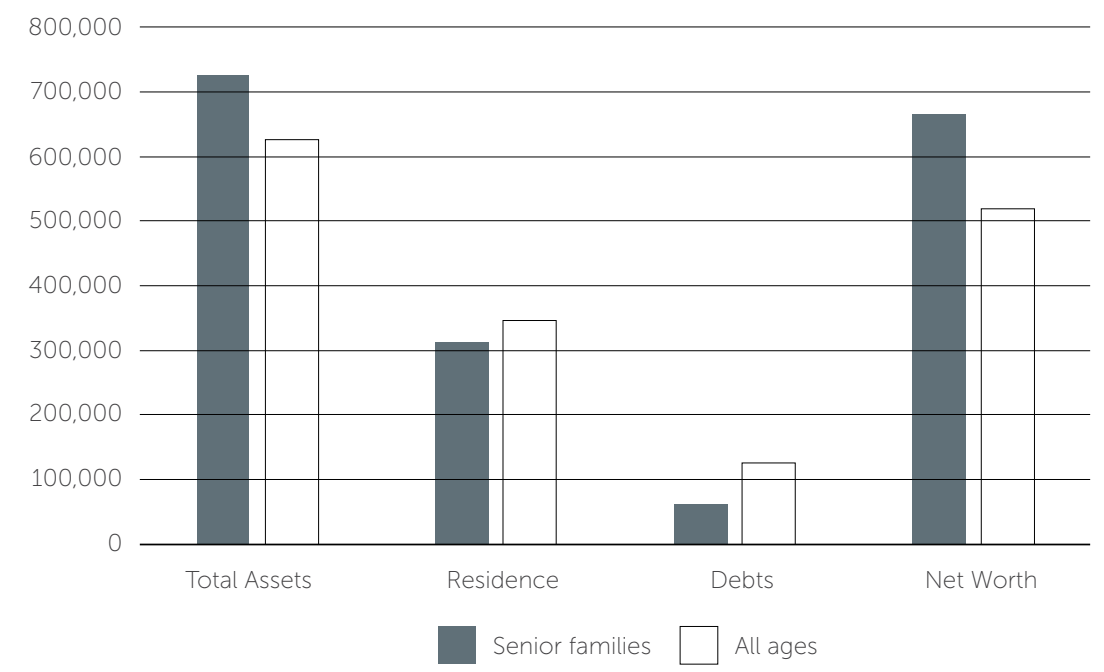

Fig. 01 / Average Assets, Debts and Net Worth

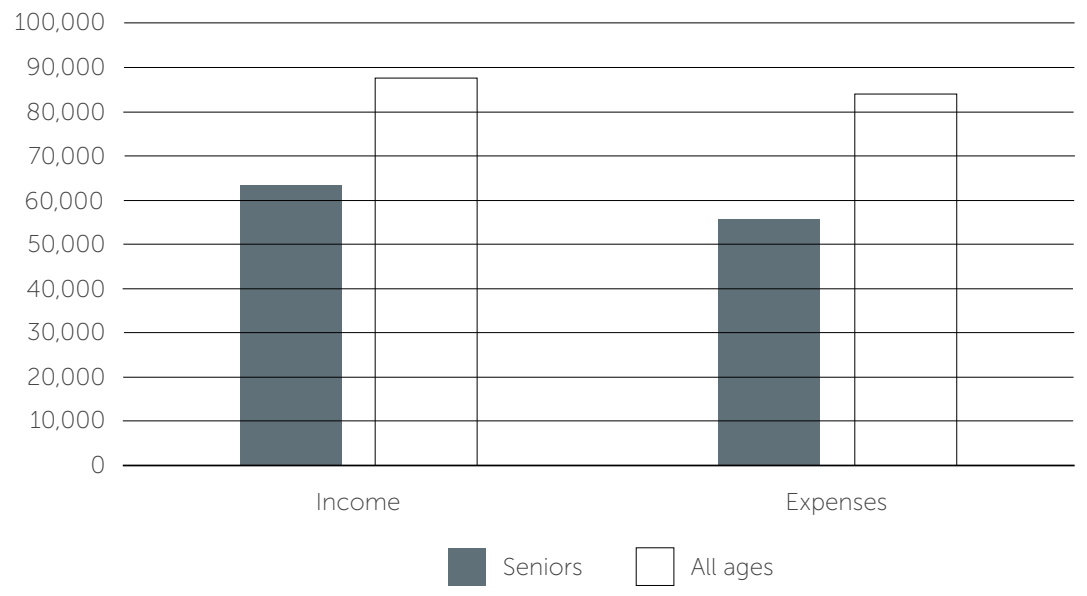

Fig. 02 / Average Income and Expenses

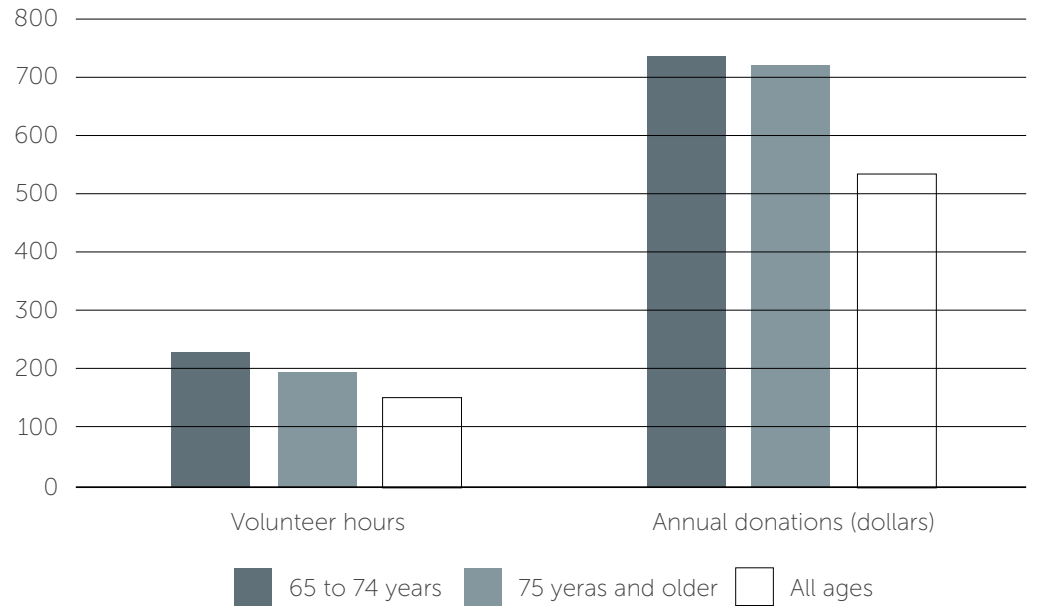

Fig. 03 / Average Community Contributions 


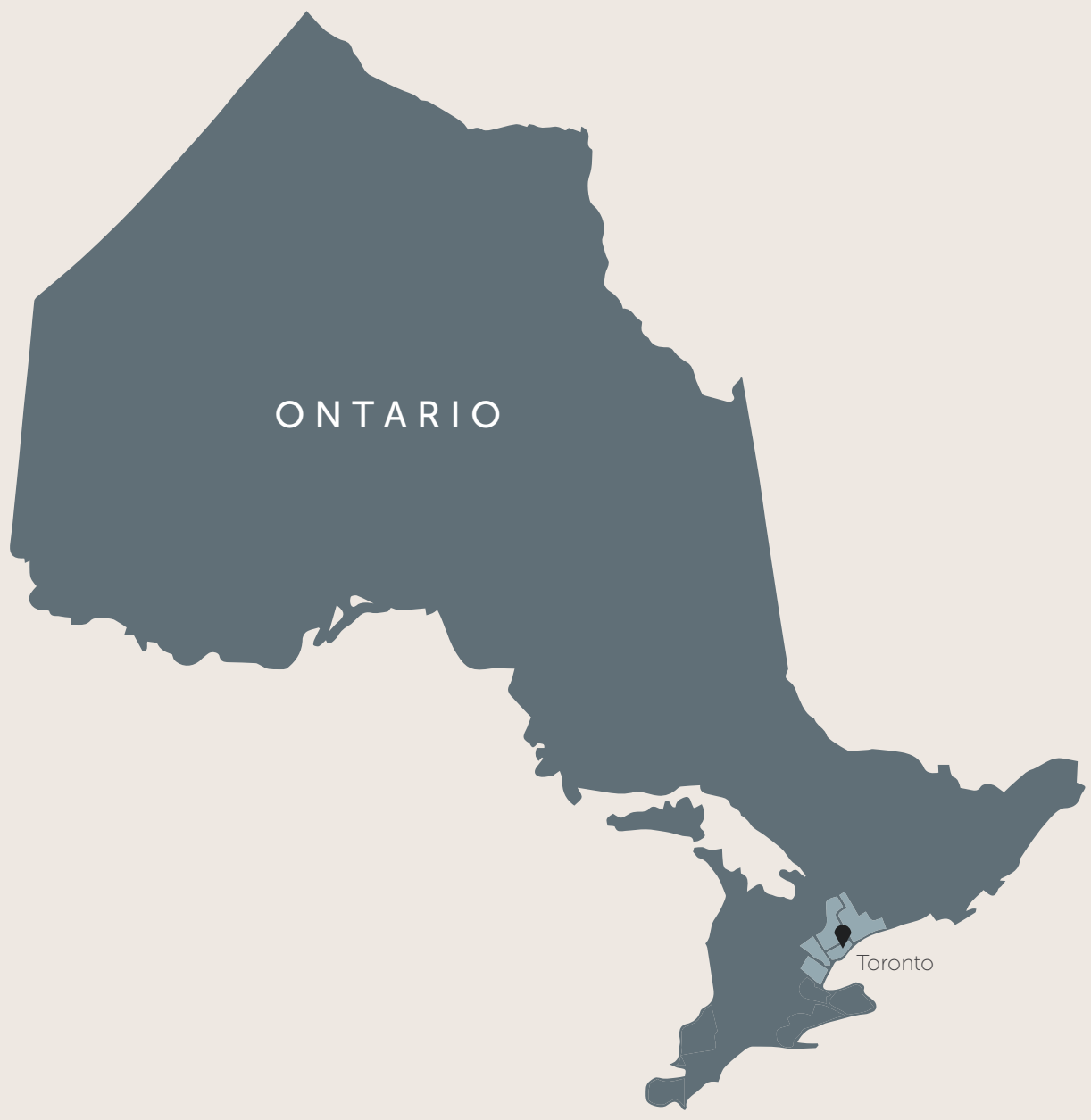




\section{CHAPTER TWO}

\section{Present-day Toronto}

2.1 Approaching 2030 and Beyond

2.2 Existing Seniors' Living Conditions

- Housing as Heterotopia

- Stories of Long-term Care

2.3 Idealizing 'Aging in Place' 
'What is Toronto? In 2017 it is a global city: economically stable, culturally sophisticated, extremely diverse. Yet many Torontonians, new as well as long-established, have trouble explaining the essential qualities of this place. Above all, people will tell you that this is "a city of neighbourhoods." The phrase seems inadequate - doesn't every city have neighbourhoods? And yet it says much about the culture of the place: This is a metropolis that privileges the small, the local, and the domestic, not the agora or the café but the front lawn and the sidewalk. These attitudes are closely linked with the city's physical form: Toronto began as a city of houses, and for most of its powerful and influential people it remains that. A red-brick Victorian house is the city's architectural emblem. But there is another symbol, too: the CN Tower. It is barely 40 years old today, the product of

20 Patricia McHugh and Alex Bozikovic, Toronto Architecture: A City Guide (Toronto: Penguin Random House, 2017), 5 modern technology, a symbol of the city's aspirations toward bigness and primacy. ${ }^{20}$ - Patricia McHugh and Alex Bozikovic 
21 Statistics Canada. 2014. Baby-boomers accelerate Canada's aging population Statistics Canada Catalogue no. 91-215-X. Ottawa. Version updated November 2015. Otta wa. https://www150.statcan.gc $\mathrm{ca} / \mathrm{n} 1 /$ pub/91-215-x/2014000/ part-partie2-eng.htm (accessed March 21, 2021).

22 City of Toronto. Toronto Seniors Strategy 2.0, 2018: 8 .
"The pace of population aging will remain rapid until 2031, when the last baby boomers turn 65."21 - Statistics Canada

Toronto is an eclectic mix of people, culture, religion, opportunity; yet the representation and consideration in design remains relatively biased toward a certain age demographic. It is evident, that Toronto, with its focus on the downtown core and its booming vertical communities, is a city for the youth, or the young professional. However, over the last several decades, there has been a steady increase in Toronto's population aged 65 and above. As of the 2016 Census, this demographic comprised $15.6 \%$ of Toronto's population, or 426,945 people and is expected to almost double by the year $2041 .^{22}$ So where does the senior population live in Toronto? According to data from Statistics Canada, seniors are living in a variety of housing models nearly everywhere in Toronto. (See Figure 05 for long-term care locations). The crisis as we approach 2030, is how to best prepare for this growing demographic - to ensure the equal opportunity for everyone to live a healthy life. This is especially important for those in non-amenity dense neighbourhoods (as discussed in Chapter 1.2), which are simultaneously the neighbourhoods affected most by the COVID-19 pandemic. (See Figure 06). 


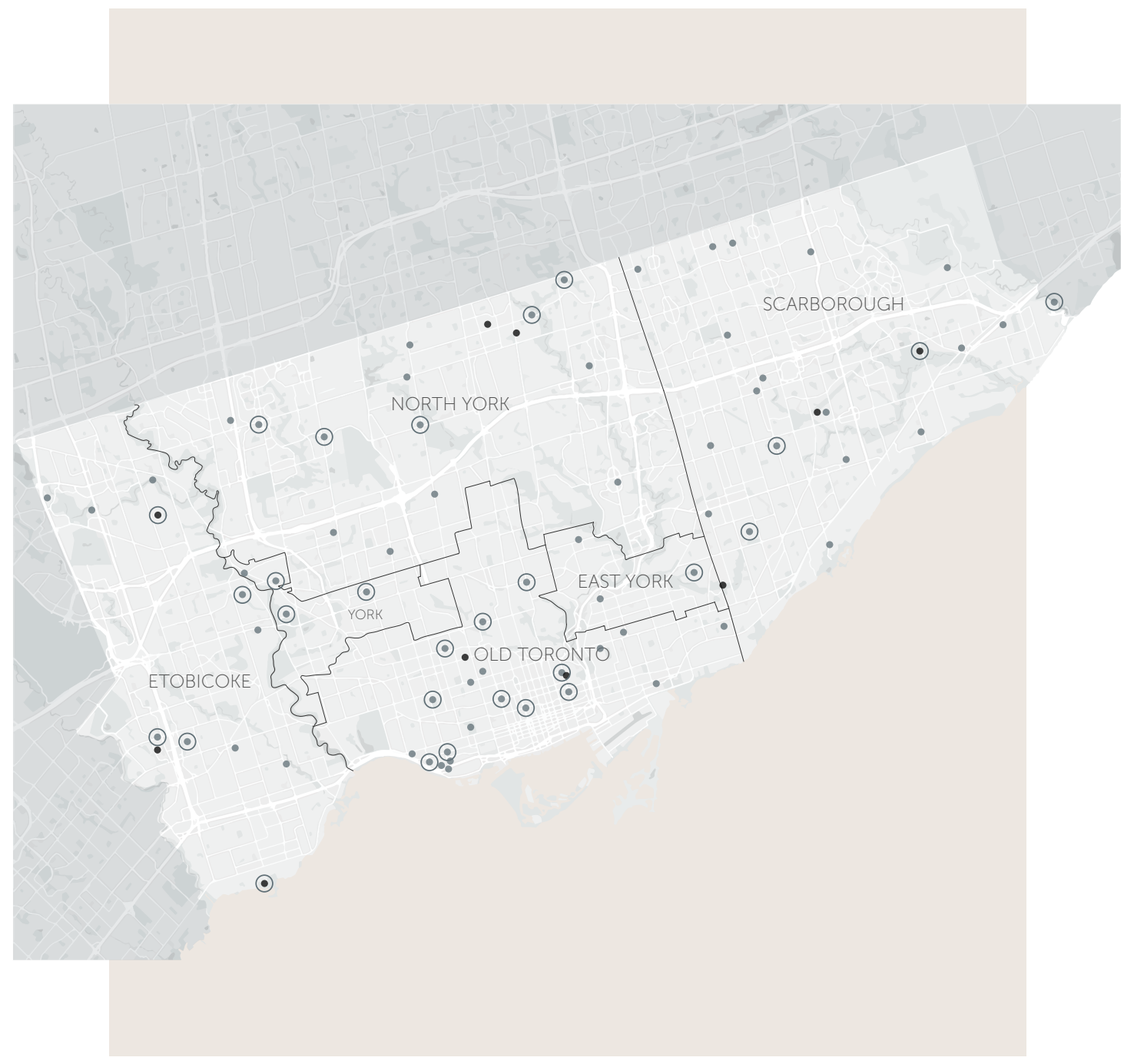

- Long Term Care Homes

- City Operated Long Term Care Homes (10)

- Hardest-Hit by COVID-19 (28) 


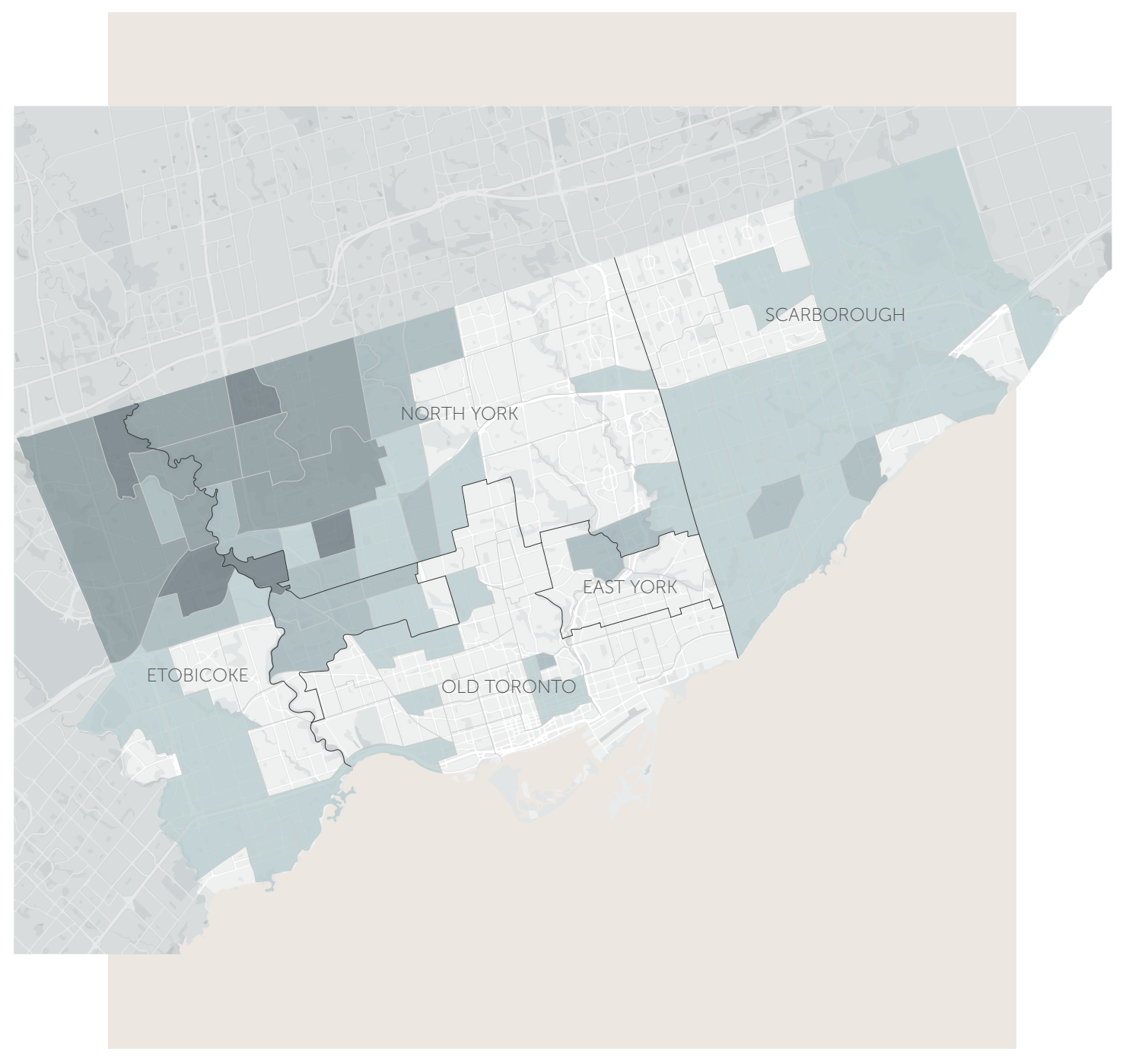

COVID-19 Cases per 100,000

$<203$

203

357

636

$921+$ 
Note / In accordance with Statistics Canada projections, a senior may be considered as anyone over the age of 65. However, in Toronto there is no single accepted definition of a senior: "Programs, services, and initiatives for seniors within the City and other governments have different definitions reflecting different program requirements and target audiences." ${ }^{23}$ For the sake of this thesis, a senior will be defined as anyone aged 65+, unless where otherwise stated, or in accordance with specific data. 


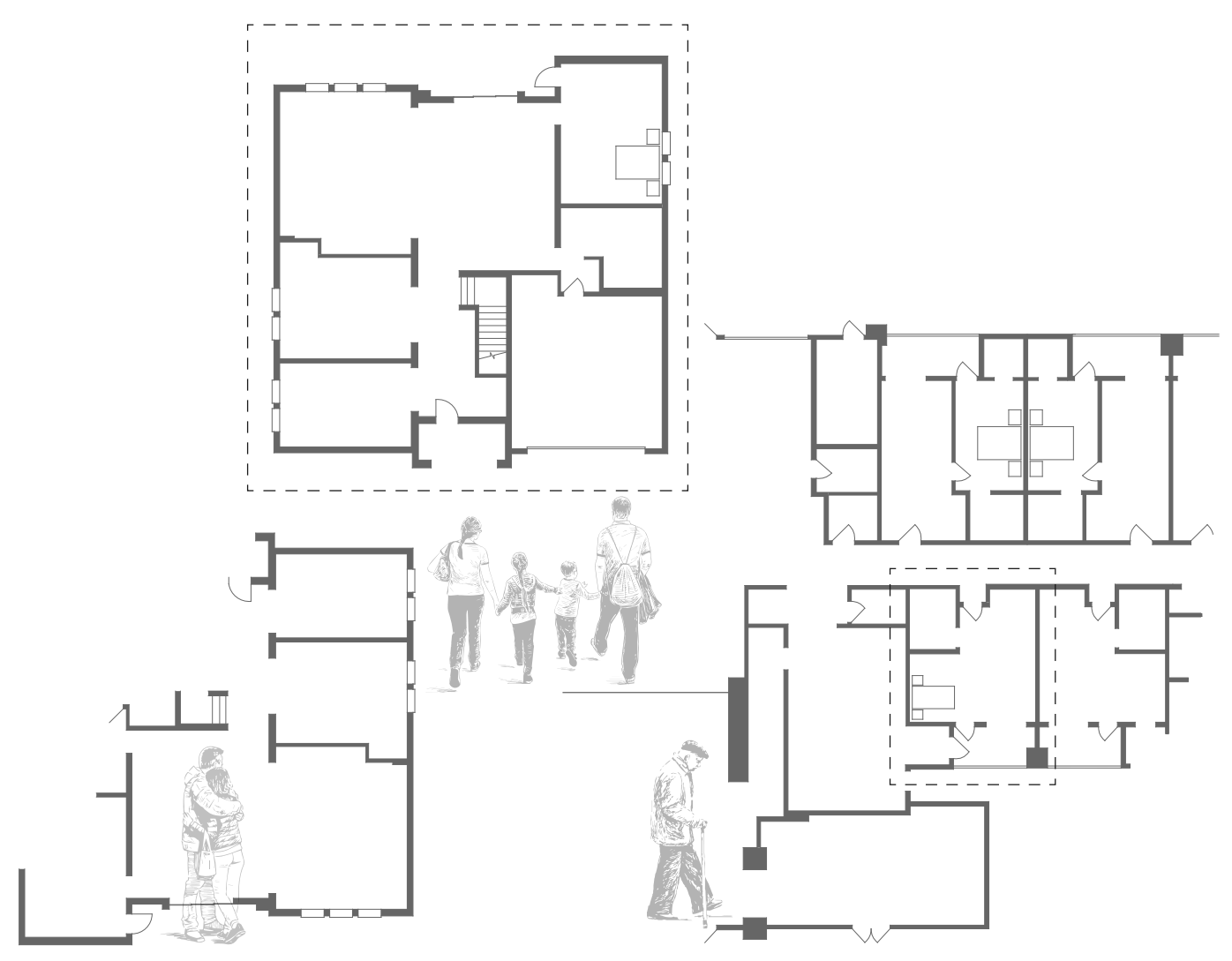


To begin to understand the lives of seniors in Toronto, this thesis seeks to understand the circumstances within which seniors are currently living.

Housing as Heterotopia

24 Michel Foucault and Jay Miskowiec, Of Other Spaces (The Johns Hopkins University Press, 1986), 25
In French philosopher, Michel Foucault's OfOther Spaces (1986), he discusses the concept of heterotopias as places that are somehow 'other.' Existing seniors housing facilities in Toronto can be revealed as such places of otherness; of exclusion from social norms; as heterotopias of deviation: spaces "in which individuals whose behaviour is deviant in relation to the required mean or norm are placed." ${ }^{24}$ As exemplified by Foucault, these may be rest homes, psychiatric hospitals, prisons, and retirement homes. These sites often become 'invisible' places, separated from, and lacking meaningful integration with their surrounding context, or becoming ostracized to the fringes of society altogether.

The following images aim to highlight various institutional settings in Toronto and how they foster a disconnect between seniors and the city at large. (See Figures 08, 09 and 10) 

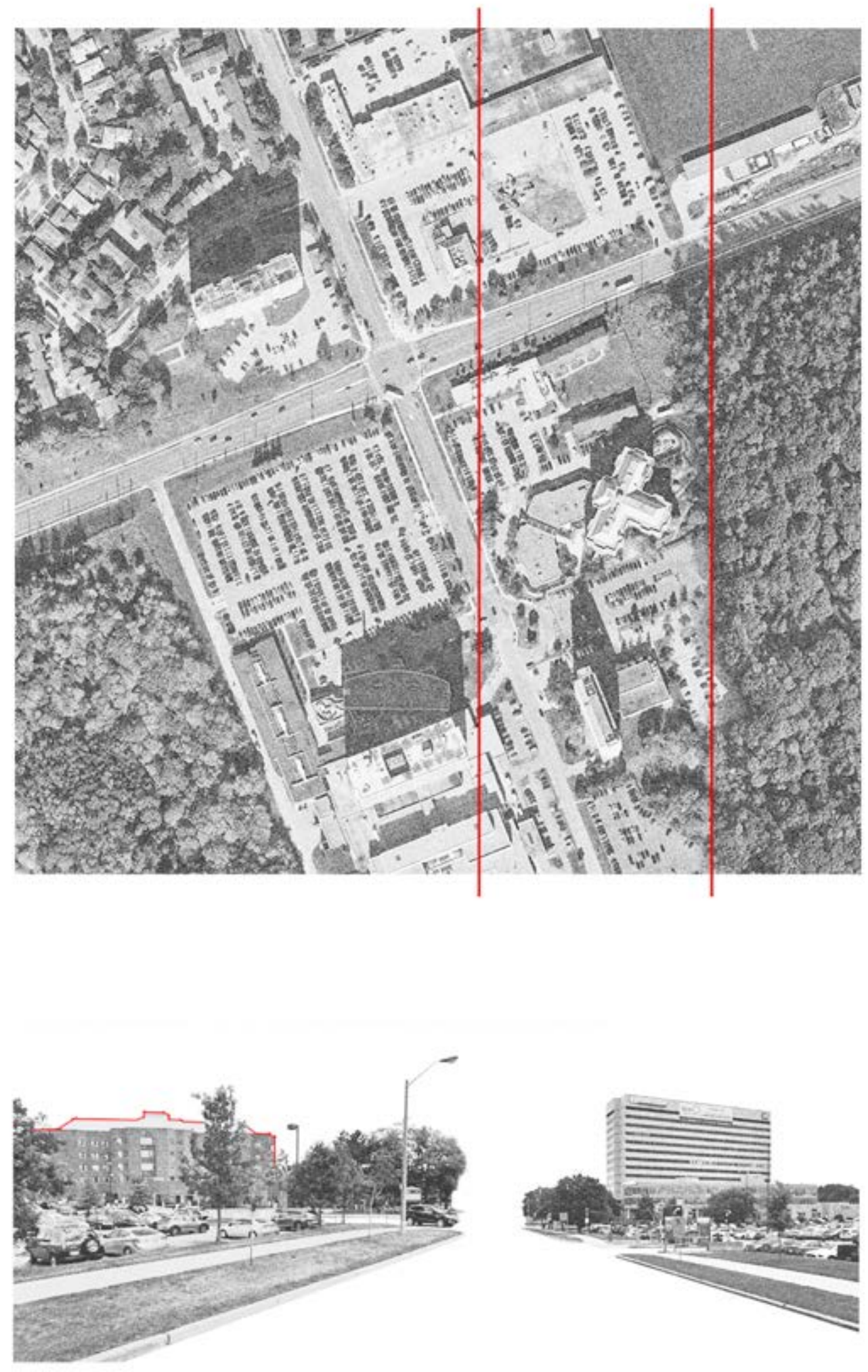

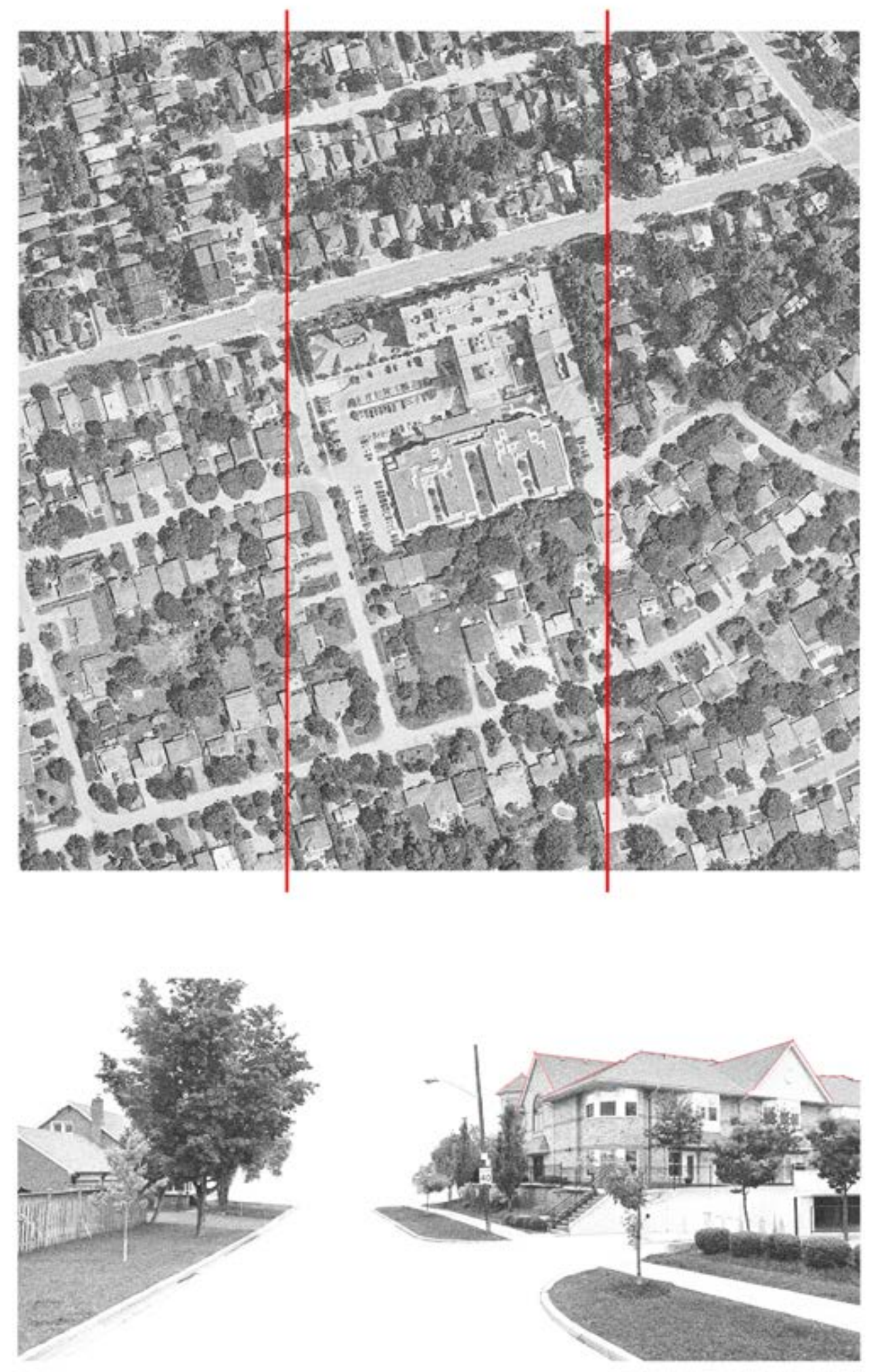

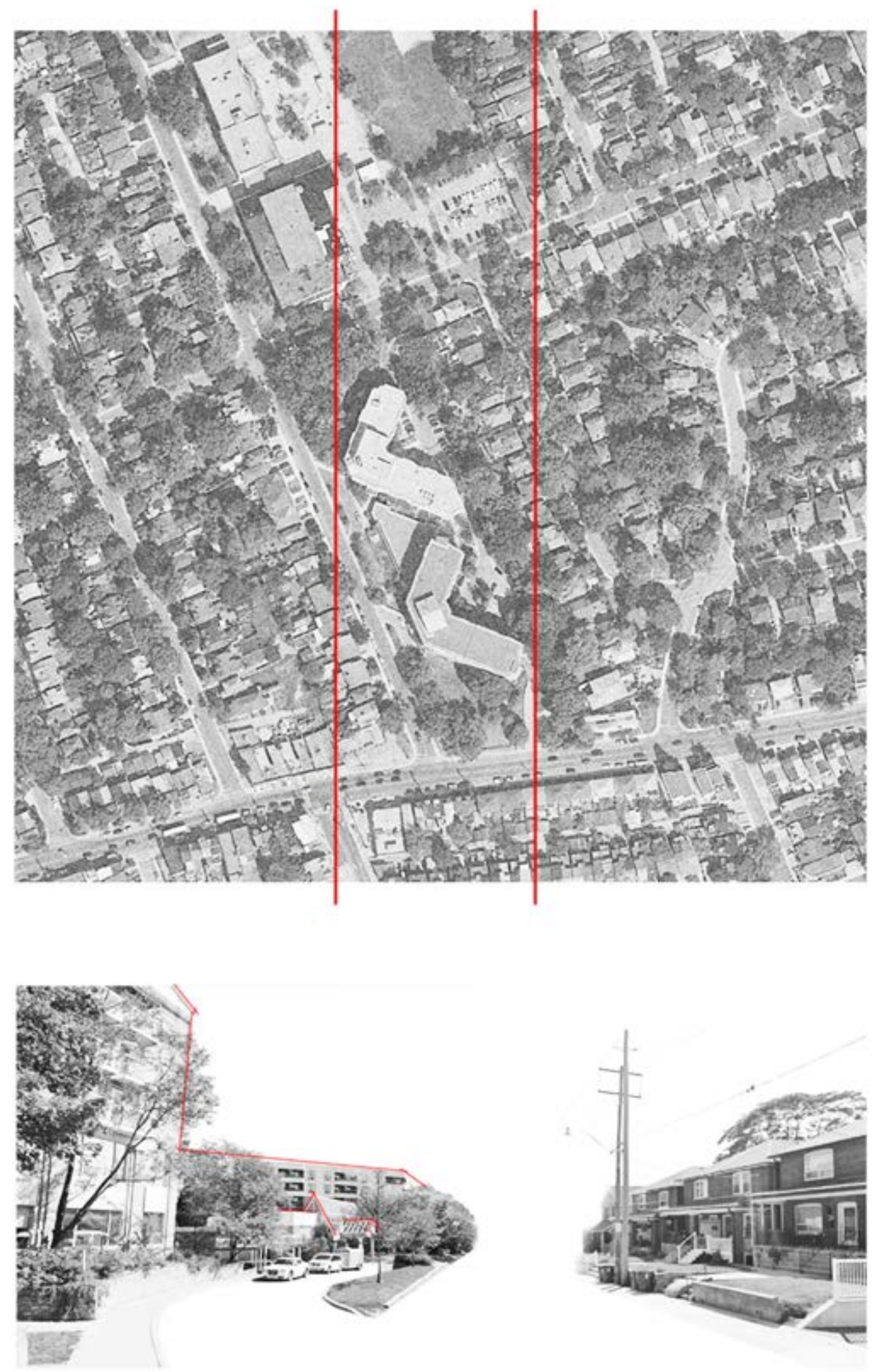
With the increasing transmission of COVID-19, a state of

25 Canadian Institute for Health Information, Pandemic Experience in the Long-Term Care Sector, June

2020, https://www.cihi.ca/ sites/default/files/document/ covid-19-rapid-response-longterm-care-snapshot-en.pdf. (accessed March 21, 2021).

26 Robert Davies, "Pandemic Effect: Long-Term Care Homes," Canadian Architect, August 2020, 22.
According to the Canadian Institute for Health Information, as of May 2020, over 80\% of COVID-19 related deaths in Canada were linked to Ontario's long-term care facilities and retirement homes. ${ }^{25}$ These facilities may be home to some of the country's most vulnerable citizens, however, what is important to note is the role design played - and continues to play - in expediting the virus's impact on residents. While there has been success in controlling the virus in many facilities, there are also many facilities that do not meet the design standards of today. ${ }^{26}$ The reality of multiple residents sharing one room made even the simplest of measures such as social distancing and self-isolating, near impossible. Then, faced with an overwhelmed health care system and a mix of highly vulnerable residents, senior care facilities were forced under extreme measures that meant confining residents to their rooms, with no outside visitors. While these extreme measures were necessary and effective in containing the spread of COVID-19, they highlighted and exacerbated the effects of loneliness that many seniors are already faced with in long-term care, and other institutional facilities.

While these circumstances of COVID-19 further alienated seniors, and ostracized them from society, they brought the issues of long-term care facilities and the like to the forefront of the media. 
Note / The following excerpts from various news articles are intended to highlight the reality of institutional settings and the need for alternative living arrangements. 


\section{ARTICLE 1}

Source: Toronto Life

Article Title: Houses of Horror

Published: November 11, 2020

"Bob lived alone in an apartment on Wellesley Street. Bill and their sister, Susan Hynes, checked in on him several times a week. [...] they moved him to Guildwood, a long-term care facility in Scarborough. It seemed comfortable and clean, and was a convenient 10 -minute drive from their respective homes.

But Guildwood was built in 1967 and in the parlance of longterm care, was a C-bed home. That is, it only met the design standards set out in the 1972 Nursing Homes Act, which permitted smaller ward rooms with up to four residents, making infection control difficult. The one-storey complex housed 159 people, employed 225 staff and was run by Extendicare, a for-profit corporation [...]. Most rooms had two beds and a shared bathroom [...].

In October 2019, Bob moved into a room with one other resident. [...] Things started off relatively well, but after a couple of months, Susan and Bill noticed that Bob's cognition had eroded precipitously. Before he'd moved into the home, Bob could carry on a conversation. ${ }^{27}$ 


\section{ARTICLE 2}

Source: Toronto Sun

Headline: BILD: Canadians look at aging in place

Published: February 05, 2021

"A recent survey conducted by the National Institute on Age-

ing at Toronto's Ryerson University [says] that COVID-19

has more people thinking about aging in place.

The survey of 1,517 Canadians suggests more seniors want

to continue living at home as they age, rather than move to a retirement home or long-term care facility.

Sixty per cent of respondents aged 65 and older said they would try to live safely and independently in their own home as long as possible." 28 


\section{ARTICLE 3}

Source: CBC News

Headline: As COVID-19 exposes long-term care crisis, efforts grow to keep more seniors at home

Published: February 03, 2021

"Lucy Fernandez volunteered in a long-term care home for 20 years.

Although she saw first-hand how much of an effort staff and her fellow volunteers made to keep the residents happy, she also saw many seniors languishing in their rooms.

"While she was still, you know, fairly cognizant, [she] expressed her desire of not wanting to go to a long-term care facility," her daughter, Laura Fernandez, said.

Lucy, now 85, suffers from advanced Alzheimer's disease, with limited ability to speak and move. Because she's one of 850 people in Ontario's High Intensity Supports at Home program, [...] personal support workers come in for several hours a day - in addition to others who work with her on cognitive development $[. .$.

"She is in her own environment, she's happy," Fernandez said.

"Just knowing that I'm there, I know is giving her comfort." That's the level and quality of home care that should be much more widely available to seniors, according to several health policy advocates, including the National Institute on Ageing and the Ontario Community Support Association.

In addition, they say, it would ultimately save governments money by keeping more seniors out of long-term care facilities, which are expensive to build and run." ${ }^{29}$ 
30 Janice M. Blanchard and William H. Thomas, "Moving Beyond Place: Aging in Community," Generations 33, No. 2 (2009).
31 Statistics Canada. 2011. Living arrangements of seniors. Census Program. Ottawa. Version updated July 2018 Ottawa. https://www12

statcan.gc.ca/census-recensement/2011/as-sa/98-312-x/98312-x2011003_4-eng cfm (accessed March 21, 2021).

32 City of Toronto. Toronto Seniors Strategy 2.0, 2018: 13

33 National Institute on Aging, Social Isolation, loneliness in older people pose health risks, April 23, 2019, https:// www.nia.nih.gov/news/ social-isolation-loneliness-older-people-pose-health-risks. (accessed March 21, 2021).
On the opposing end of the spectrum from institutional settings, is the highly sought-after option: aging in one's own home (often referred to as aging in place). As discussed in Moving Beyond Place: Aging in Community, "our culture has constructed a continuum that positions institutional long-term care at one end of a spectrum, and an idealized vision of aging in place at the other. The challenge is to escape this false choice." 30 While aging in one's own home may be the goal, it may not always be the answer to the problem. Depending on individual needs, homecare can be a short-term or long-term option that offers a cost-effective alternative to living in an institutionalized setting. However, not all homes have been considered for senior living whether by design or location. While the idea of aging in one's own home fosters a sense of autonomy and feelings of familiarity, there is an opposing narrative concerning safety and the effects of loneliness. Data from Statistics Canada has shown that approximately one-quarter $(24.6 \%)$ of the population aged 65 and over lived alone as of 2011, and this population only increases after the age of $70 .{ }^{31}$ In Toronto, those aged 75 and older are concentrated across the city, suggesting that "the potential for isolation is pervasive." 32

The effects of social isolation and loneliness are two states often felt by seniors, and while they can be linked, they are not to be mistaken. While social isolation is an objective measure of the number of contacts that a person has, loneliness is a subjective feeling resulting from a person's desired levels of social contact not matching with their actual levels of social contact. ${ }^{33}$ Like anyone, seniors 
may face the effects of loneliness due to several factors. With seniors, however, the effects of loneliness become more prominent as their lifestyle begins to shift dramatically. Seniors may face loneliness due to retirement, loss of a partner or companions, a change in living arrangements, chronic medical conditions, the inability to drive or access public transportation. The reality is that loneliness is an epidemic

34 Anne-Marie Botek, "Combatting the Epidemic of Loneliness in Seniors," Aging Care. https://www.agingcare.com/ Articles/loneliness-in-the-elderly-151549.htm. (accessed March 21, 2021) among seniors. Several studies have shown that loneliness is a risk factor for mortality in both men and women and can expedite their need for assistance or long-term care. ${ }^{34}$ The secondary reality is that as people age, they can grow increasingly dependent on their family members. However, not all families are able to support their elders, whether that be financially, or through regular assistance and care, and the pressures to support one's elders can often become a burden met with unintentional resentment. It is also not uncommon for family members to live at far distances from their elders or to have a significant disconnect. As such, it is especially unfair to put a senior's mental and physical wellbeing under the sole discretion of whether they have strong family ties or not. It is therefore imperative that in the absence of familial support, communities can support their seniors' emotional and social needs in meaningful ways and delay the need for institutional settings.

Institutional settings such as long-term care homes and retirement homes, foster settings specifically designed to support seniors' needs in a safe and secure way. One of the key differences when compared to aging in place and the option of home care, however, is the level of attention and focus given to medical needs. (Figure 11) Institutional settings are a service-based approach to seniors housing, 
providing medical care, monitoring, personal assistance etc. $24 / 7$ or on an as-needed basis. This level of service is often chosen by or for those with heightened or specific care needs associated with serious illnesses or diseases, such as dementia.

Where institutional settings are about dependence, aging in place and home care are about independence. The intent of this thesis however, is to explore the in-between of these opposing options - to bridge the support of an institutional setting with the autonomy and desirability of aging in place. While institutional settings and existing seniors' homes require their own set of improvements to become truly humanized and supportive spaces, the imbalanced population of seniors to youth, is making alternative arrangements increasingly important. As discussed in Moving Beyond Place: Aging in Community:

"The cost of an independence-based public policy, centered on the concept of aging in place, lies far beyond what our society can afford. At the same time, the use of mass institutionalization to cope with the needs of frail older people is gradually being seen as morally

The response to this reality has included several population-based and place-based strategies to enrich neighbourhoods and improve aging in community, as well as a range of successful innovations at the scale of the dwelling and the neighbourhood. 


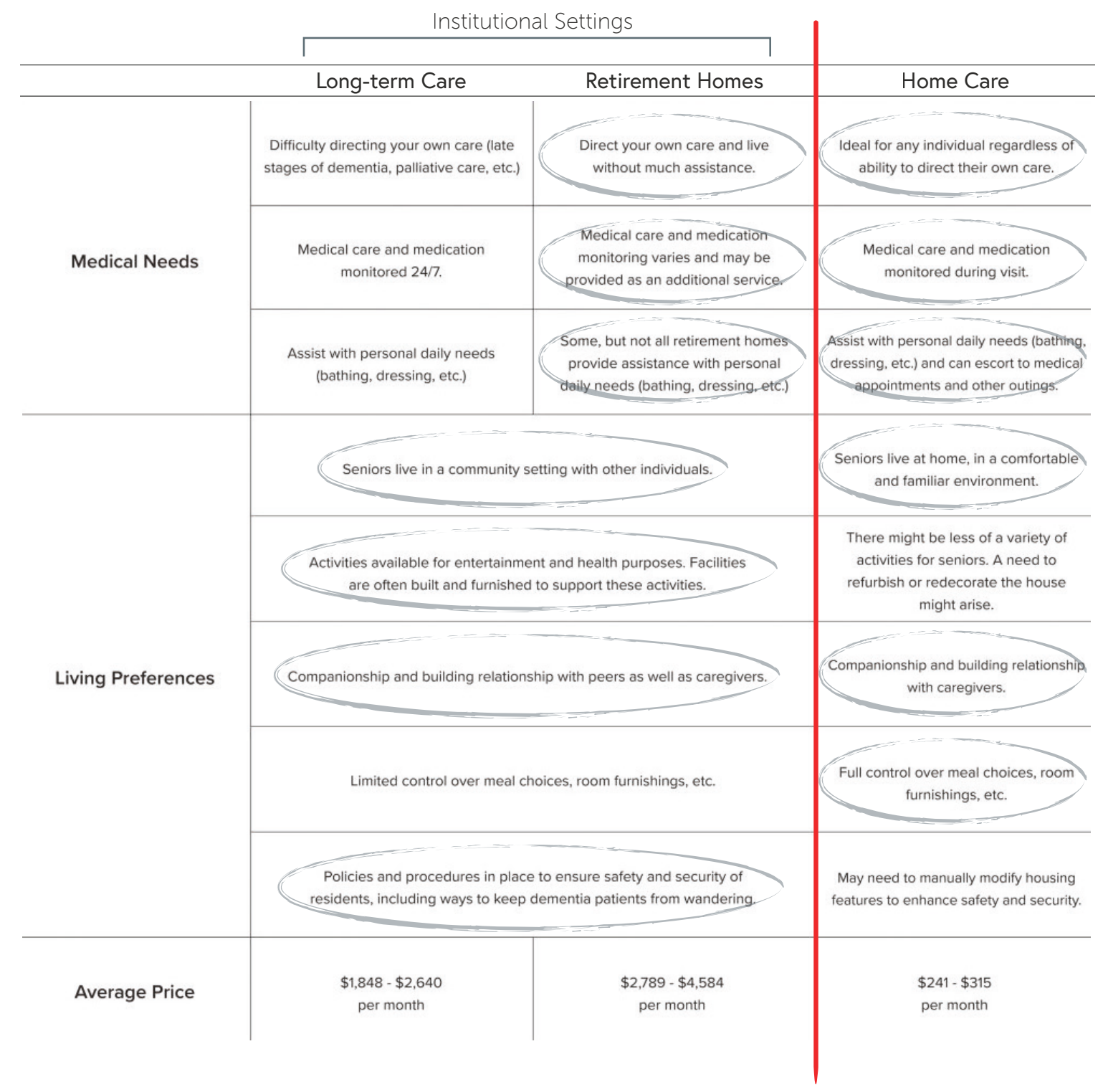


${ }^{\boldsymbol{c}}$ Fundamentally, Canada needs to rethink its whole strategy in regards to our aging population. Our country spends 87 per cent of its long-term care dollars on warehousing older people in care homes, and only 13 per cent on enabling home and community-based care. Meanwhile, according to the Canadian Institute for Health Information, 22 per cent of Canadians in care homes could easily remain in their own homes with community support. A nursing home is often a last resort; given the choice, most of us would prefer to age in our homes. It costs about $\$ 182$ a day to house a high-needs person in a long-term care home, compared to about $\$ 103$ a day to provide at-home care. Imagine if we had that extra money to spend on more home care, as well as more day programs, meals on wheels and transportation. When you allow community agencies to be flexible and work in partnership with families, often they can do a heck of a lot more for a heck of a lot less. A shift to home care would save taxpayer money from being wasted building unnecessary beds-not to mention set us up for success in the event of an infectious outbreak. " 36

- Dr. Samir Sinha, Director of Geriatrics, Sinai Health System and University Health Network 


\section{CHAPTER THREE}

\section{Planning for Improvement}

3.1 Strategies and Guidelines

- Global Age-Friendly Cities: A Guide

- Toronto Seniors Strategy 2.0 (TSS 2.0)

- Toronto Strong Neighbourhoods Strategy 2020 (TSNS 2020)

3.3 Neighbourhood Improvement Areas

- Neighbourhood Selection

- Victoria Village: Introduction

3.3 Innovations in Seniors Living

- Precedents / Case Studies 
Over the next two decades, the population aged $65+$ is expectticipation of the future has long challenged city officials and government policies with how to best support seniors, especially within their existing communities. Additionally, this anticipation has challenged both urban planners and designers to create alternative arrangements for seniors to live.

In 2013, Toronto's city council established what would be the first version of Toronto's Seniors Strategy in an effort to align with the goals of an age-friendly city. The term age-friendly city derives from the Global Age-Friendly Cities Project established by the World Health Organization (WHO) and recognizes the need for not only homes, but communities to be designed with seniors' needs in mind. 


\section{Global Age-Friendly Cities: A Guide}

38 World Health Organization, Global Age-Friendly Cities Project (2020).
39 World Health Organization, Global Age-friendly Cities: A Guide. (2007)
40 Ibid., 1.
In 2002, the World Health Organization (WHO) released their policy framework of eight domains for "active aging" to "[optimize] opportunities for health, participation and security in order to enhance quality of life as people age." 38 (See Figure 12) Those eight domains include: (1) Outdoor spaces and buildings; (2) Transportation; (3) Housing; (4) Social Participation; (5) Respect and social inclusion; (6) Civic participation and employment; (7) Communication and information; (8) Community support and health services. In recognition of the trends of global aging and urbanization, these domains were established through consultation with focus groups of older city dwellers in 33 cities within the World Health Organization regions, including four cities across Canada. Within these focus groups, seniors were asked to describe both the advantages and barriers they experienced in each of the eight domains, and the findings ultimately led to the development of eight age-friendly city checklists. ${ }^{39}$ (See Appendix A for key checklists.) These cities are representative of both developed and developing countries and the results/checklists are therefore a comprehensive reflection of seniors' needs and concerns in urban environments worldwide. Additionally, most city's focus groups were "complemented by evidence from focus groups of caregivers and service providers in the public, voluntary and private sectors." ${ }^{40}$ Therein, the findings of the guide are reflective of varying perspectives and experiences and can be used "to help cities see themselves from the perspective of older people, in order to iden- 
Chapter Three

41 World Health Organization, Global Age-friendly Cities: A Guide. (2007): 11 tify where and how they can become more age-friendly.”41

The first three topics including outdoor spaces and buildings, transportation, and housing reflect key features of the physical environment and will therefore take precedence within this thesis. As outlined in the Global Age-Friendly Cities: A Guide, these three domains "have a strong influence on personal mobility, safety from injury, security from crime, health behaviour and social participation.” ${ }^{22}$ Of course all eight domains overlap and influence each other and will therefore influence the final design proposal of this thesis.

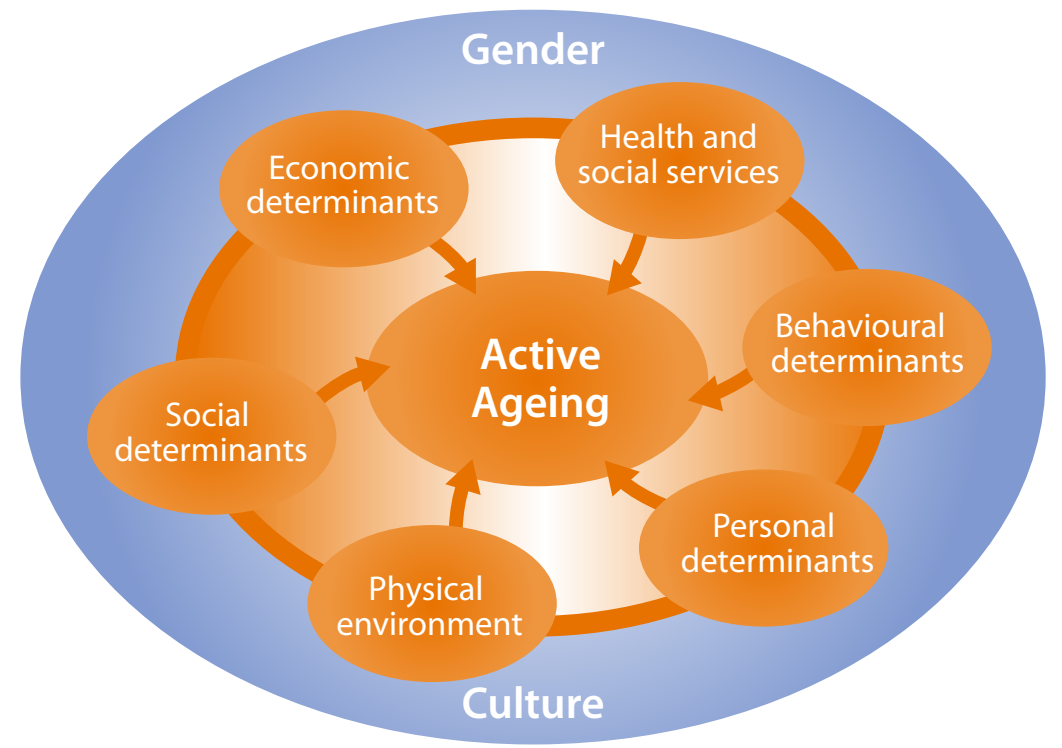


Through version 1.0 of the Toronto's Seniors Strategy, 91 recommended actions were deployed, with all but one recommendation being either fully or partially implemented. As a result, in 2016 Toronto was officially recognized by the World Health Organization as a member of the Global Age-Friendly Cities and Communities Network. ${ }^{43}$ However, city council members remain aware of Toronto's need to become inclusive of all seniors, including those who are most marginalized. The result: Toronto Seniors Strategy 2.0 (TSS 2.0). Between these two versions, the Toronto Seniors Strategy has emphasized the importance of supporting seniors to "live independently in their neighbourhoods and avoid or delay the need for long-term care.”44

Research and survey results in version 2.0 have pointed to three major areas of concern for seniors in Toronto: health, housing, and transportation - the same top three concerns of version 1.0. In total, the City consulted with approximately 3,000 residents and surveyed another 7,000, with a particular focus on marginalized and equity-seeking groups, including: black, racialized and LGBTQ2S seniors, low-income seniors, seniors whose primary language is not English, those experiencing housing security as well as older women experiencing homelessness, victimization, and violence. ${ }^{45}$ Studies within the Toronto Seniors Strategy 2.0 have identified the following trends for this aging population: 
1 "People age $65+$ make up $15.6 \%$ of Toronto's population," and outnumbered children in Toronto for the first time in 2016.

2 “The proportion of Toronto's population over age 65 is projected to grow to $21.2 \%$ in 2041 ."

3 "Half of Toronto's seniors have individual incomes in the $\$ 10 \mathrm{~K}$ to $\$ 30 \mathrm{~K}$ range."

4 "Gender and race are linked to income differences of seniors."

5 "Housing affordability is a serious issue for senior renters."

6 "Nearly $15 \%$ of Toronto seniors are unable to speak English.”

7 "People age 75 and older who live alone are concentrated in various areas across the city."

8 "A significant number of seniors are still working or looking for work. Many seniors are continuing to work past age 65." 46

These and other findings from specific engagement with seniors in equity-seeking groups have led to the development of $\mathbf{2 7}$ recommendations addressing seniors needs and barriers to aging in Toronto, a number of which are considerably spatial issues. (See Appendix B for excerpts of key recommendations as they pertain to this thesis). 
"Toronto is known as a city of unique neighbourhoods. From Etobicoke to Scarborough, from North York to Downtown, the diversity of our neighbourhoods is well-known and well-loved. Many of the differences between neighbourhoods add to the vitality of our city and are celebrated. However, if differences between neighbourhoods are unnecessary, unjust and unfair, they lead to inequality. This inequality divides Toronto, preventing social cohesion and shared prosperity." ${ }^{47}$ - Toronto Strong Neighbourhood Strategy 2020

The Toronto Strong Neighbourhood Strategy 2020 (TSNS 2020) is a place-based initiative/action plan shaped by residents and research intended to support all 140 neighbourhoods' varying needs. To further support the endeavours of the TSNS 2020, specific 'Neighbourhood Improvement Areas' (NIAs) were determined using the World Health Organization's research approach: Urban Health Equity Assessment and Response Tool (Urban HEART). This research approach established five key domains that are imperative to a 'strong neighbourhood,' including: physical surroundings, economic opportunities, healthy lives, social development, and participation in civic decision-making - each used to measure the neighbourhoods of Toronto. From this research, each neighbourhood was given a Neighbourhood Equity Score, effectively determining a benchmark for a 'strong neighbourhood,' by which 31 neighbourhoods did not meet. These 31 neighbourhoods became the designated 'Neighbourhood Improvement Areas' in 2014 and are the focus of the TSNS 2020 plan. 
Chapter Three

48 City of Toronto. Toronto Strong Neighbourhoods Strategy: 8

49 Ibid.
As outlined in the TSNS 2020, activating resources is a key component to creating change, and a strong neighbourhood should therefore include: "services, programs, public spaces, and amenities that are relevant and accessible to residents." ${ }^{48}$ As outlined, the TSNS 2020: "aims to build up these resources in the 31 Neighbourhood Improvement Areas, through direct City of Toronto investment and by leveraging and aligning resources from funding partners. A core goal is to ensure that new investments are relevant, sustainable, and strategically targeted to the inequalities that a neighbourhood is facing. " ${ }^{49}$ Key establishments involved in the development of the NIAs include the Partnerships Opportunities Fund (POL), the City of Toronto Participatory Budgeting, and the Toronto Neighbourhood Funders Network. 


\section{The Partnerships Opportunities Fund (POL):}

- 4 year, \$12 million capital investment fund

- For building/enhancing community infrastructure in Cityowned and City-leased locations in NIAs (e.g. community hubs, kitchens, cultural facilities)

- Proposals developed locally and with residents

\section{City of Toronto Participatory Budgeting:}

- Pilot project in designated neighbourhoods

- Involves community residents in proposing and voting on infrastructure projects to improve their neighbourhoods (e.g. parks, streetscape improvements)

\section{Toronto Neighbourhood Funders Network:}

- A forum for private, public and community funding organizations to align their priorities, policies, and programs toward NIAs

- To ensure place-based investments are complementary and mutually reinforcing 
Note / To propose a project that is inclusive of senior residents, this thesis first sought to understand the characteristics of the city that seniors consider advantageous versus those considered as barriers. From this conclusion, this thesis takes advantage of established guides and strategies that have consulted with various focus groups, both population-based and place-based, to form a well-rounded understanding. While the Global Age-Friendly Cities: A Guide and the Toronto Seniors Strategy 2.0 provide a number of checklists and recommendations acting as a means of guidance, the Toronto Strong Neighbourhoods Strategy acts as a secondary means of support to further understand the neighbourhoods of Toronto and the City's intended direction for improvement. See Figure 13 for a side-by-side summary/comparison of these documents and their findings as they pertain to this thesis. 


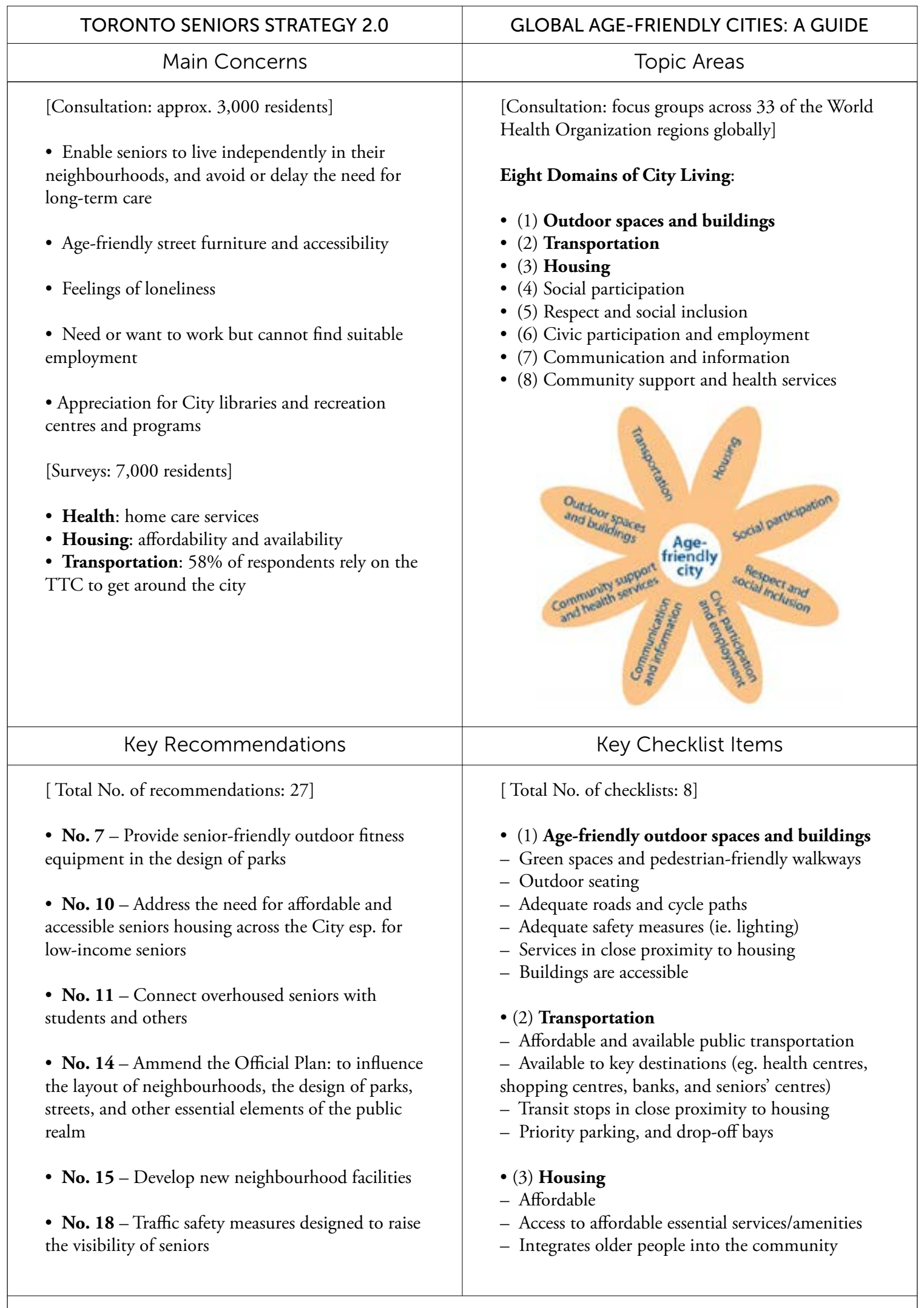

Key Themes: (1) Outdoor Spaces \& Buildings (2) Housing (3) Transportation 


\subsection{Neighbourhood Improvement Areas 54}

As discussed, the Neighbourhood Improvement Areas (Figure

50 City of Toronto. Neighbourhood Improvement Area Profiles. https://www. toronto.ca/city-government/ data-research-maps/neighbourhoods-communities/ nia-profiles/. (accessed March 21, 2021).
14) were established in Toronto in 2014 as a result of the neighbourhood equity evaluations and Toronto Strong Neighbourhoods Strategy 2020 (TSNS 2020). To support this work, the City of Toronto developed neighbourhood profiles for each of the 31 Neighbourhood Improvement Areas (NIAs) and have since updated them to reflect data from the 2016 Census conducted by Statistics Canada. ${ }^{50}$

While this thesis is an exploration of seniors and their relationship to the City of Toronto, there is a particular focus on those experiencing marginalization and adversity in their existing environments. Therein, this thesis will work with the NIAs as they are by definition already designated improvement areas within the city, Neighbourhood Selection

As a point of departure, an evaluation of each of the 31 neighbourhood profiles was completed to get an understanding of which neighbourhoods are home to the most seniors.

As one of the neighbourhoods with a consistently high rate of senior residents at $18 \%$ (or 3,090 people), 'Victoria Village' (Neighbourhood \#43) was selected for further exploration. 


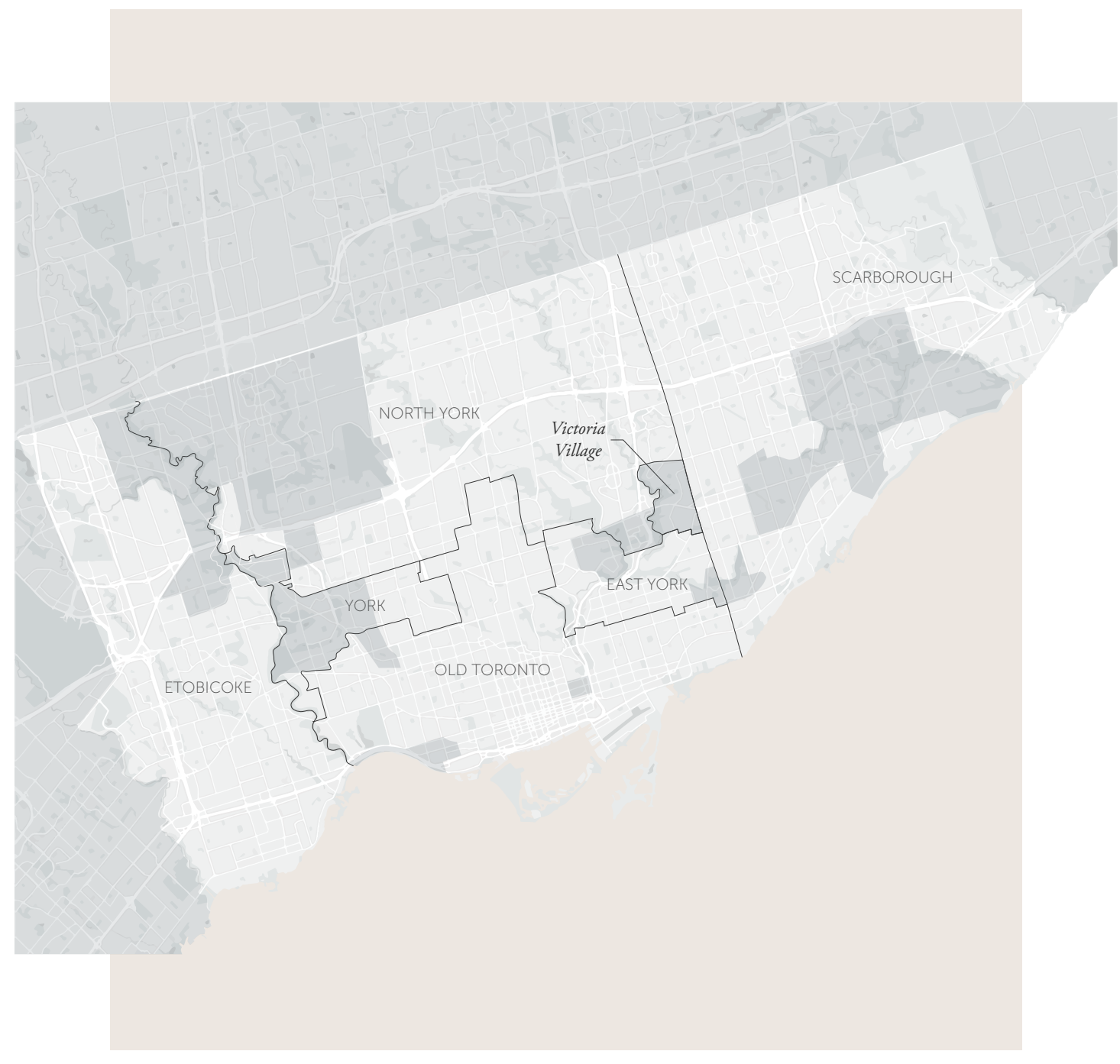

1 
51 "Victoria Village - Neighbourhood Guide," Neighbourhood Guide. https://www.

neighbourhoodguide.com/ toronto/north-york/victoria-village/?wplpage=2. (accessed March 21, 2021)
Victoria Village (Figure 15) is a neighbourhood of 17,510 people, bound on the north by Lawrence Avenue East, on the east by Victoria Park Avenue, on the south by Eglinton Avenue East, and on the west by the Don Valley Parkway. A small area beyond Eglinton Avenue East is however included as well. With close proximity to the Don Valley Parkway, the neighbourhood is well-situated within the city of Toronto at large, and has great potential for improvement and connectivity.

Originally planned as a self-contained community with its own schools, shops, parks, and industry, ${ }^{51}$ Victoria Village is now considered a "community in transition" with new families moving to the neighbourhood and the new Eglinton Crosstown LRT expecting completion in $2022 .{ }^{52}$ As a largely residential neighbourhood of mostly bungalows, semi-detached homes, detached homes, and high- and low-rise buildings, residents must travel to its peripheries to access amenities such as supermarkets, departments stores, restaurants, and small retailers. Although considered in good standing for transportation with many interior streets running bus services, there is potential to improve walkability in the neighbourhood, and move toward the goals of the 15-minute city as discussed in Chapter 1.

While the neighbourhood is seeing more and more young families from a "myriad of cultural backgrounds" migrate to Victoria Village for its affordability, this reality also presents the opportunity to merge affordable housing for young families with housing for aging adults. $^{53}$ 


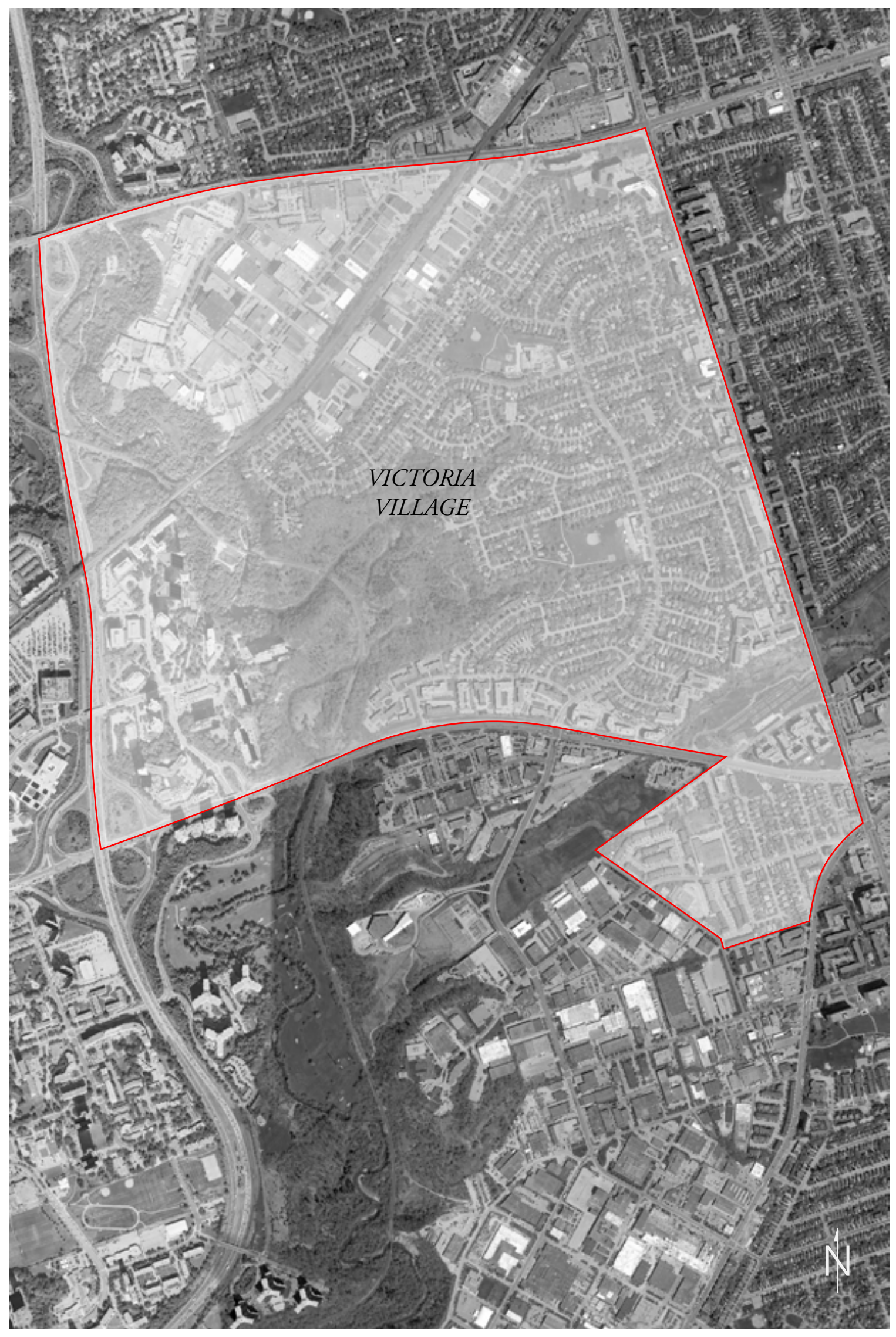

Fig. 15 / Aerial image of Victoria Village, Toronto, Ontario. (Image from: Google Maps 
54 Janice M. Blanchard and William H. Thomas, "Moving Beyond Place: Aging in Community," Generations 33, No. 2 (2009).

55 Ann Forsyth, http://annforsyth.net/ (accessed March 21, 2021).
Design alternatives such as intergenerational living, co-housing, and village communities, "point to the emergence of a new doctrine: People working together can create mutually supportive neighborhoods to enhance the well-being and quality of life for older people at home and as integral members of the community." ${ }^{4} 4$ This notion of a mutually supportive neighbourhood is a particularly key concept embodied by many innovations in seniors living, and is where the distinction between aging in community and aging in place can be made.

Ann Forsyth is an urban planner and professor of urban planning at the Harvard Graduate School of Design and the Editor of the Journal of the American Planning Association. ${ }^{55}$ In the journal article, Improving housing and neighbourhoods for the vulnerable: older people, small households, urban design, and planning, Ann Forsyth et al. introduce a number of emerging innovations for houses and neighbourhoods that are considerate of senior residents and their needs. These innovations span two different scales: that of the neighbourhood, and that of the dwelling/site, and include: collective care, enriched neighbourhoods, all-age communities, serviced housing clusters, intergenerational homes, and technological innovations. (See Figures 16 and 17.) 


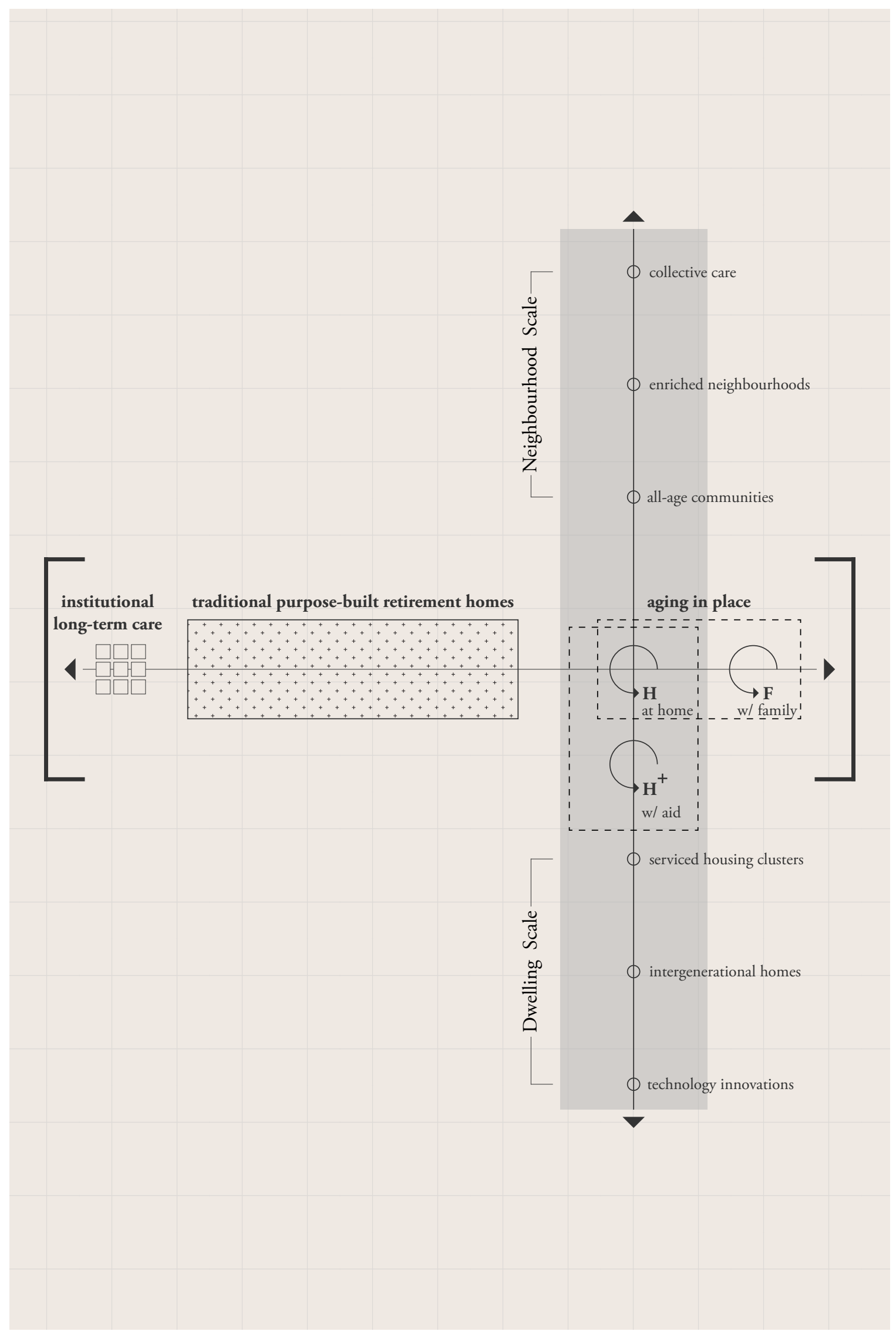




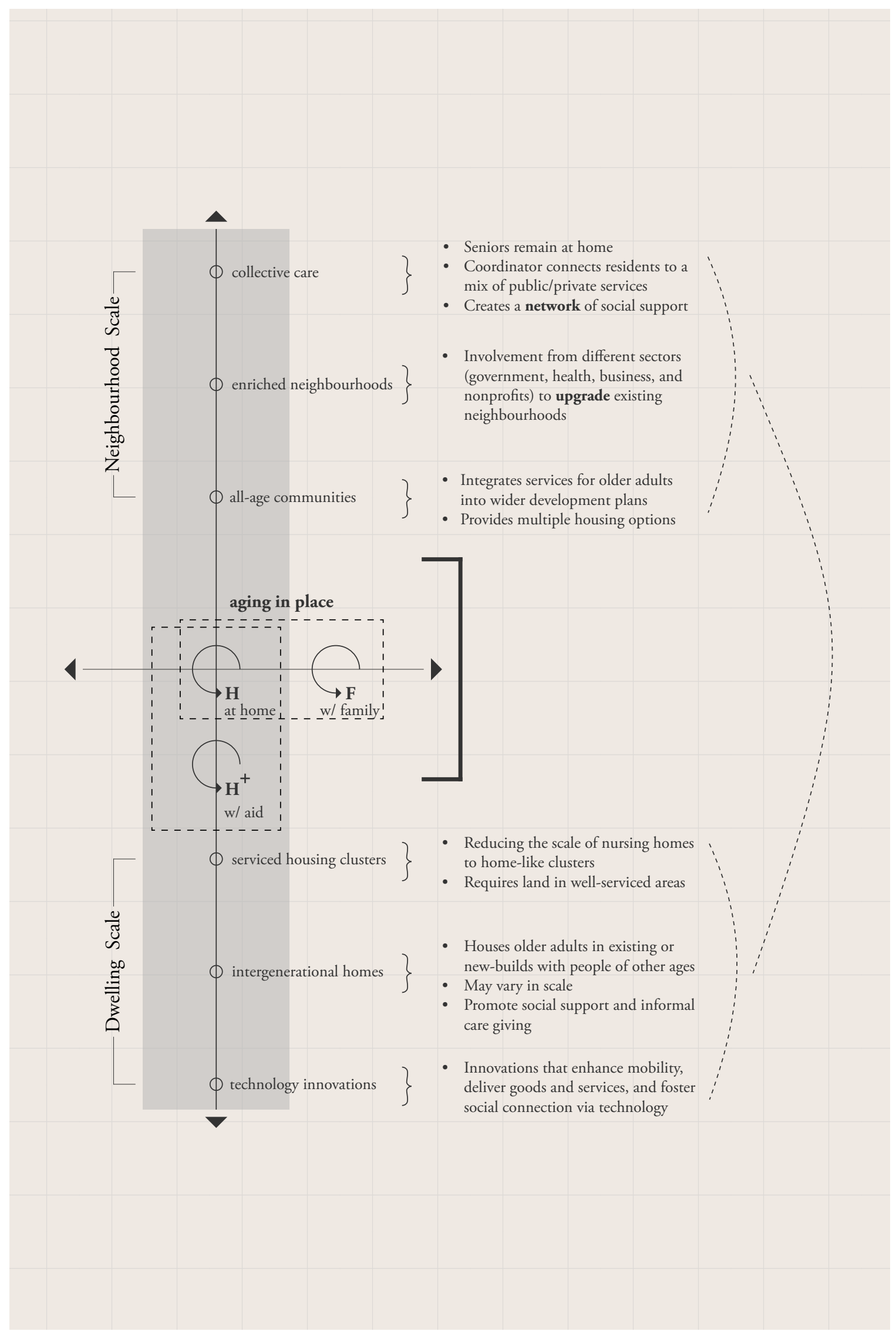




\title{
Precedents
}

\author{
Projects \\ - Beacon Hill Village \\ - Humanitas Deventer \\ - Holly Street Comprehensive Estate Initiative \\ - The Green House Project \\ - The Alcabideche Social Complex \\ - De Hogeweyk
}

Case Study

- The Villages, Florida 
Note / The following are a series of precedents that take an alternative approach to housing for seniors. These projects are succesful in their attempts to foster social connectivity and age-friendly environments both in and beyond the individual dwelling unit. This ability is where the design proposal of this thesis seeks to engage. These precedents are ultimately a means of justifying unconventional models as a response to the demand for new seniors housing. 
Project: Beacon Hill Village

Location: Boston, Massachusetts, United States

Innovation Category: Collective Care

Founded in 2002, Beacon Hill Village offers a compli-

mentary model to aging in place for those over the age of 55. Rather

than acquiring any physical property, Beacon Hill provides a means

of aging in place with mutually supportive neighbours. Members

of the village simply pay a yearly fee for access to a small staff that is

capable of providing necessary services. This allows seniors who do

not require the full service of long-term care, the opportunity to stay

safely and comfortably within their own homes and/or communi-

ty. Additionally, the membership has proven to create a community

within a community, where members meet on a regular basis. Ulti-

mately, the concept has provided many with a much-desired social

life and is a proven means of combating social isolation. ${ }^{56}$

Key Finding(s): Aging in place can be made not only possible, but practical through fostering a sense of community amongst seniors.

Community $=$ social support.

Key theme(s) engaged: (circled)

(1) Outdoor Spaces \& Buildings (2) Housing (3) Transportation

56 Chris Bentley, "Why More Seniors Are Forming Their Own 'Villages,"' Bloomberg CityLab, September 17, 2015, https:// 
Project: Humanitas Deventer (Retirement Home)

Location: Deventer, Netherlands

Innovation Category: Intergenerational Homes

"Assisting with and helping the elderly is a very import-

ant part of the Dutch housing system." ${ }^{57}$ The Humanitas Deventer

Retirement Home therefore provides the opportunity for younger

individuals to live alongside their elders and assist with day-to-day

activities and spend quality time together. Students live rent free in

return for a minimum of 30 hours a month spent helping residents. ${ }^{58}$

This particular project has accommodated 6 student residents among 160 senior residents, and has been a successful means of providing informal care.

Key Finding(s): Intergenerational living is not only a great means of combatting ageism and segregation by age, but has proven to improve overall health for seniors through cognitive stimulation, and social connectivity. ${ }^{59}$

Key theme(s) engaged: (circled)

(1) Outdoor Spaces \& Buildings (2) Housing (3) Transportation 
Project: Holly Street Comprehensive Estate Initiative

Location: London, England

Innovation Category: All-age communities

In Improving housing and neighbourhoods for the vulnerable:

older people, small households, urban design, and planning, Ann Forsyth

discusses all-age communities as: "new-build alternatives to the large-

scale active retirement community." Holly Street is such a project

involving the rebuilding of a large estate into nearly 1000 homes

including "smaller units, a tower block with concierge and acces-

sibility features, a serviced housing/assisted living scheme that also

includes a senior center with adult day care, and 40 apartments for

frail older people." ${ }^{00}$ Forsyth references author of From 'special needs' to

'lifestyle choices': articulating the demand for 'third age' housing, Julienne

Hanson, stating "this is much more than just a mix of housing types

and tenures as it includes social services, health, and transportation el-

ements, all of which require collaboration among various agencies." 61

Key Finding(s): All-age communities are a feasible alternative to large-scale retirement communities and offer services beyond the boundaries of the dwelling unit/home.

Key theme(s) engaged: (circled)

(1))Outdoor Spaces \& Buildings (2) Housing (3) Transportation 
Project: The Green House Project

Innovation Category: Serviced Housing Clusters

With support from the Robert Wood Johnson Foundation (RWJF), the concept to abandon the traditional approach to institutional care for seniors evolved into The Green House project: a supportive venture to help companies build or convert residential homes into spaces for care. Green House projects are typically small homes of 9-12 residents in studio apartments with shared dining, kitchen, and living areas, as well as access to the outdoors. ${ }^{62}$ The approach differs significantly from traditional care homes and is designed to "look and feel like a real home.”63

"To date, more than 260 Green House homes in 32 states are open or under development. And in general, studies suggest that elders living in the homes are happier and healthier." ${ }^{64}$

Key Finding(s): 9-12 residents per shared living arrangement (ie. individual apartments with shared dining, kitchen, and living areas) is a successful alternative model to traditional care homes.

Key theme(s) engaged: (circled)

(1) Outdoor Spaces \& Buildings (2) Housing (3) Transportation 
Project: The Alcabideche Social Complex

Location: Alcabideche, Portugal

Innovation Category: Serviced Housing Clusters

The Alcabideche Social Complex is a social housing project in Portugal, intended to "fill a gap in the elderly support system." ${ }^{5}$ Inspired by the Mediterranean lifestyle, the project offers an abundance of intertwined outdoor spaces that act as an extension of the individual housing units. (Figure 18) In addition to the individual units, a central building on site houses common services for the property and its residents. A particularly unique feature however, is the ability of the individual, modular units to light up in the evening, providing a safe and easily navigable environment for seniors within the complex. The units act as an additional means of safety by illuminating in red during the event of an emergency.

Key Finding(s): Intertwining housing units with pedestrian-friendly outdoor spaces makes for an age-friendly environment.

Key theme(s) engaged: (circled)

(1))Outdoor Spaces \& Buildings (2) Housing (3) Transportation 


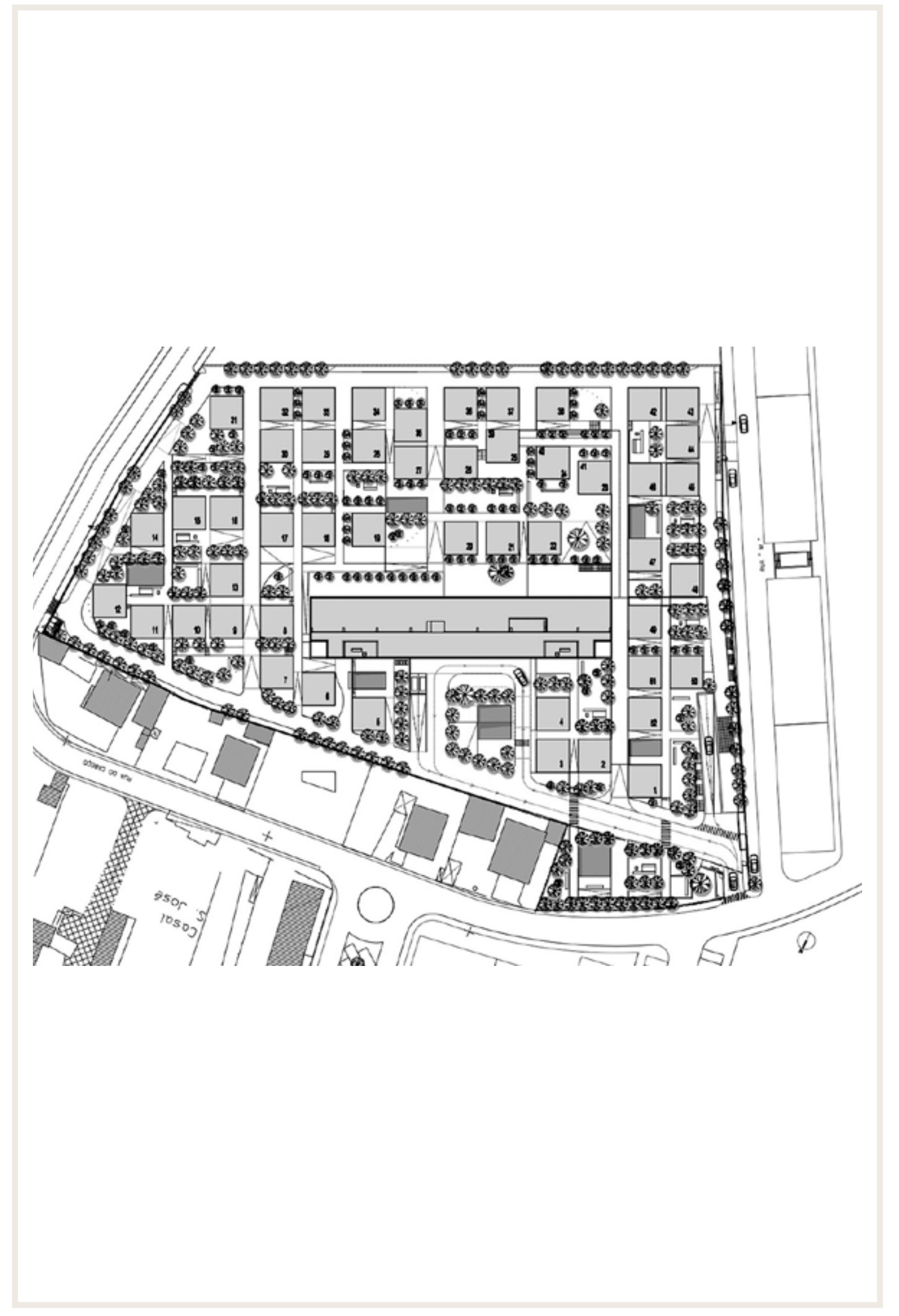


Project: De Hogeweyk

Location: Weesp, Netherlands

Innovation Category: Serviced Housing Clusters

Designed specifically for citizens with dementia, this small village is often referred to as "Dementia Village" and is considered one of the most innovative elder care facilities in the world. ${ }^{66}$ The intention of the village is to restore a sense of autonomy in dementia patients while maintaining a level of safety and security. De Hogeweyk uses theming to distinguish different areas: each block or "house" is therefore themed to be familiar to the lifestyle or era that the patients best associate themselves with. Each "house" provides individual rooms for 6-7 residents with shared common areas.

(Figure 19) Additionally, the complex is distinguished from the rest of the neighbourhood and provides its own community spaces such as a grocery store, movie theatre, and post office. ${ }^{67}$

Key Finding(s): 6-7 residents per shared living arrangement (ie. individual apartments with shared dining, kitchen, and living areas) is a successful model. Situating housing in close proximity to community spaces and services enables seniors (especially those with dementia) to maintain a sense of autonomy.

Key theme(s) engaged: (circled)

(1))Outdoor Spaces \& Buildings (2) Housing (3) Transportation 


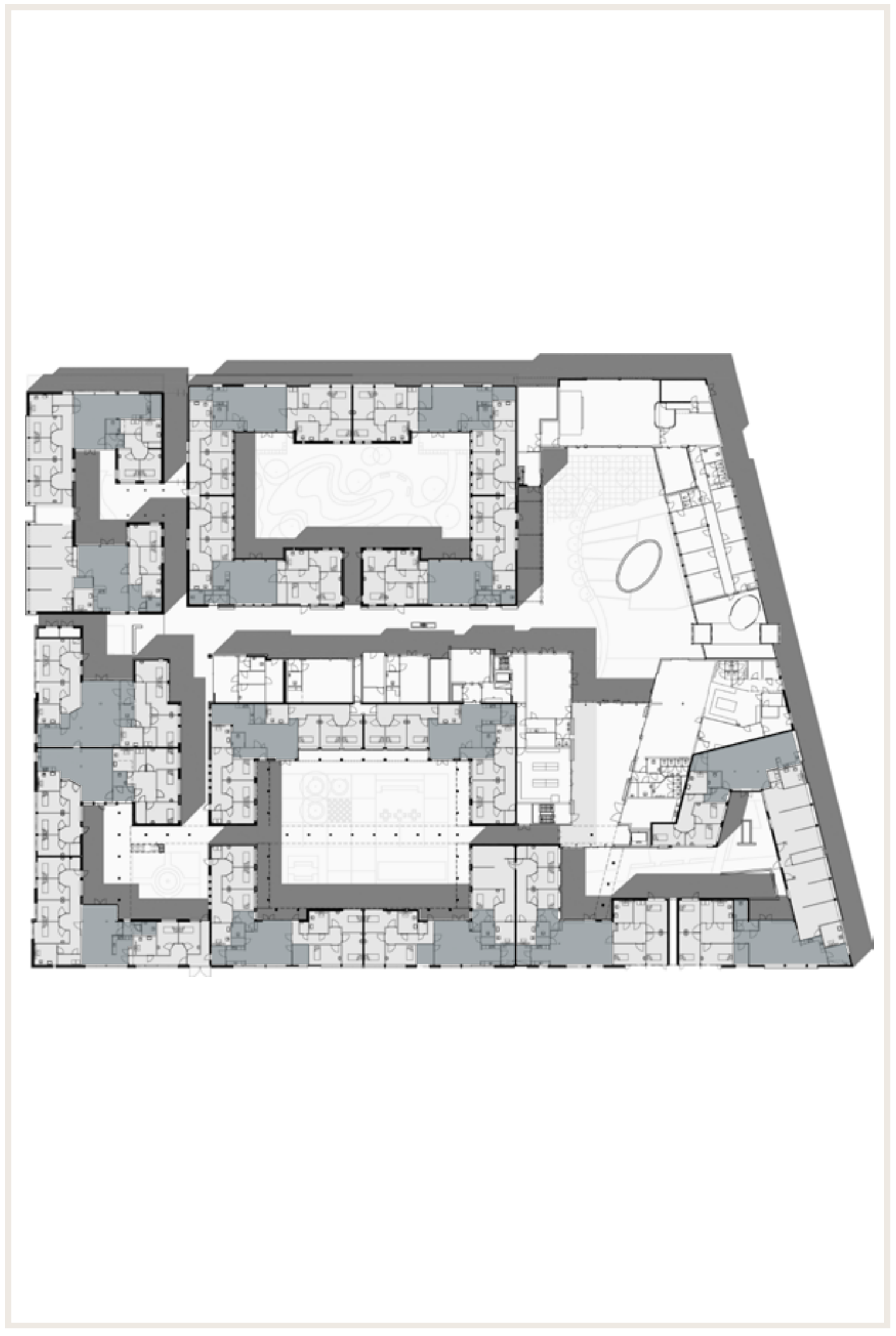


Case Study: The Villages

Location: Sumter County, Florida, United States

The Villages is a census designated place for the Young-Old: those over 55 years of age who live a healthy, active lifestyle. It is the fastest growing metropolitan area in the United States, and has been likened to a utopia, referenced as the "Senior's Disney World". ${ }^{68}$ The Villages offers a life of luxury with a selection of private neighbourhoods stitched together by themed resorts, town squares, and seemingly endless golf courses; all contributing factors to a life of endless leisure and the sense of a never-ending vacation.

Note / Young-Old: a term referring to those who are retired and in relatively good health, roughly from the ages $55-75 .{ }^{69}$ The term was first coined and theorized by gerontologist Bernice Neugarten in 1974, before British social historian, Peter Laslett developed the concept into a theory of the Third Age. ${ }^{70}$

Deane Simpson is an architect, urbanist, and educator at The Royal Danish Academy of Fine Arts School of Architecture in Copenhagen. ${ }^{71}$ In 2015, he published his book Young Old: Urban Utopias of an Aging Society, an exploration that shifts "from the architectural scale toward larger urban phenomena concerning public spaces, quarters/neighbourhoods, towns/cities, networks, infrastructure, and territories." ${ }^{2}$ Within his book, Simpson investigates a number of retirement communities similar to that of The Villages in a depar- 
ture from the established discourse that has focused on the aged as a "group of frail, inactive, and dependent subjects."

As highlighted in this thesis our aging population is growing, and the life expectancy of Canadians is increasing. This reality presents three crises as outlined by Deane Simpson: the crisis of dependency: a result of "ever greater numbers of elderly, supported fiscally by ever fewer number of working-age people"; the crisis of programming: the demand for "widespread future reprogramming of architectural and urban settings previously designed for those increasingly dominated by the young for those increasingly dominated by the old"; the crisis of precedent: "characterized by a lack of existing scripts and protocols directing how, where, and with whom persons might live in this new, historically unprecedented phase of life." 74 Therein, this thesis reflects on the approach of The Villages, Florida and Deane Simpson's critical analysis to draw precedent for the reinvention of today's neighbourhoods.

Deane Simpson discusses The Villages as fostering a homogenous demographic that can be understood as a "simulation of a larger city." ${ }^{\prime 5}$ As previously discussed in Chapter 1.2, institutional settings for seniors living can often be viewed as heterotopias for the way they separate residents from the rest of society. Similarly, The Villages can be viewed as a heterotopia as well. Michel Foucault further discusses the notion of heterotopias in Of Other Spaces as 'counter sites,' as "a 
kind of effectively enacted utopia in which the real sites, all the other real sites that can be found within [a] culture, are simultaneously represented, contested, and inverted [...] these places are absolutely different from all the sites that they reflect and speak about." ${ }^{\prime 6}$ Just like any city, The Villages offers downtown cores, town squares, restaurants, shopping plazas, neighbourhoods; but The Villages offers them through a variety of themed experiences geared specifically toward Young-Olds. (See Figure 20)

Similarly to institutional settings, The Villages functions from the ability to separate its residents from the outside world. While The Villages' approach is packaged as a vacation-like experience and is highly appealing to many, it encourages the same storyline: that the outside world is not a place for seniors to thrive. However, there is still a lot that can be learnt from The Villages. For example, the most important component of The Villages is the golf cart infrastructure (Figure 21) that supports the overall organization and lifestyle. Through the use of golf carts, a large proportion of The Villages (and therefore its amenities) is made easily accessible to its residents, providing a great sense of autonomy: a key factor contributing to one's ability to age comfortably. What this precedent demonstrates, is the possibility of, and the need for new urban infrastructure and as Simpson concludes: this growing demographic group is a "site of sociospatial experimentation."77 
Summary: The Villages demonstrates that purpose-built communities for seniors can not only be supportive, but desirable. The integration of public spaces and services in close proximity to housing fosters a great sense of community, while innovative infrastructure for alternative modes of transporation (ie. golf carts) supports an autonomous lifestyle. However, The Villages, like many institutional settings promotes the separation of residents from the outside world. This thesis seeks to engage with this notion of separation and explore the potential for housing for seniors to be truly integrated with society at large.

Key theme(s) engaged: (circled)

(1))Outdoor Spaces \& Buildings (2) Housing (3) Transportation 

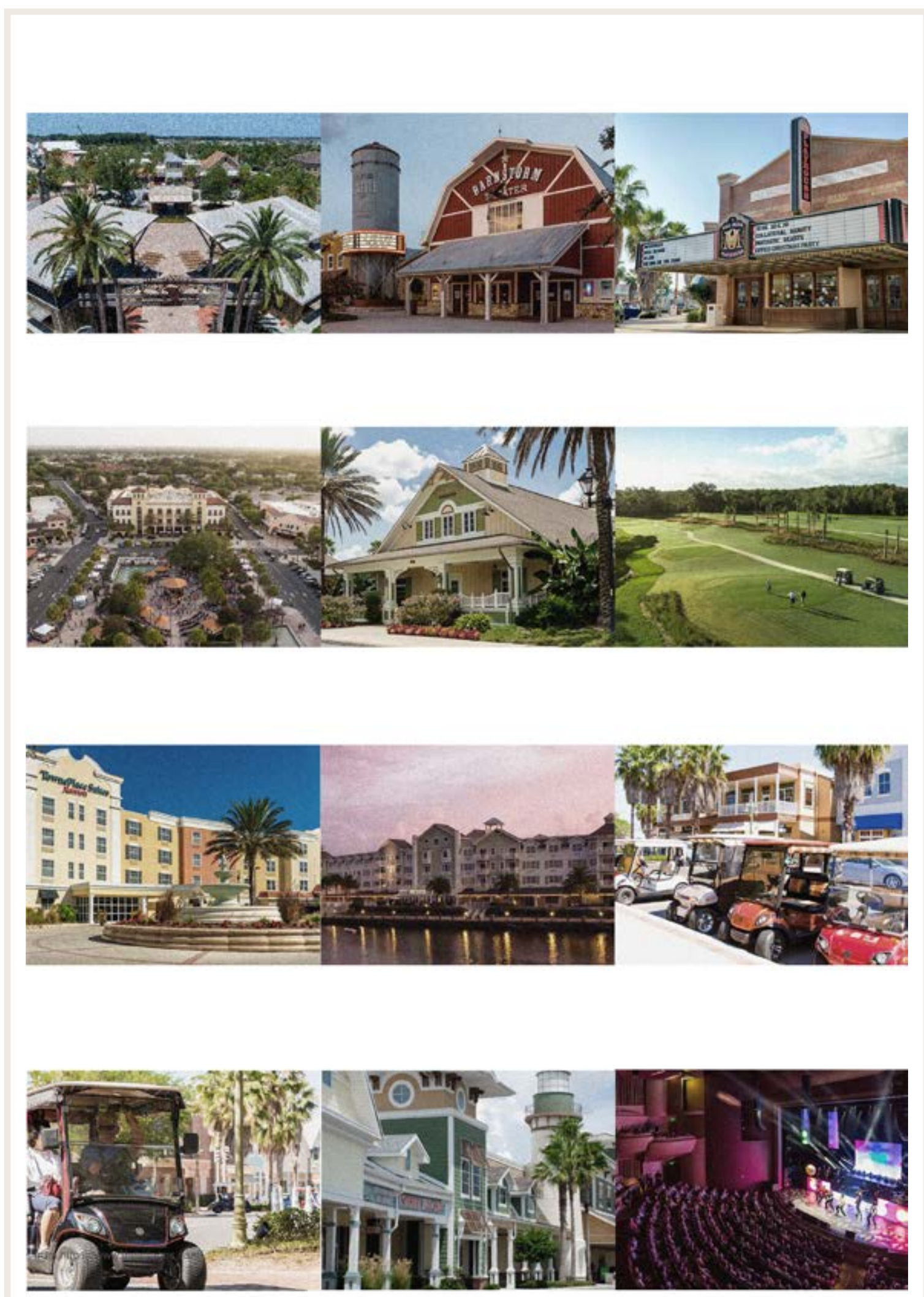


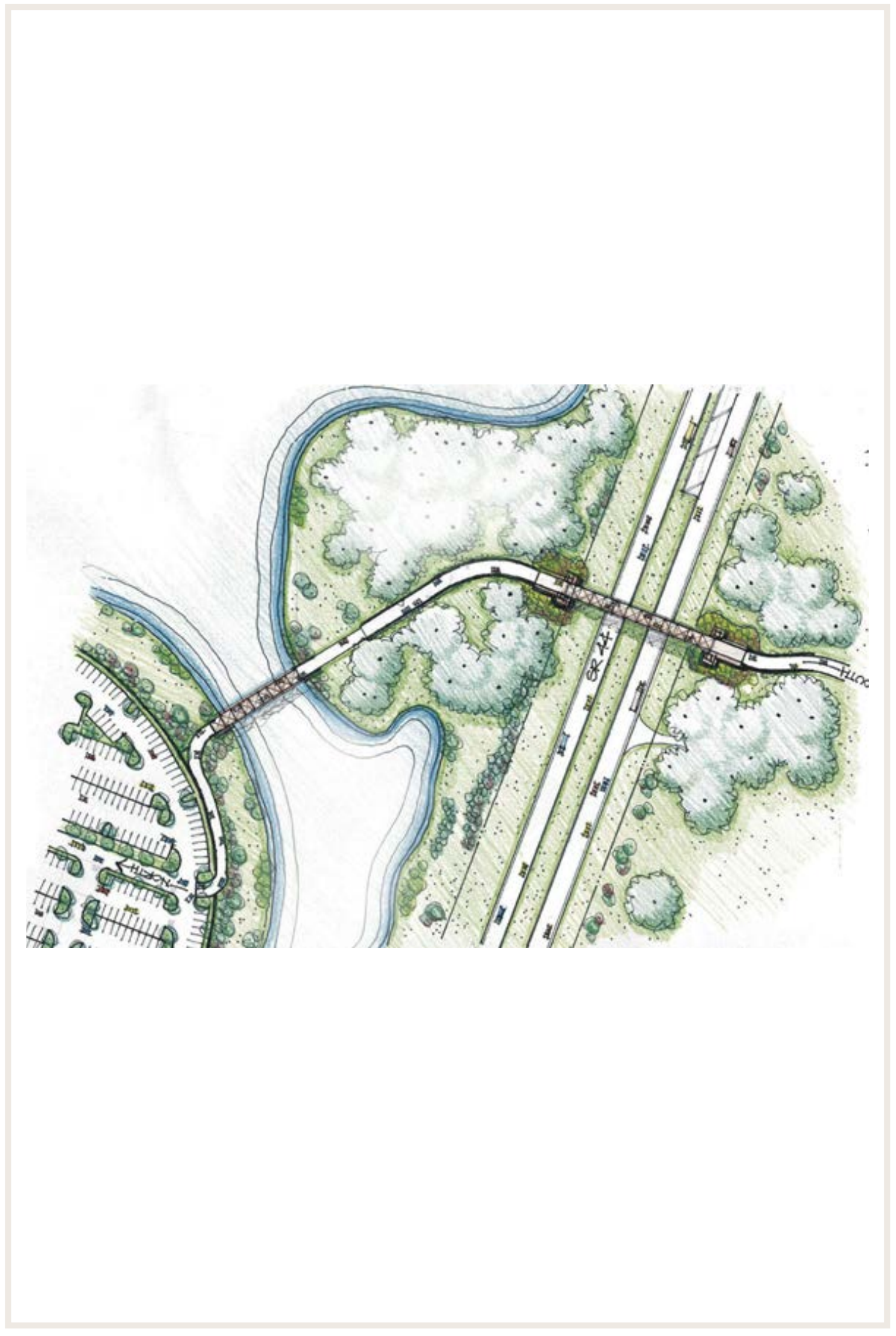




\section{CHAPTER FOUR}

\section{Design Proposal}

4.1 The Focus Area

4.2 The Age-Inclusive Neighbourhood

- Part 1: The Housing Site

- Part 2: Neighbourhood Connectivity

4.3 Towards an Age-Inclusive City 


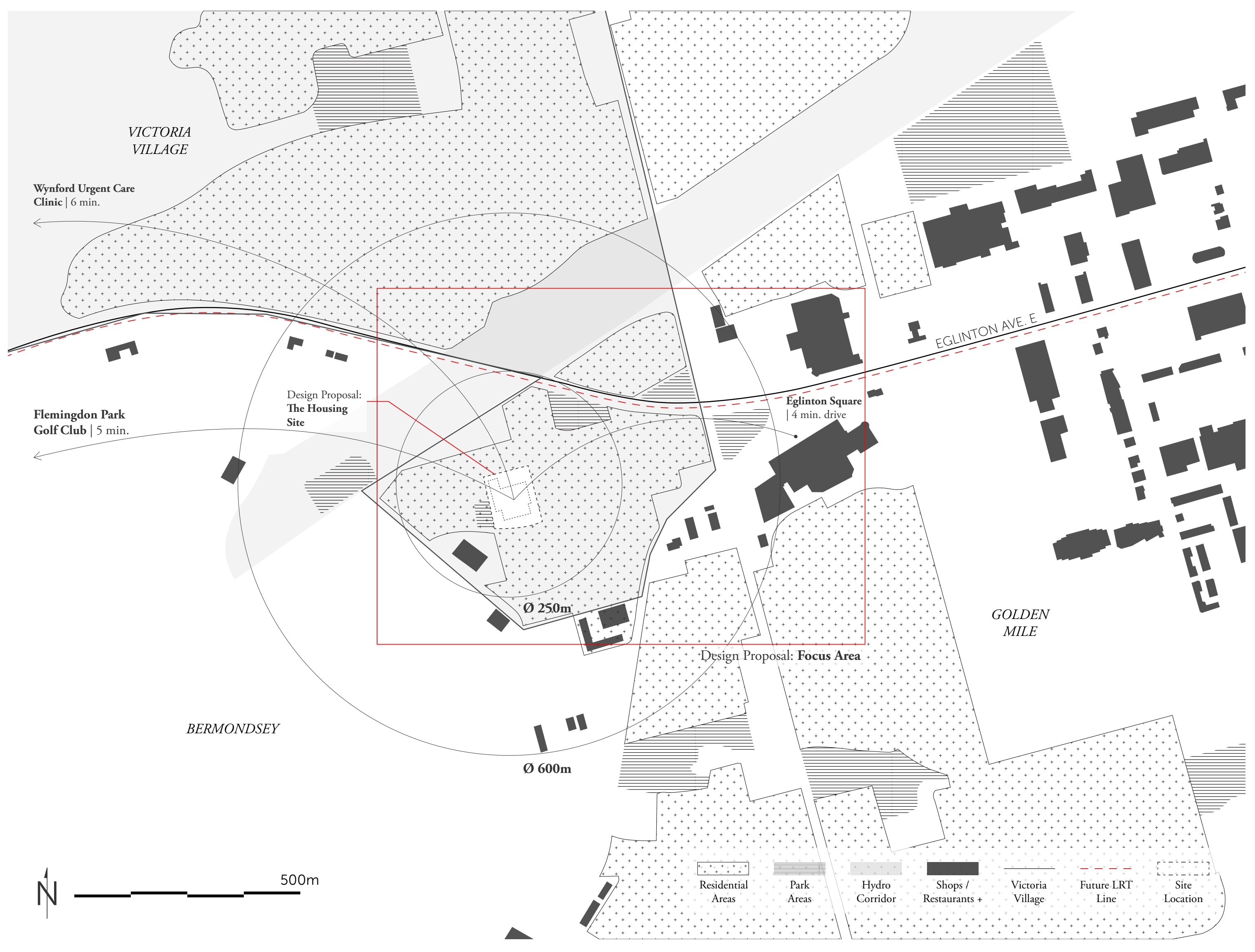




\subsection{The Focus Area}

The design proposal within this chapter is based on the

previously discussed population-based and place-based strategies, and utilizes a number of the previously discussed innovations and precedents as a means of guidance.

Part 1 of the proposal: 'The Housing Site' is located at 104110 Bartley Drive, North York, Toronto: a currently underutilized site within a developing neighbourhood of single-family homes, townhouses, and low to mid-rise residential buildings. It is located approximately 200 metres south of Eglinton Avenue East and is currently occupied by a vacant one-storey warehouse building.

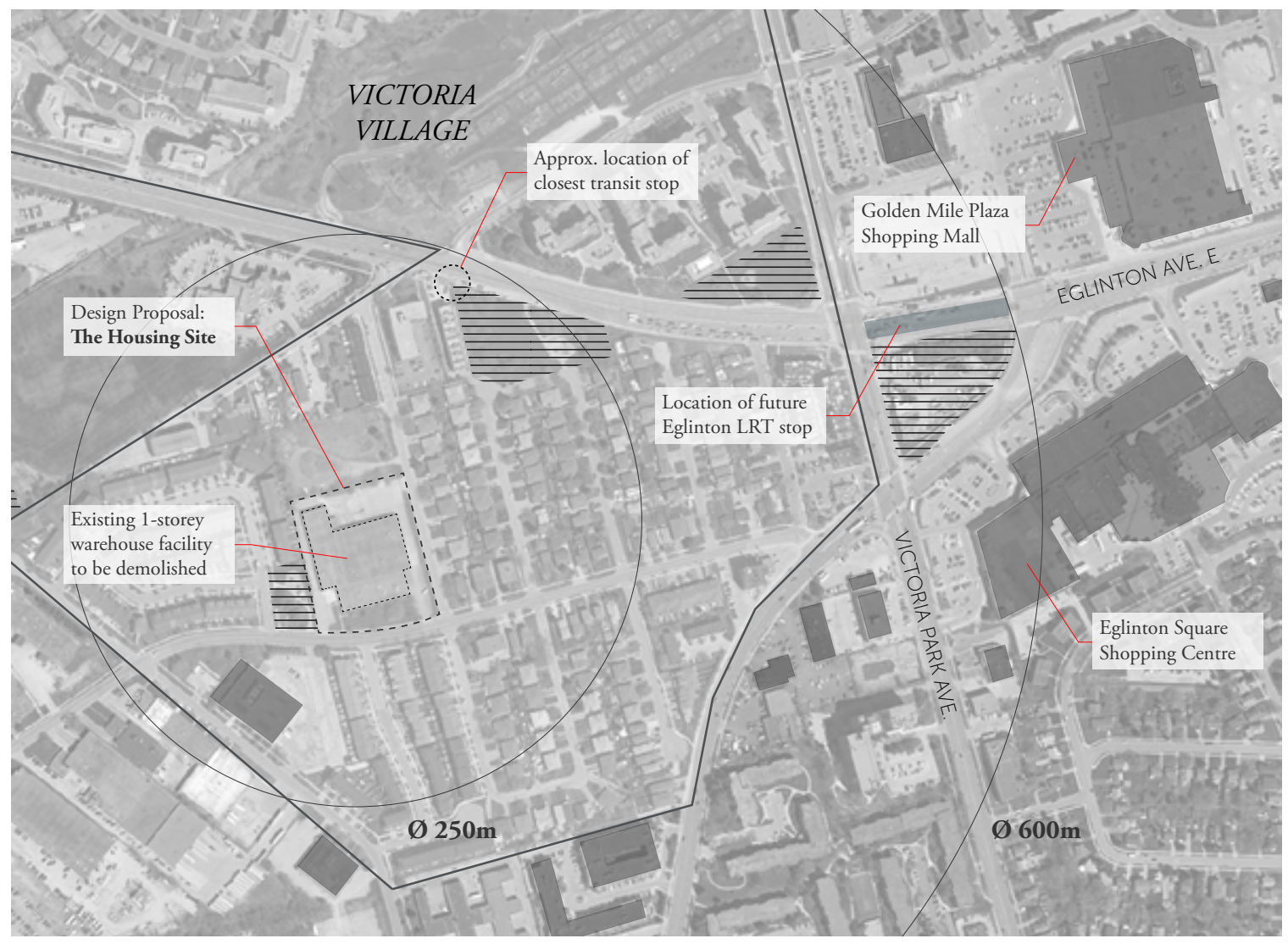

Fig. 23 / Design Proposal: Focus Area (as highlighted in Figure 23). 
Note / The following photographs are intended to capture the existing condition of Victoria Village as a Neighbourhood Improvement Area in Toronto. The photographs are intended to reveal key aspects of the built environment, and how a neighbourhood could be improved for aging in community and beyond just 'The Housing Site.' 


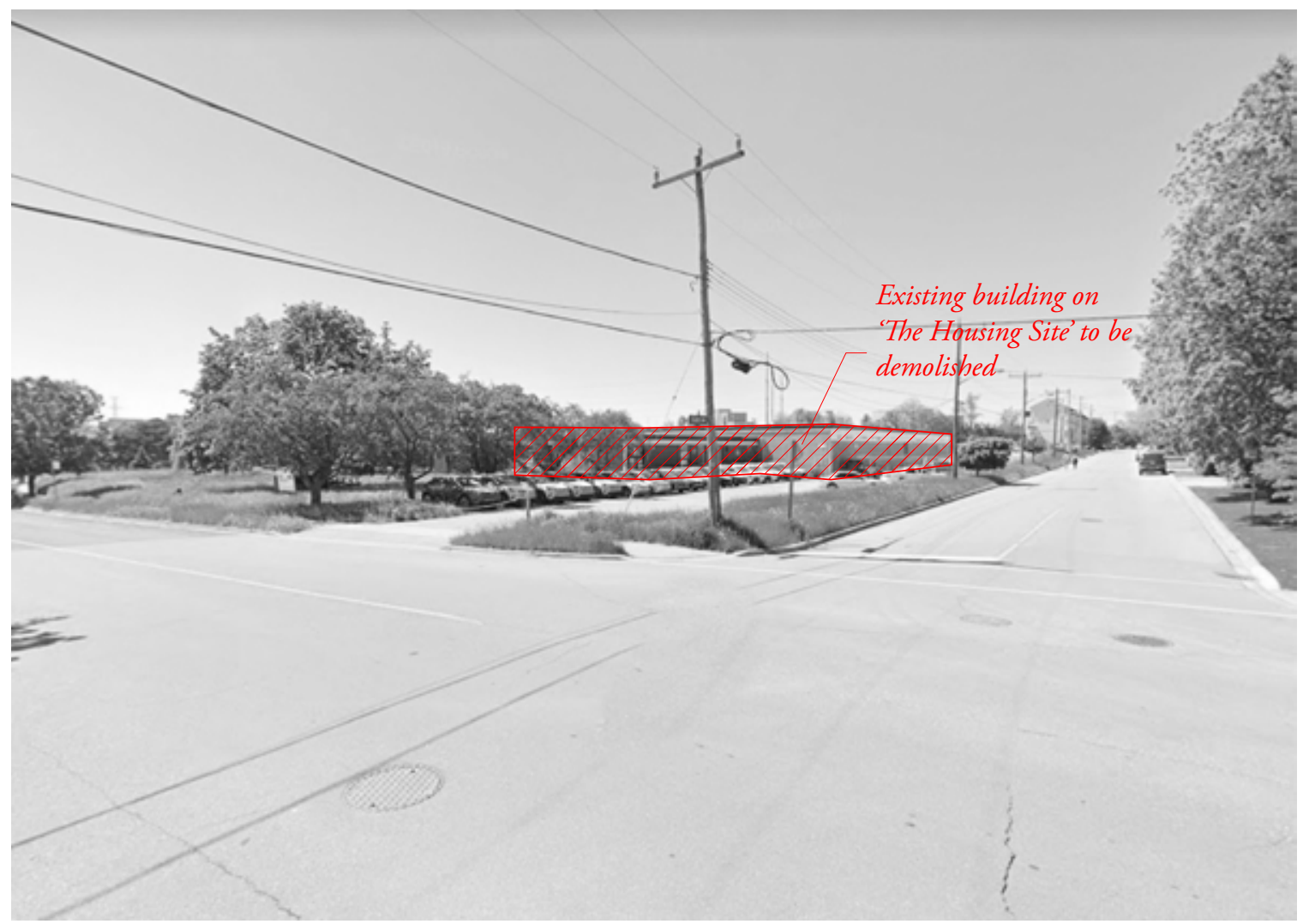

Facing the south-east corner of 'The Housing Site.'

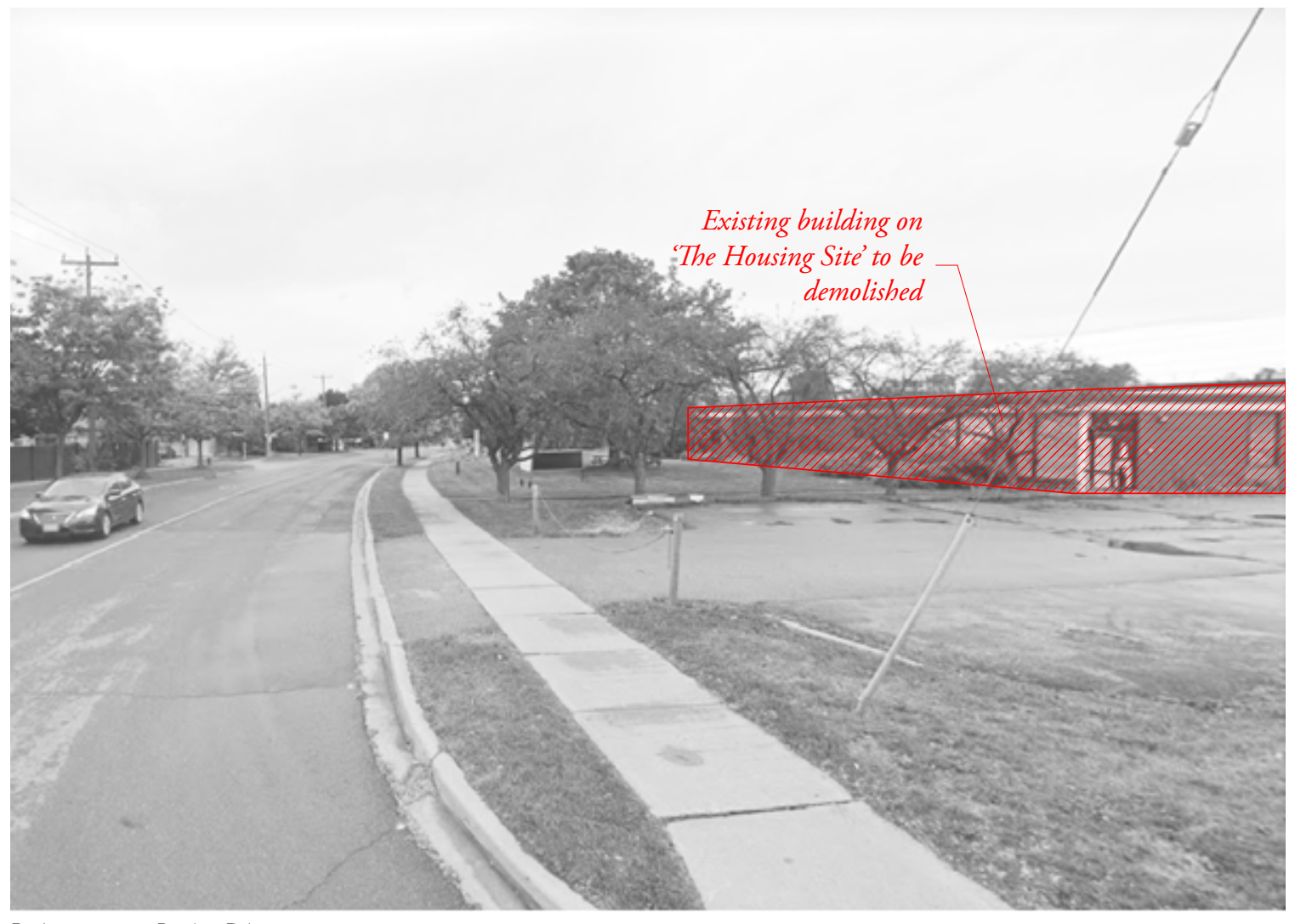

Facing west on Bartley Drive. 


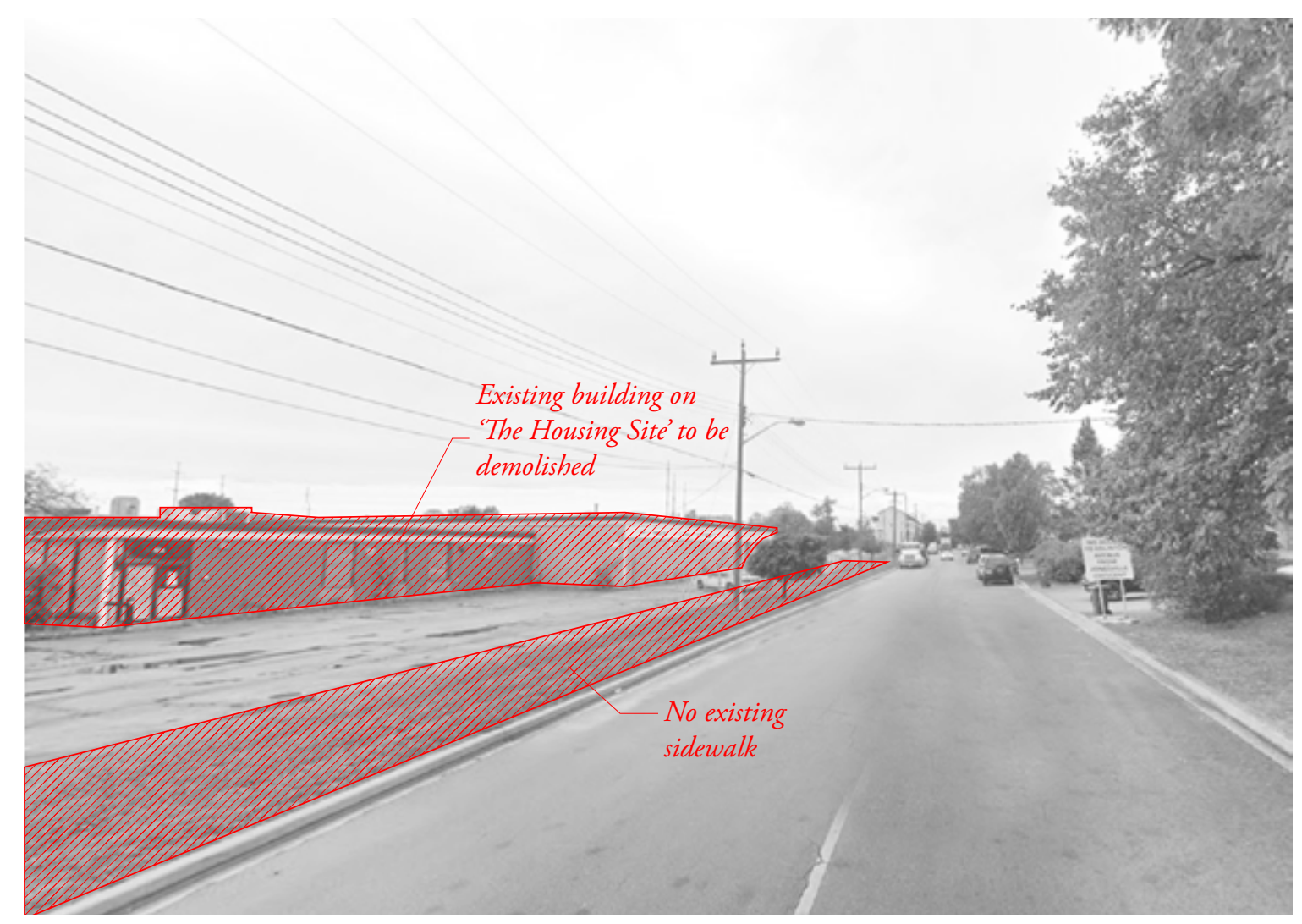

Facing north on Tisdale Avenue.

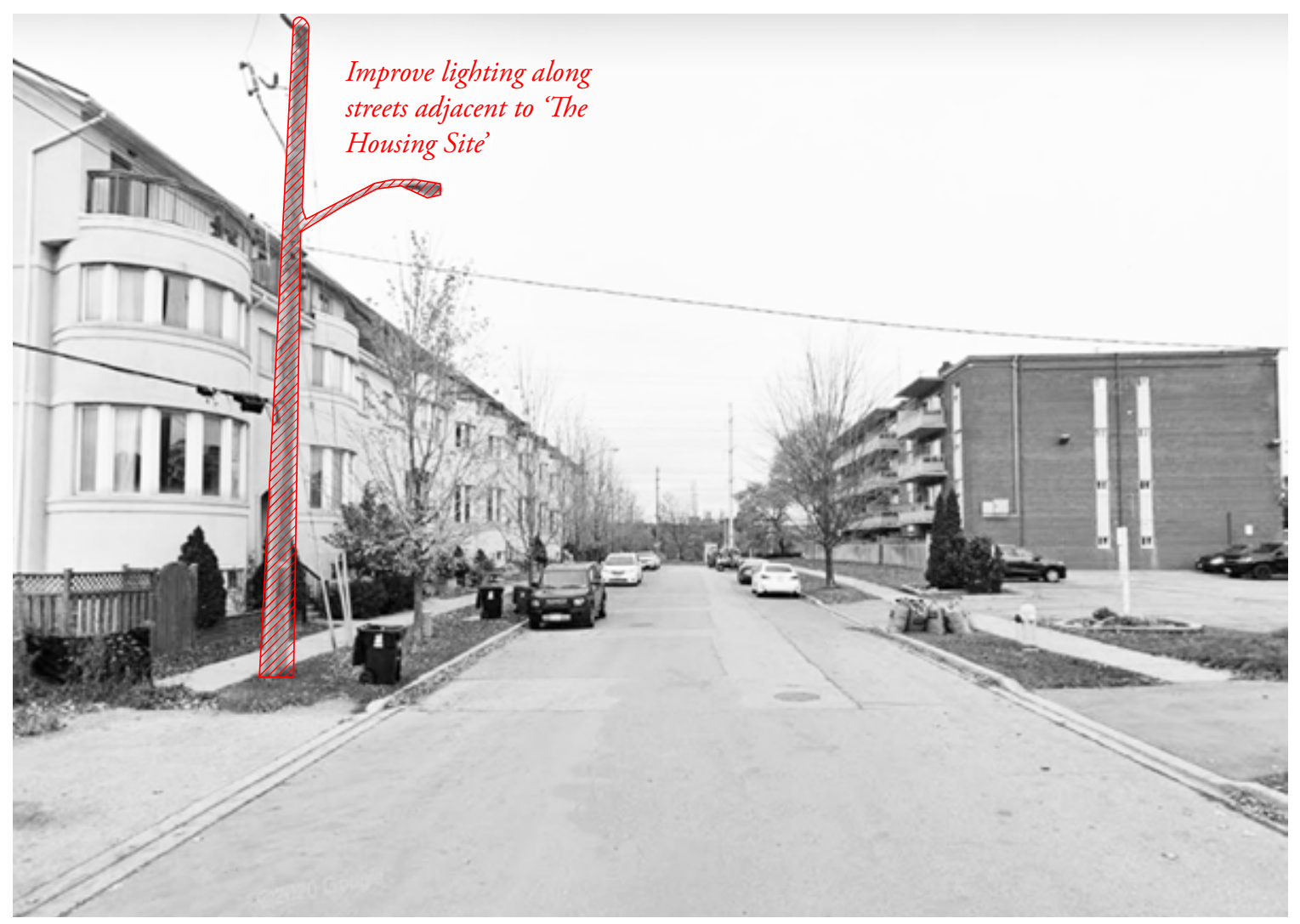

Facing north on Tisdale Avenue.

Fig. 26 and 27 / Existing conditons, Victoria Village, Toronto, Ontario. (Images from: Google Images. Annotated in red by Author) 


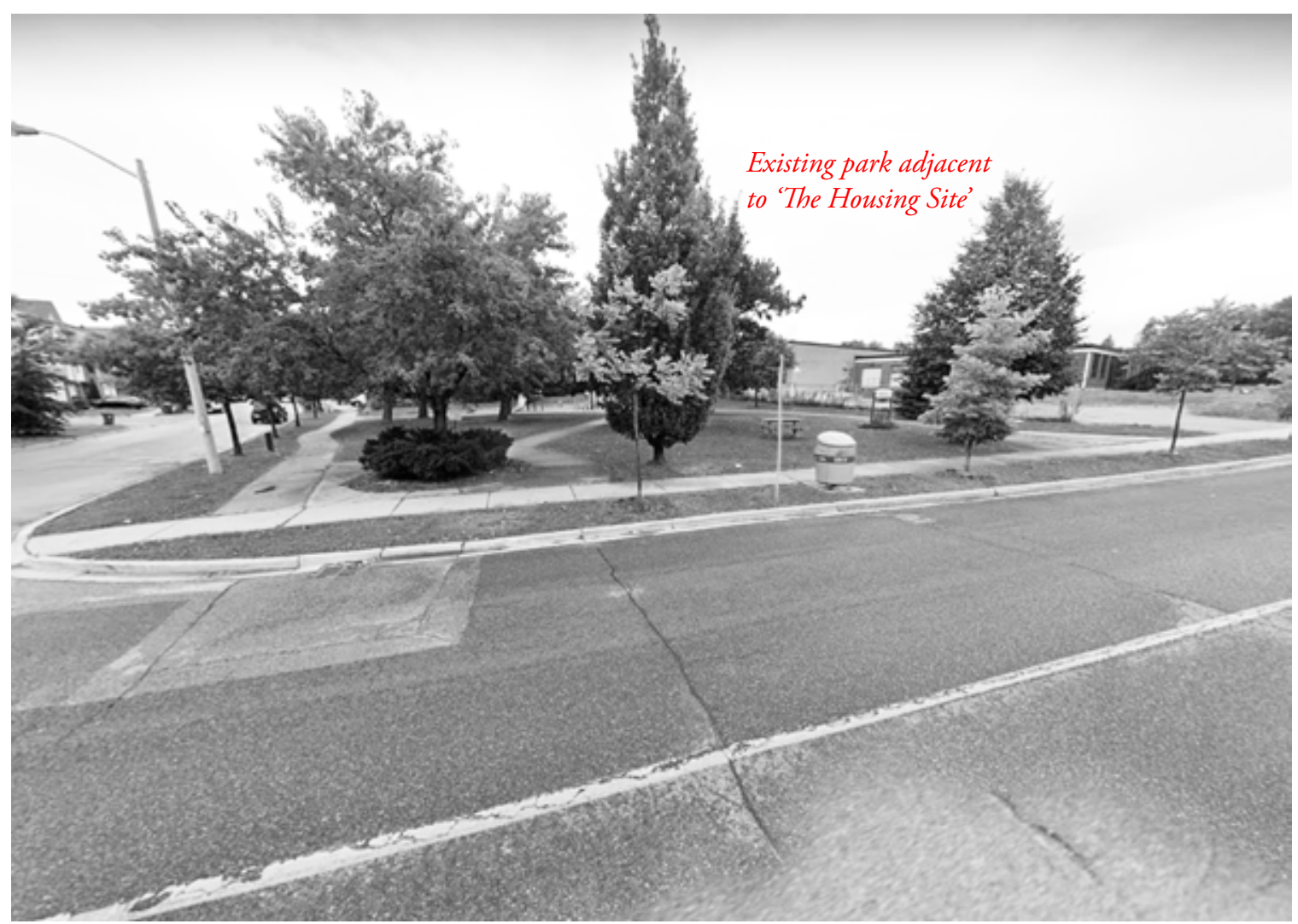

Facing north toward park adjacent to 'The Housing Site.

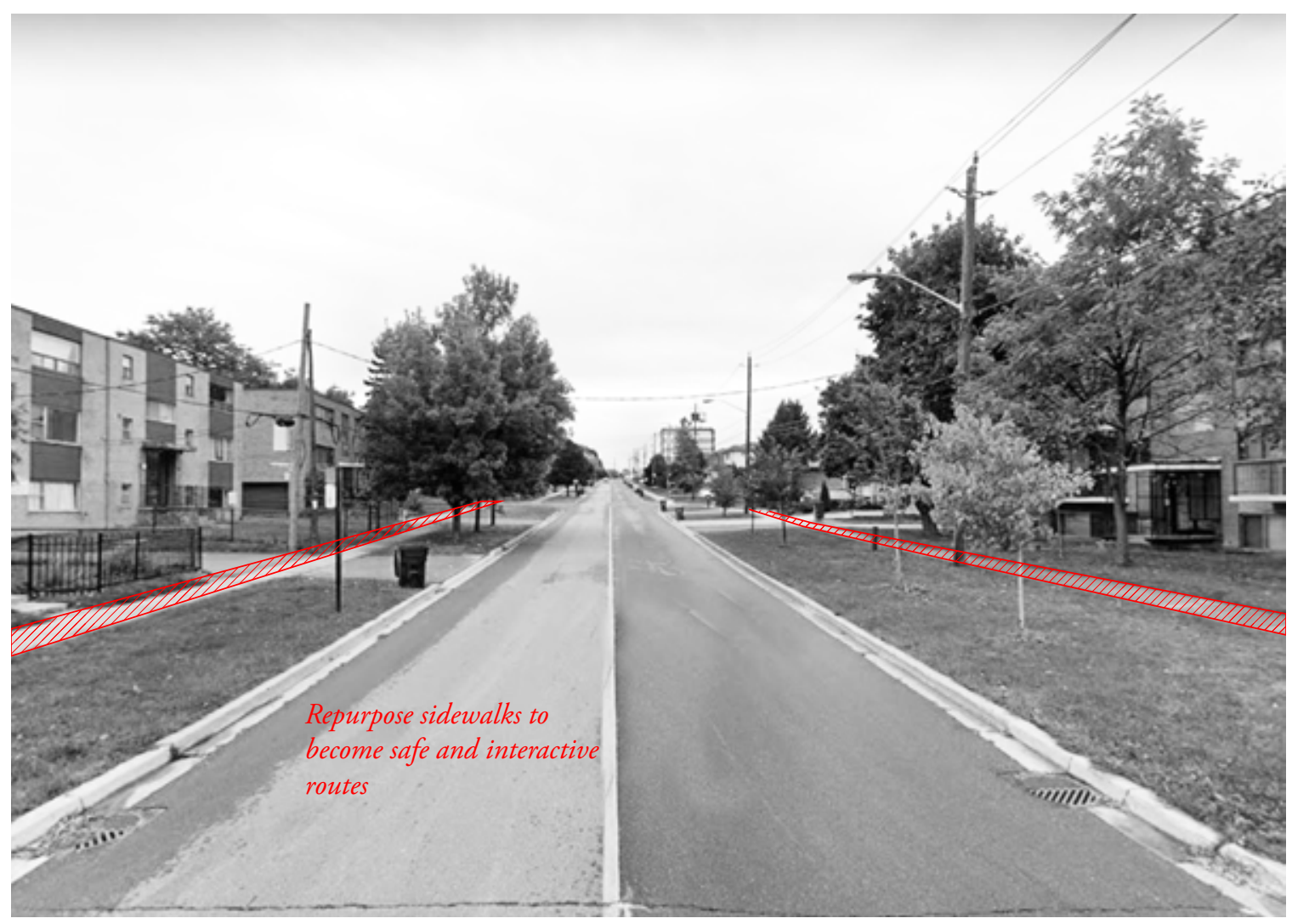

Facing east on Bartley Drive toward the commercial district.

Fig. 28 and 29 / Existing conditons, Victoria Village, Toronto, Ontario. (Images from: Google Images. Annotated in red by Author) 


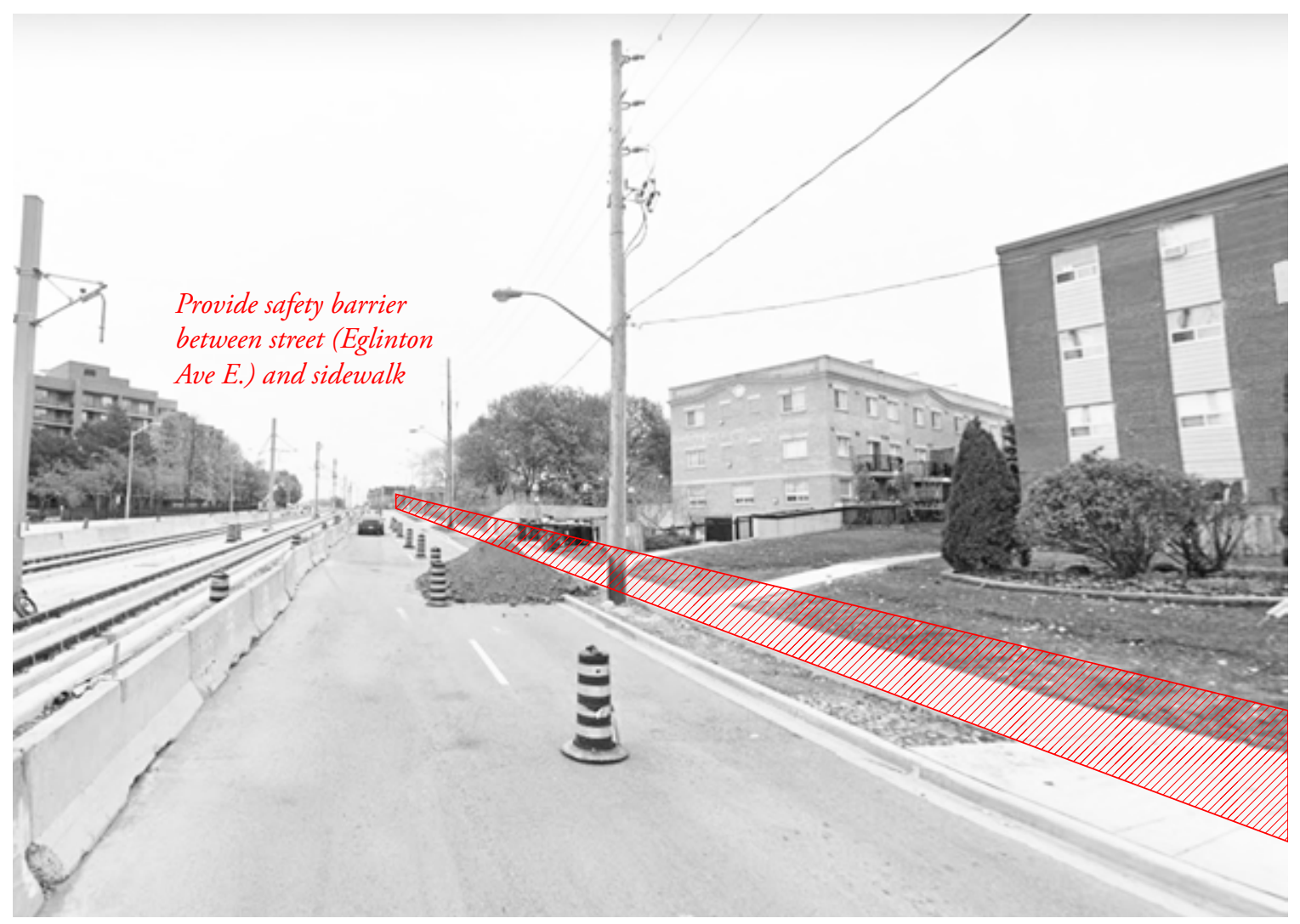

Facing east on Eglinton Ave E.

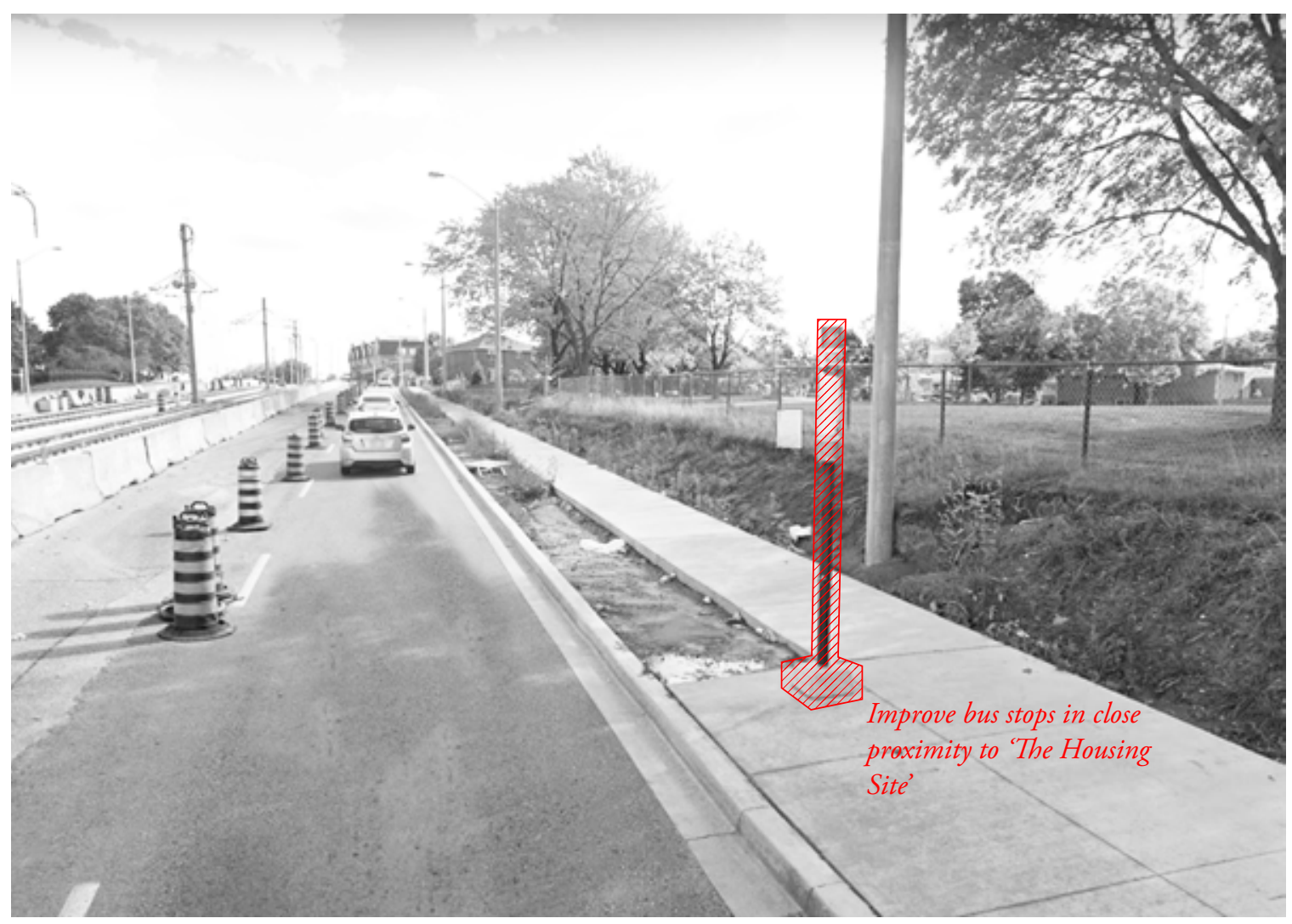

Facing east on Eglinton Ave E.

Fig. 30 and 31 / Existing conditons, Victoria Village, Toronto, Ontario. (Images from: Google Images. Annotated in red by 


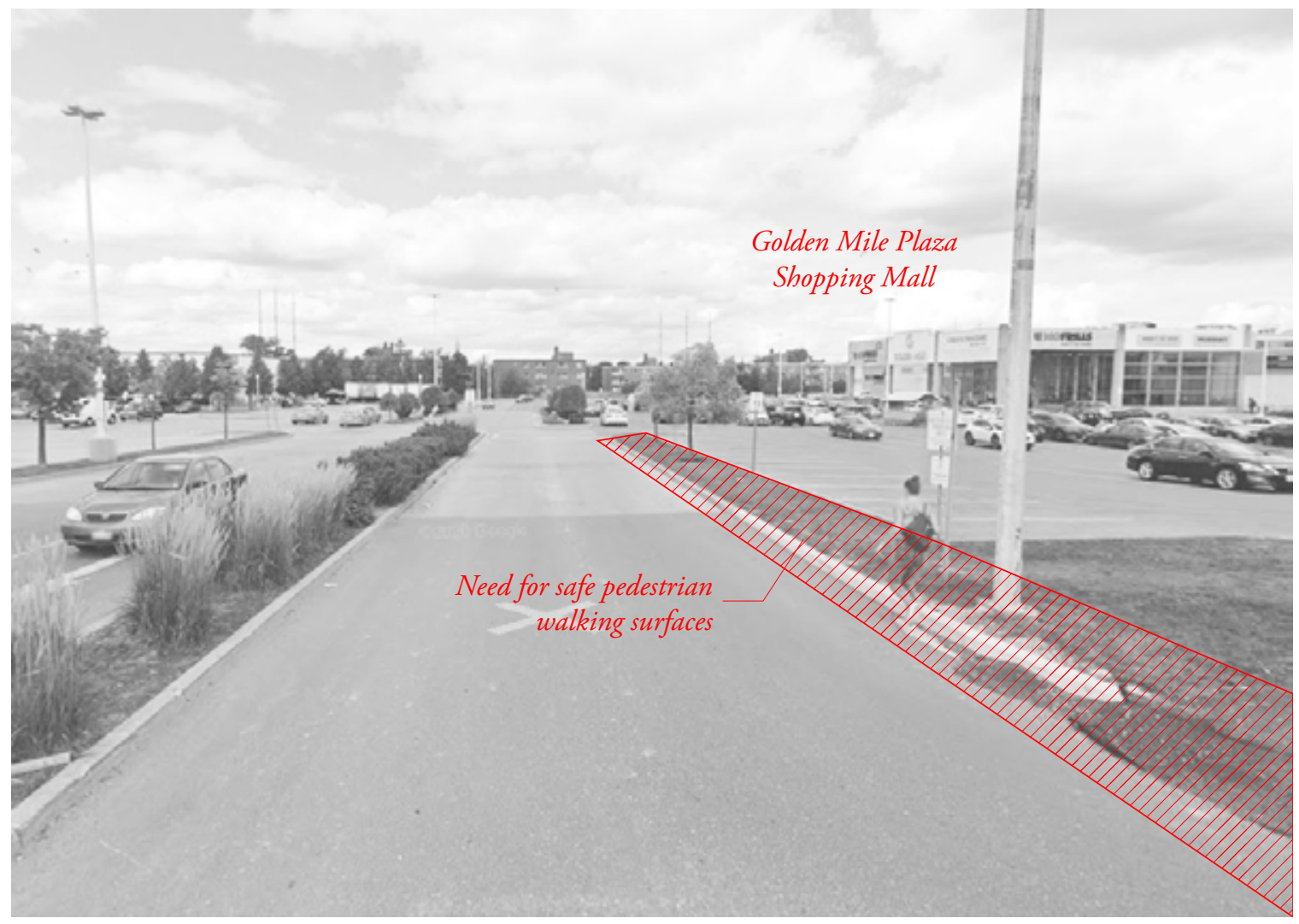

Facing north toward the Golden Mile Shopping Mall.

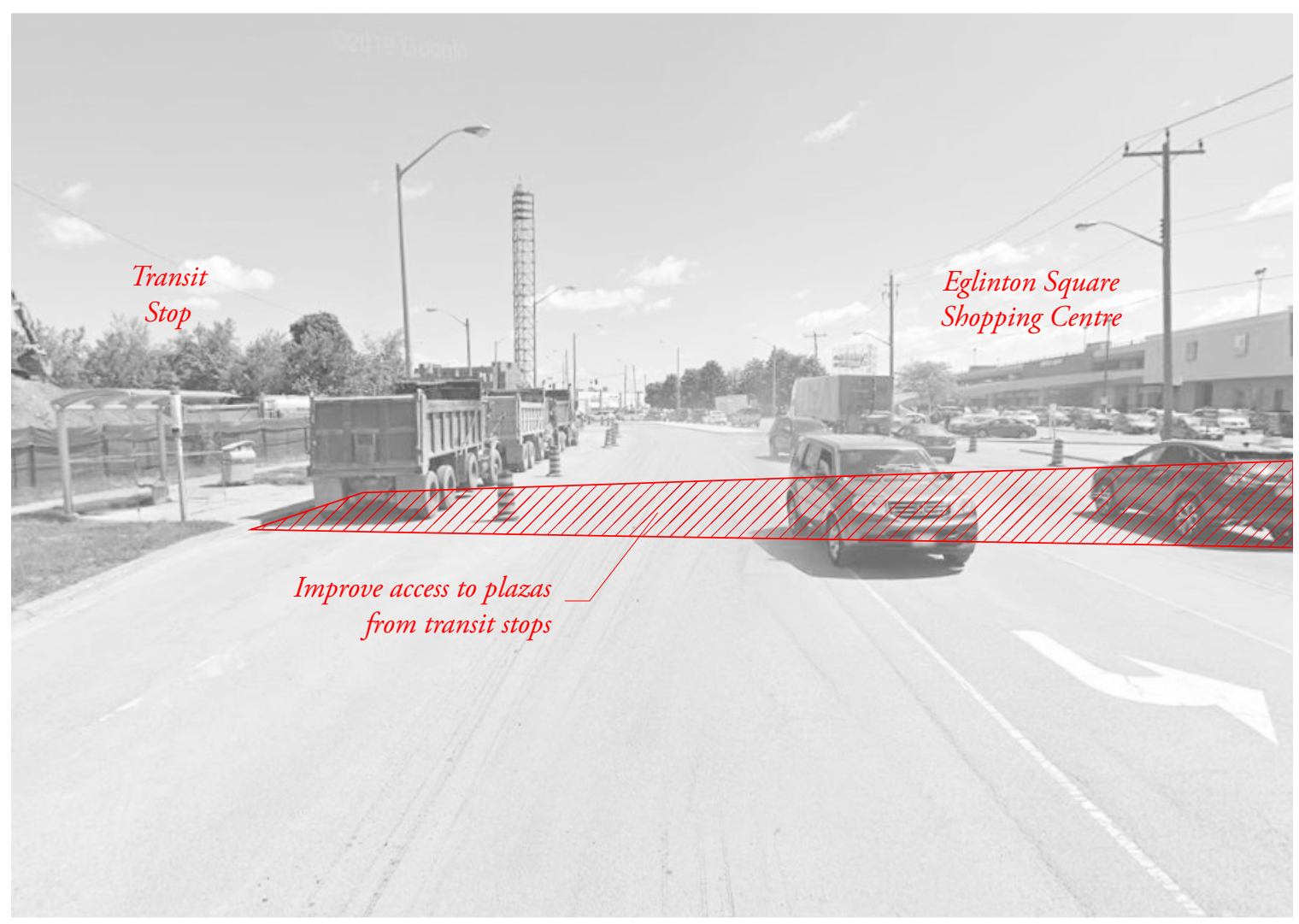

Facing east toward the Eglinton Square Shopping Centre.

Fig. 32 and 33 / Existing conditons, Victoria Village, Toronto, Ontario. (Images from: Google Images. Annotated in red by 


\subsection{The Age-Inclusive Neighbourhood 86}

78 City of Toronto, "104-110 Bartley Drive - Zoning By-law Amendment Application Final Report," June 15, 2018 https://www.toronto.ca/ legdocs/mmis/2018/ny/bgrd backgroundfile-117055.pdf (accessed March 21, 2021).

79 "Bartley Towns in North York," Condos Deal, https:// www.condosdeal.com/ bartley-towns-in-north-york (accessed March 21, 2021).
80 Forsyth et al., "Improving housing and neighbourhoods for the vulnerable: older people, small households, urban design, and planning," 172.
In accordance with a 2018 Zoning By-law Amendment Application, there is currently a proposal to develop 104-110 Bartley Drive into an 84-unit townhouse freehold and condominium development, with a maximum height of four storeys (or an average building height of 12.5 metres). ${ }^{78}$ This proposal is yet another generic composition of "exclusive enclave modern townhomes,"79 and ultimately, does not offer improvement to the existing residents. (See Figure 16).

As a point of departure, this thesis engages with the existing proposal to create a new housing proposal that would be inclusive of the needs of the increasingly aging population and a reflection of what could have been: an alternative approach to the neighbourhood block. This is Part 1, referred to as: The Housing Site.

As a secondary component, or Part 2, the proposed design explores ways to connect 'The Housing Site' with existing city infrastructure and amenities. After all, as Ann Forsyth et al. discuss in Improving housing and neighbourhoods for the vulnerable: older people, small households, urban design, and planning:

“...the physical environment plays a central role in the lives of older people at a scale beyond the individual home [...] While the home is certainly important, it is also a hub from which older people go out into their surroundings to engage with others, access services..." 80 


\title{
Part 1: The Housing Site
}

$$
+
$$

\section{Part 2: Neighbourhood Connectivity}

\author{
$=$ \\ Design Proposal: \\ The Age-Inclusive Neighbourhood Model
}


Attachment 2: Location Map

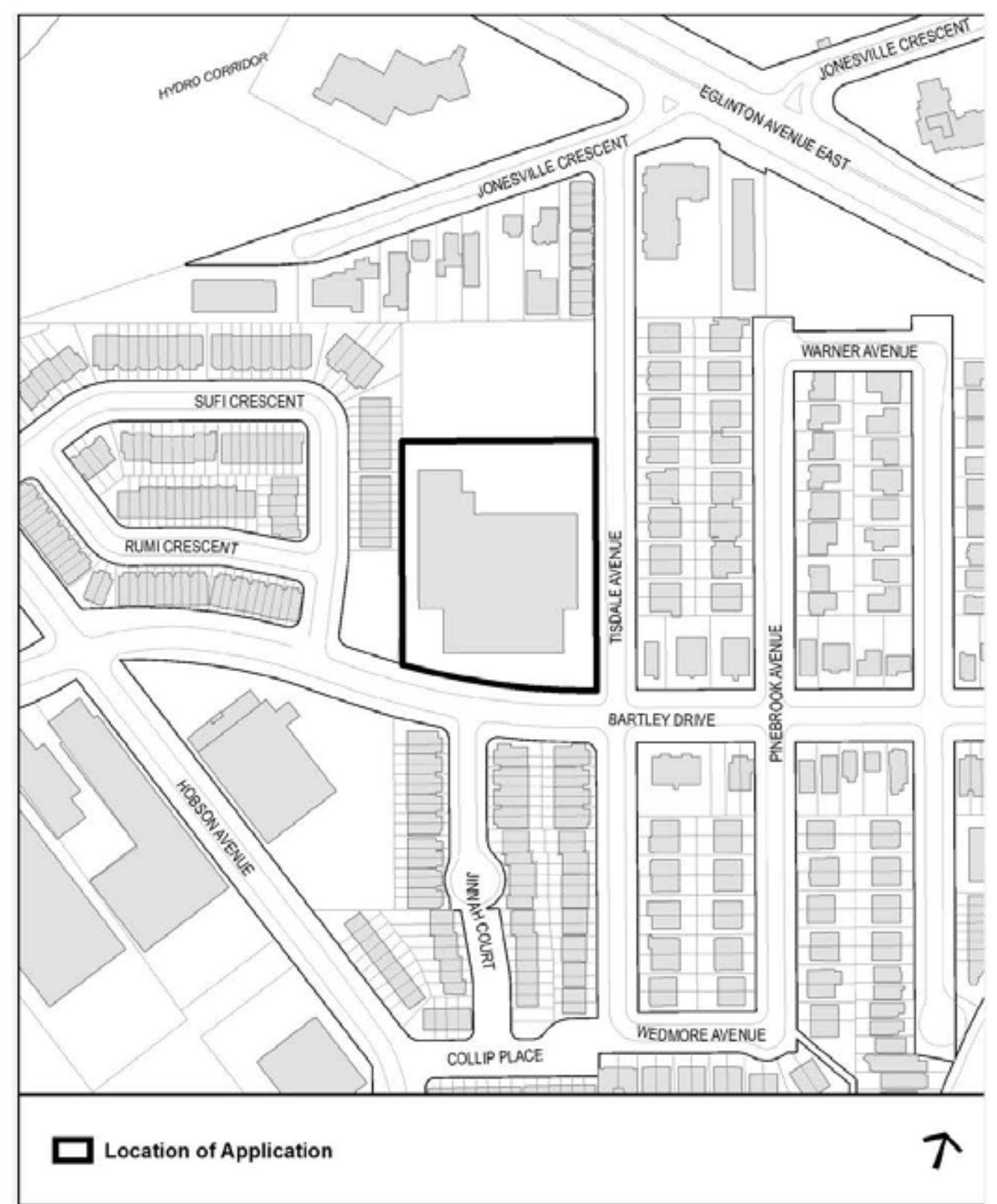


Attachment 9: Final Site Plan

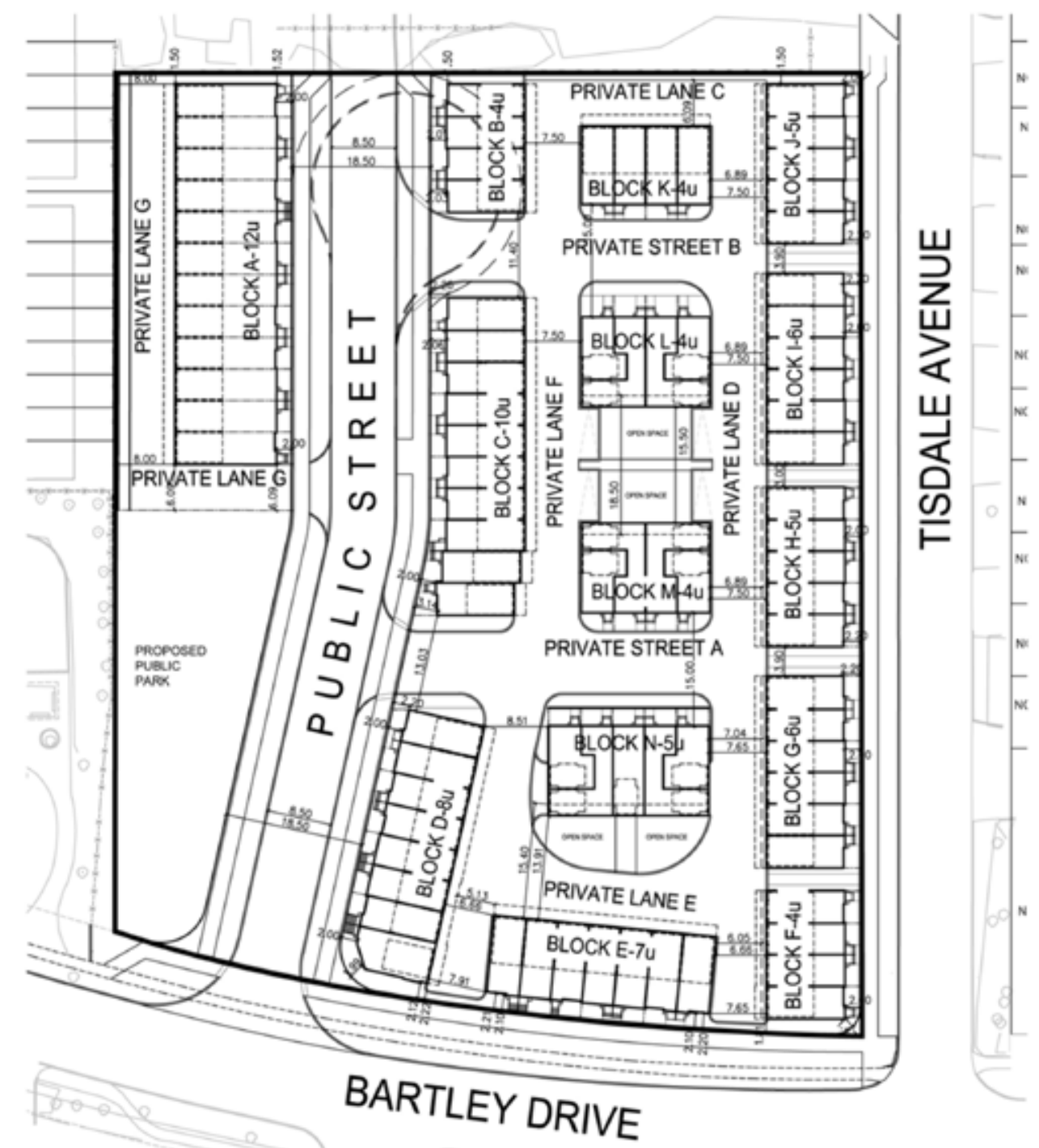

Final Site Plan

$104 \cdot 110$ Bartley Drive

Applicant's Submitted Drawing

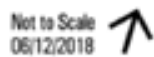

File 17209538 NNY 3402

Page 29 of 34 


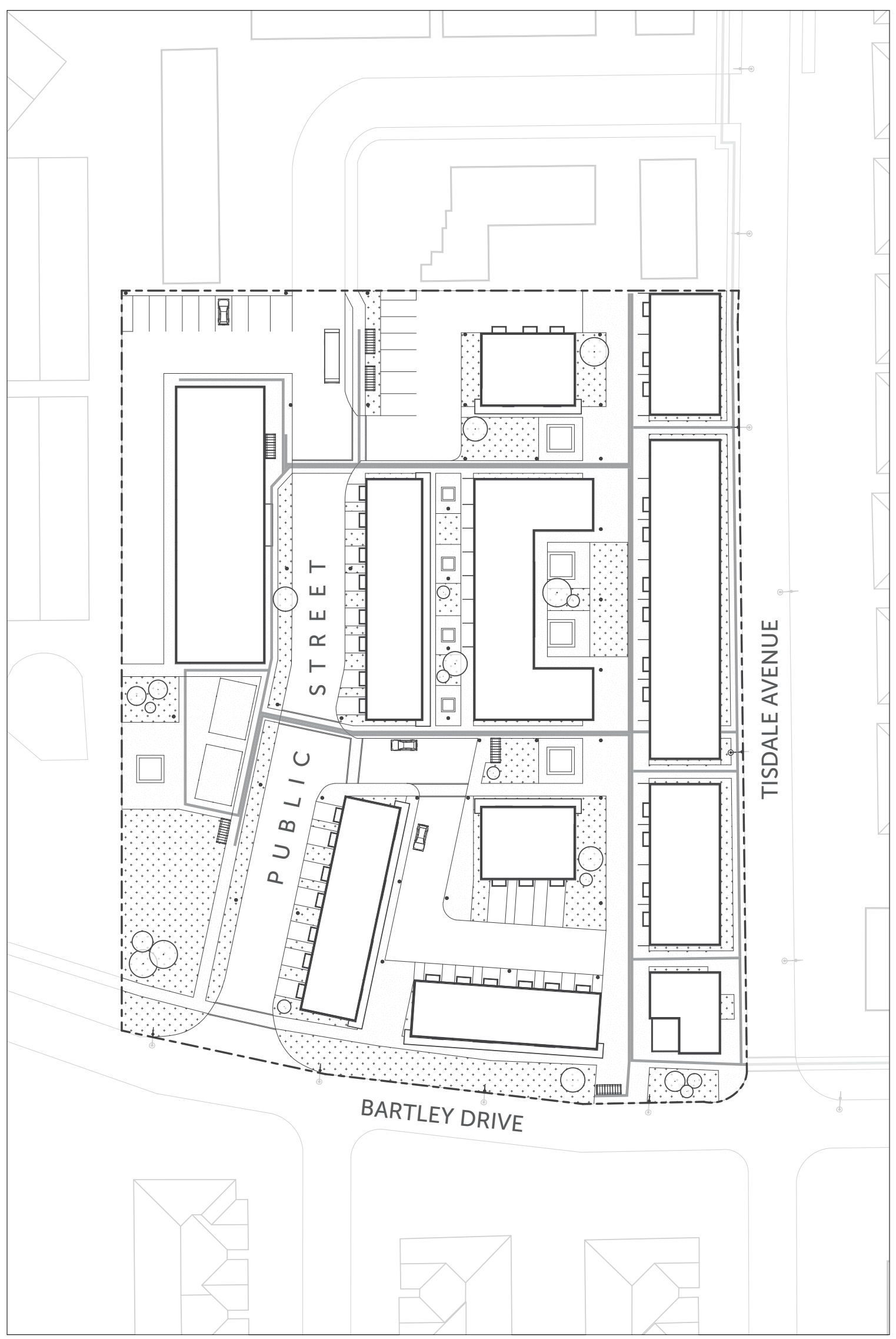

Fig. 36 / Part 1: The Housing Site - Site Plan. 
Attachment 9: Final Site Plan

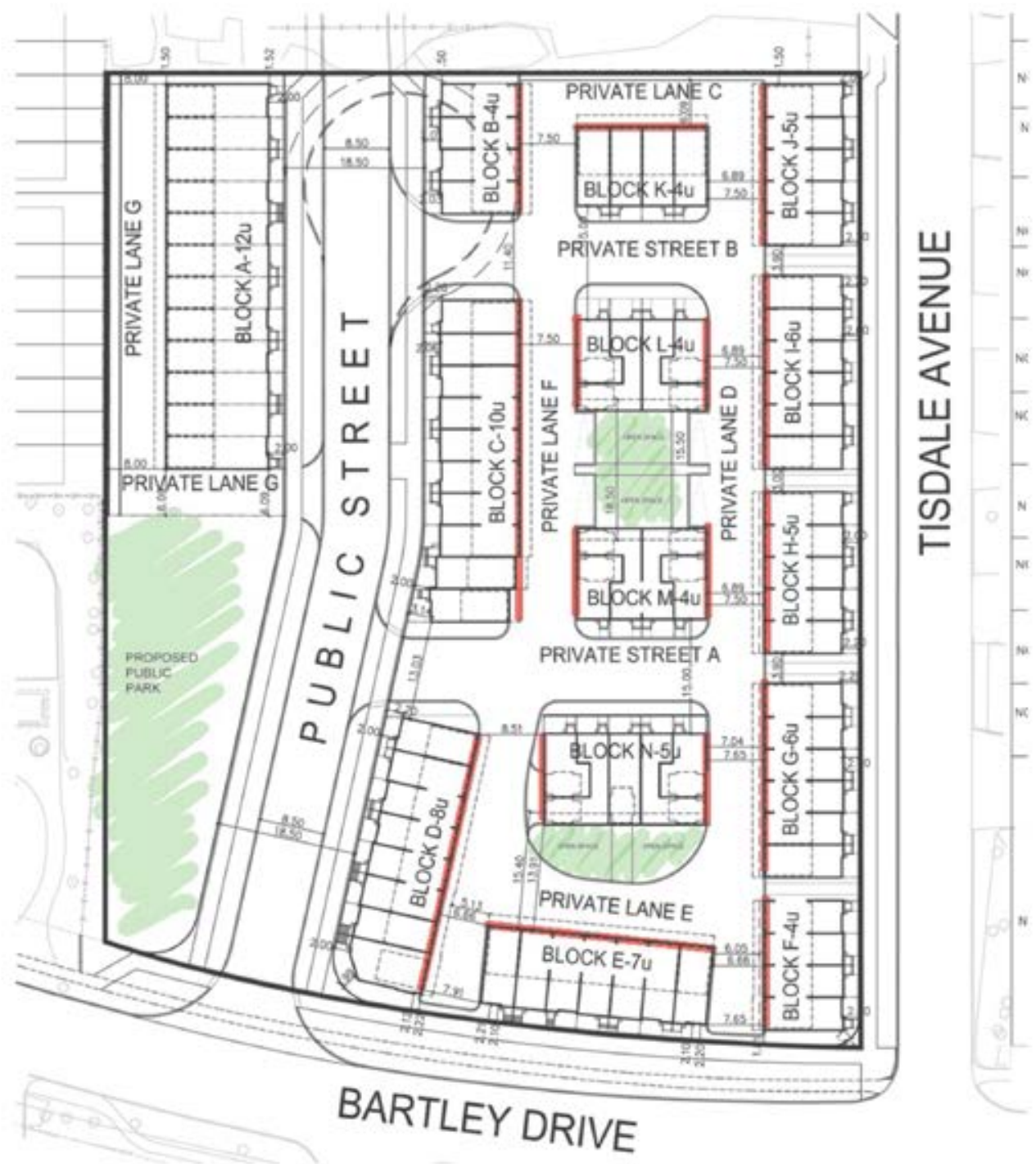

Final Site Plan

Applicant's Submitted Drawing

Not to scail $\uparrow$
$104 \cdot 110$ Bartley Drive

File 17209538 NNY $340 Z$ 


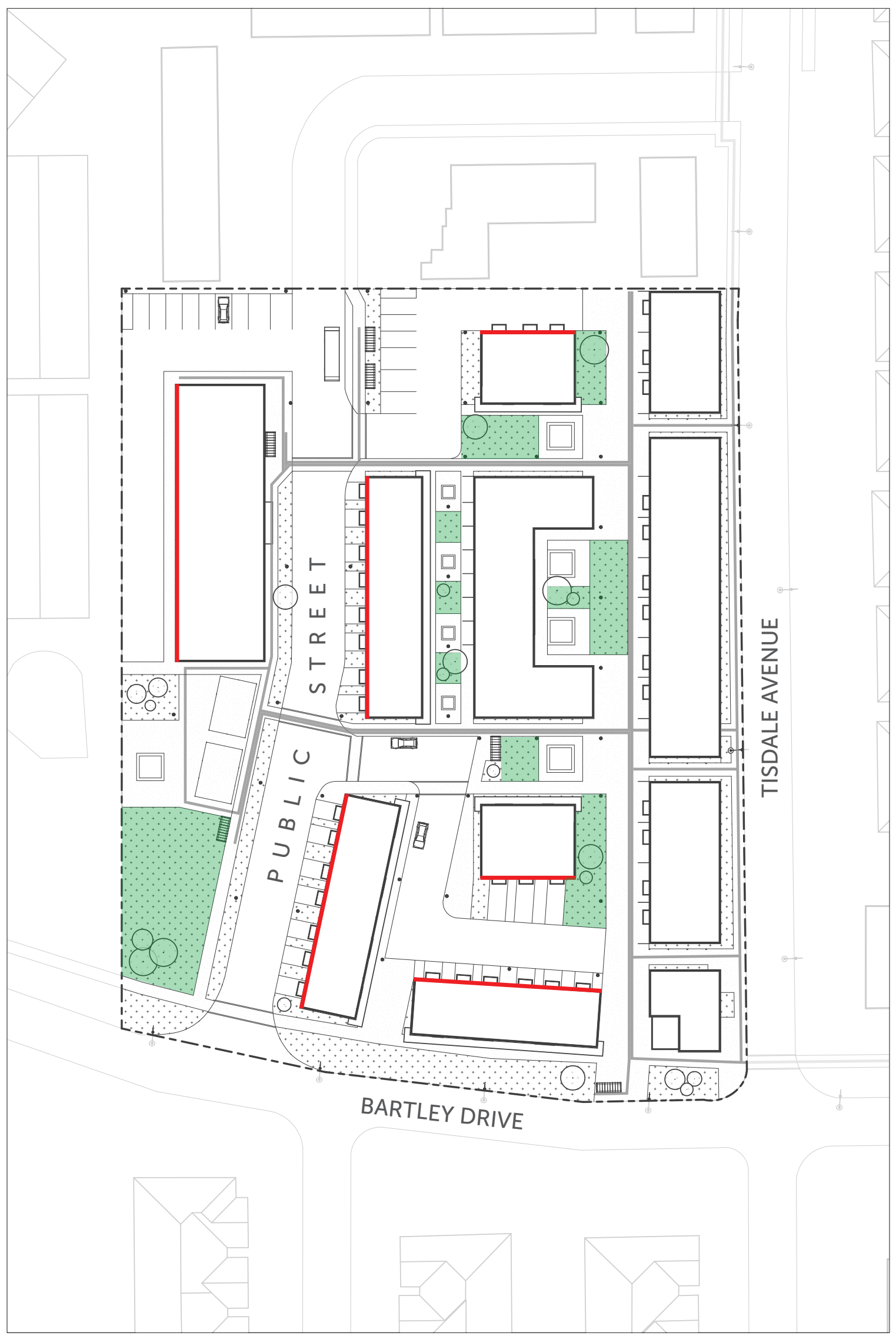

Fig. 38 / Part 1: The Housing Site - Site Plan. Annotated to illustrate open green space (green) and locations of garages occupying ground floor space (red)). 
Attachment 9: Final Site Plan

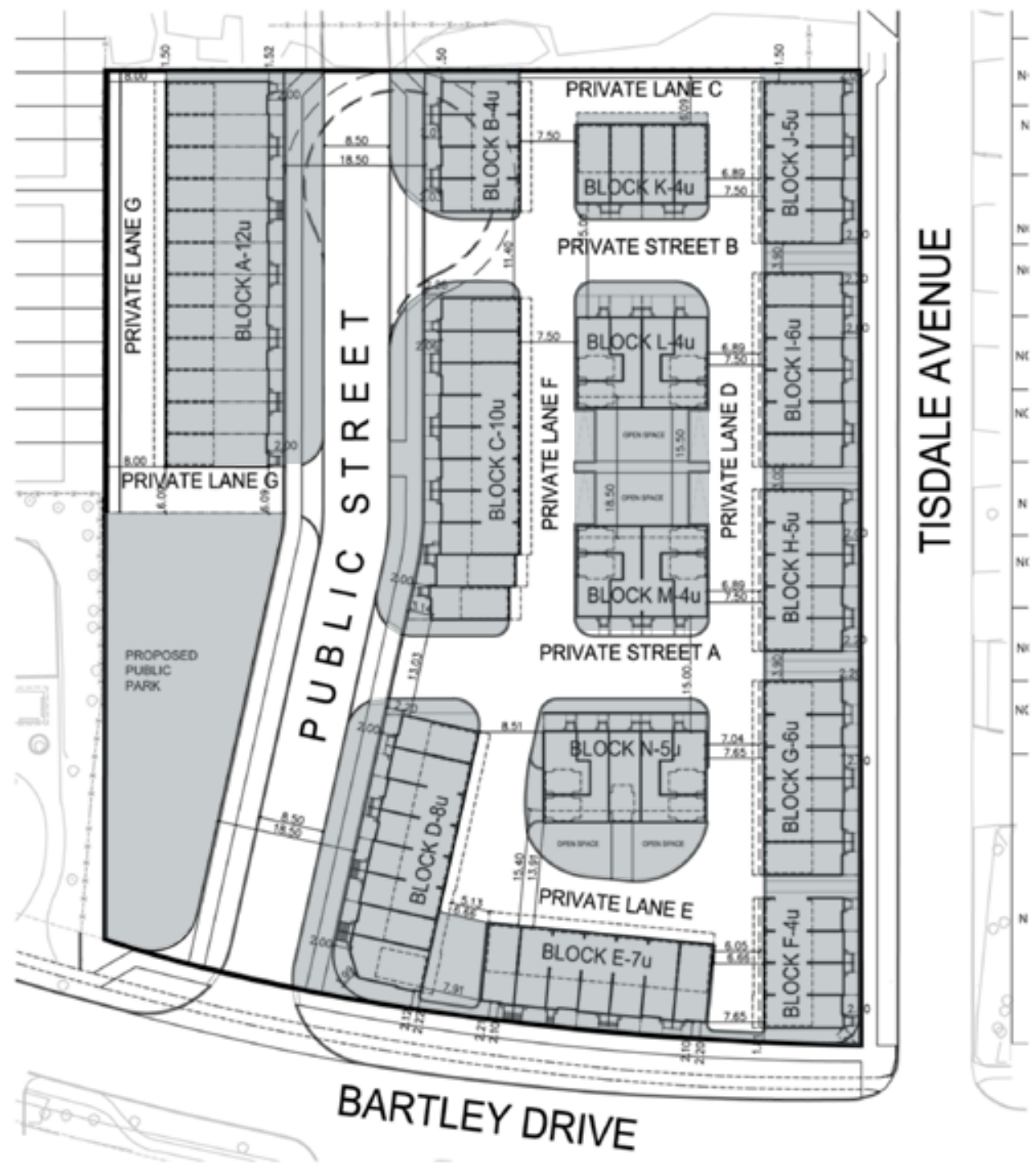

Final Site Plan

$104 \cdot 110$ Bartley Drive

Applicant's Submitted Drawing

Mon to scale 122018

File 17209538 NNY 3402 


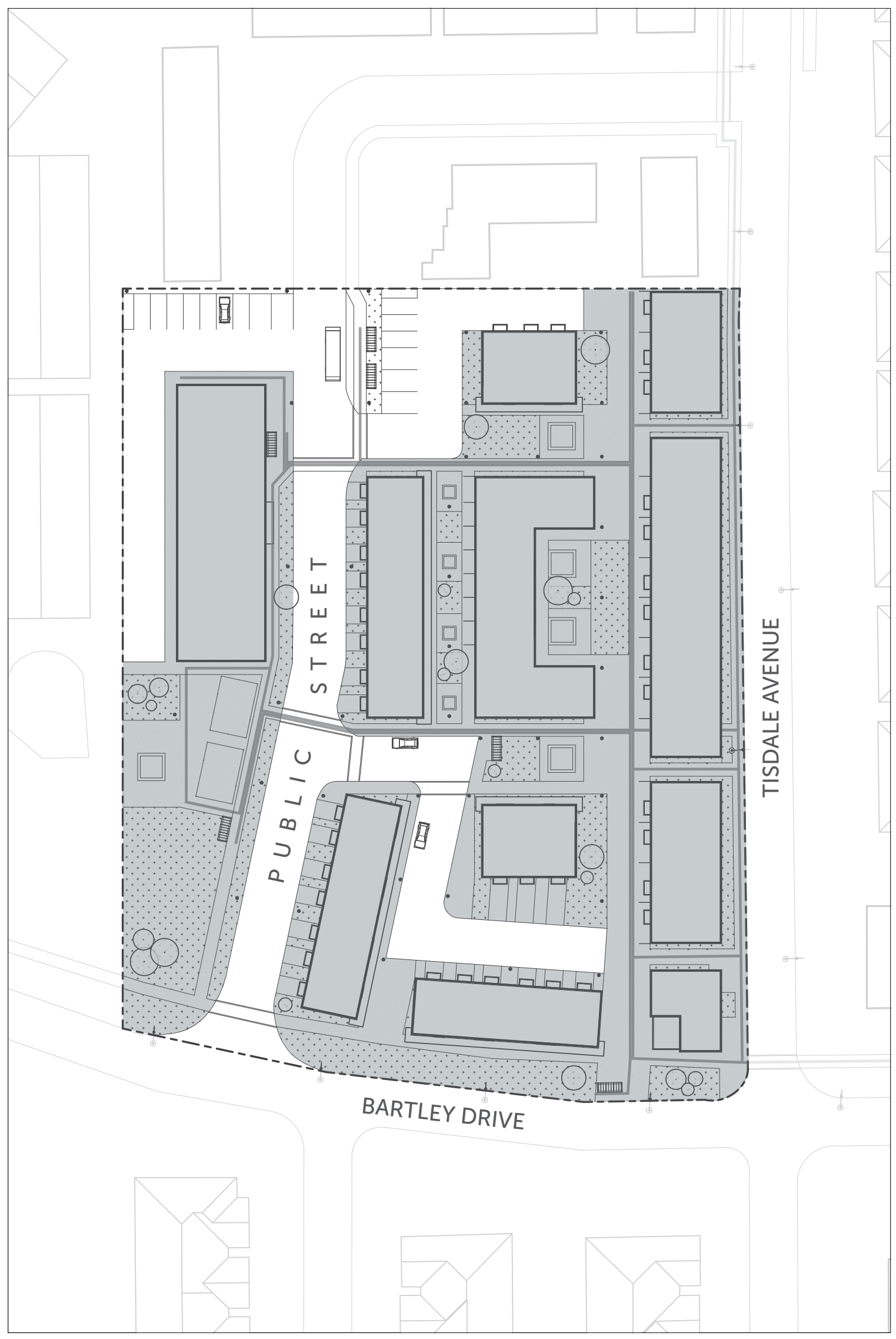

Fig. 40 / Part 1: The Housing Site - Site Plan. Annotated to illustrate the site vs. road surfaces. 


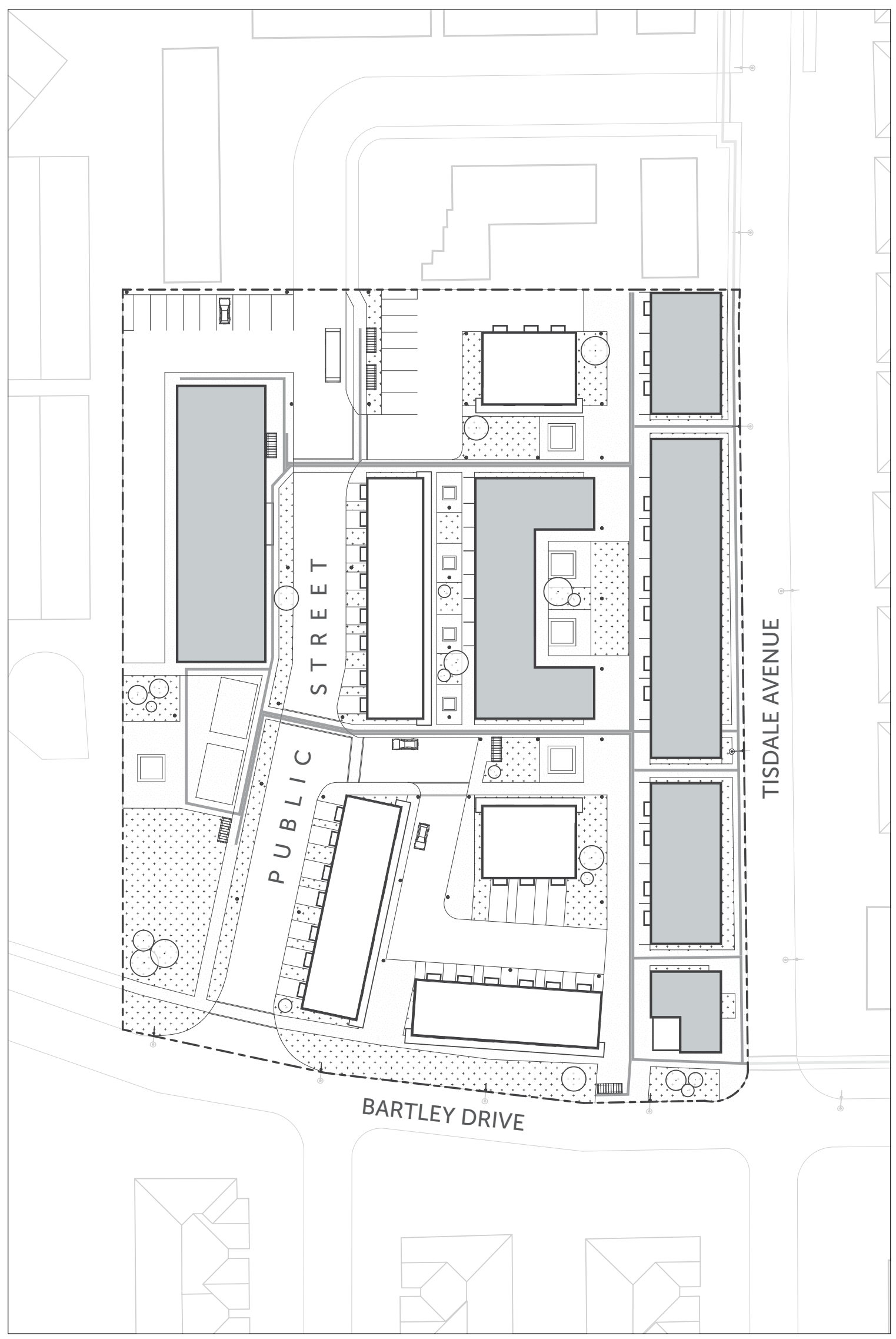

Fig. 41 / Part 1: The Housing Site - Site Plan. Annotated to highlight the buildings designed especially for seniors housing. 


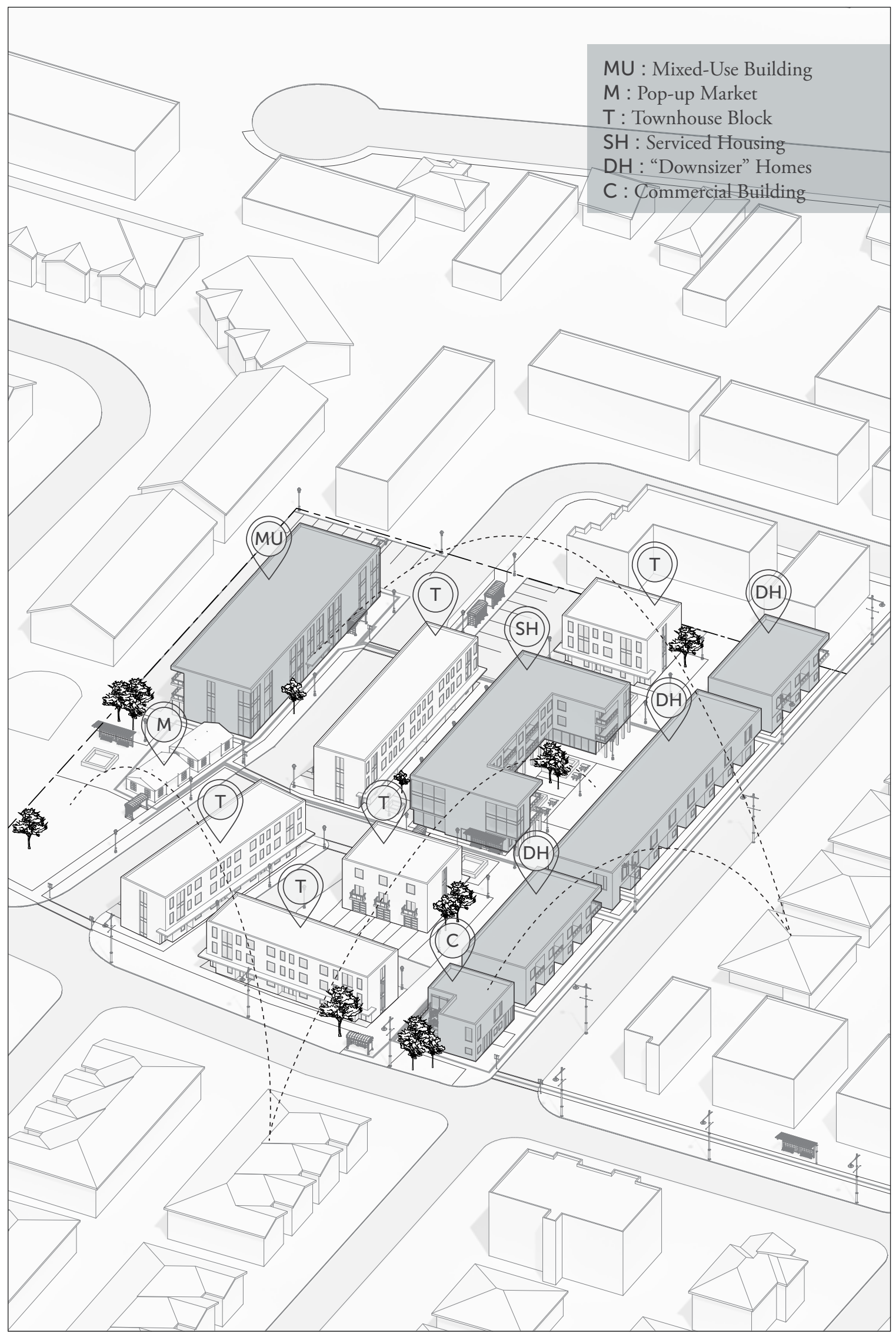

Fig. 42 / Part 1: The Housing Site. Annotated to highlight the buildings designed especially for seniors housing. 


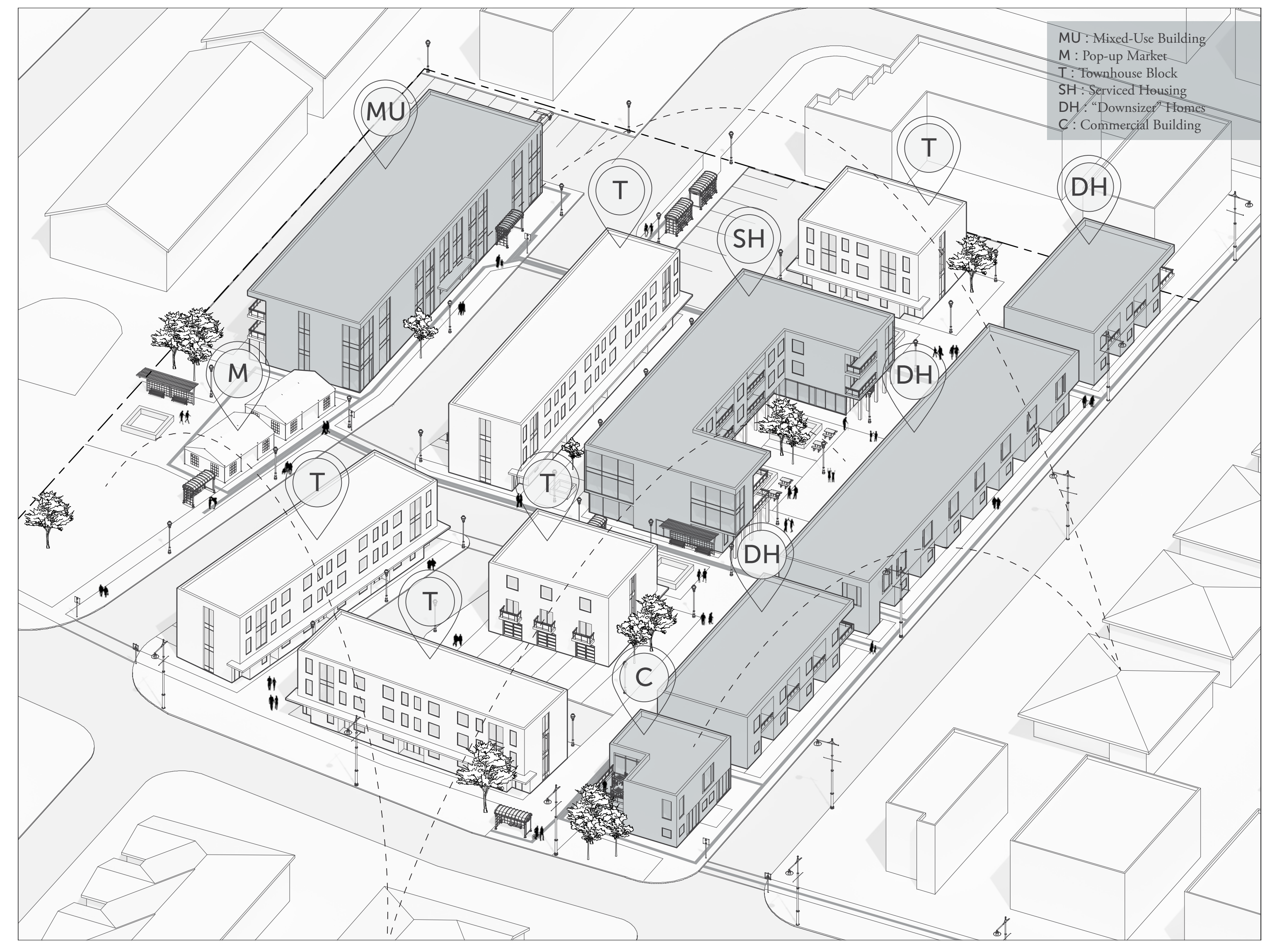




\section{TOWNHOUSES (T)}

- $\quad$ Provides standard housing options for families and aging in place

- $\quad$ Encourages a diverse age demographic for the site

\section{MIXED-USE BUILDING (MU)}

- $\quad$ Provides amenity spaces (fitness areas, event spaces) for residents on site and in the neighbourhood at large (Rec. \#15, TSS 2.0)

- Hosts apartment spaces for young professionals, couples, and the opportunity for intergenerational living (Rec. \# 11, TSS 2.0)

\section{SERVICED HOUSING (SH)}

- $\quad$ Reduced the scale of the nursing home to a home-like cluster (8-9 residents per floor with shared common areas (kitchens, living space))

- $\quad$ Access to central green space on ground level and balconies on upper levels

Precedents: The Green House Project \& De Hogeweyk

\section{"DOWNSIZER" HOMES (DH)}

- $\quad$ For couples or individuals seeking to downsize their living space and/or to age in place (age in community)

- $\quad 1$-storey and 2-storey unit options

- 2-storey option provides opportunity for shared living/intergenerational living with added space

\section{COMMERCIAL BUILDING (C)}

- $\quad$ Addresses the corner of the site with a restaurant and convenience stores/pharmacy

\section{OUTDOOR SPACE}

- Opportunity for pop-up market

- Opportunity to integrate senior-friendly fitness equipment (Rec. \#7, TSS 2.0)

- Opportunity for community gardens 


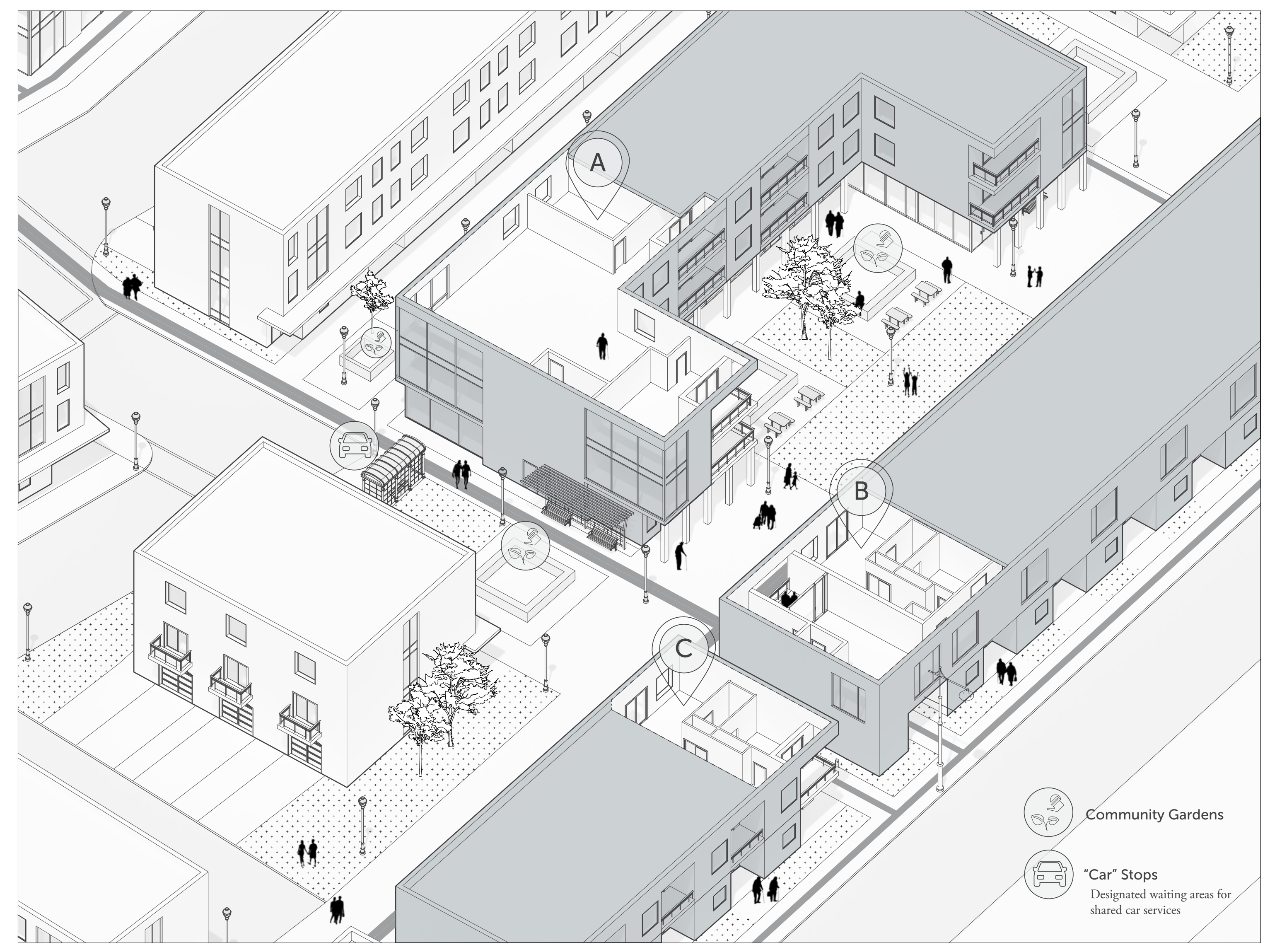




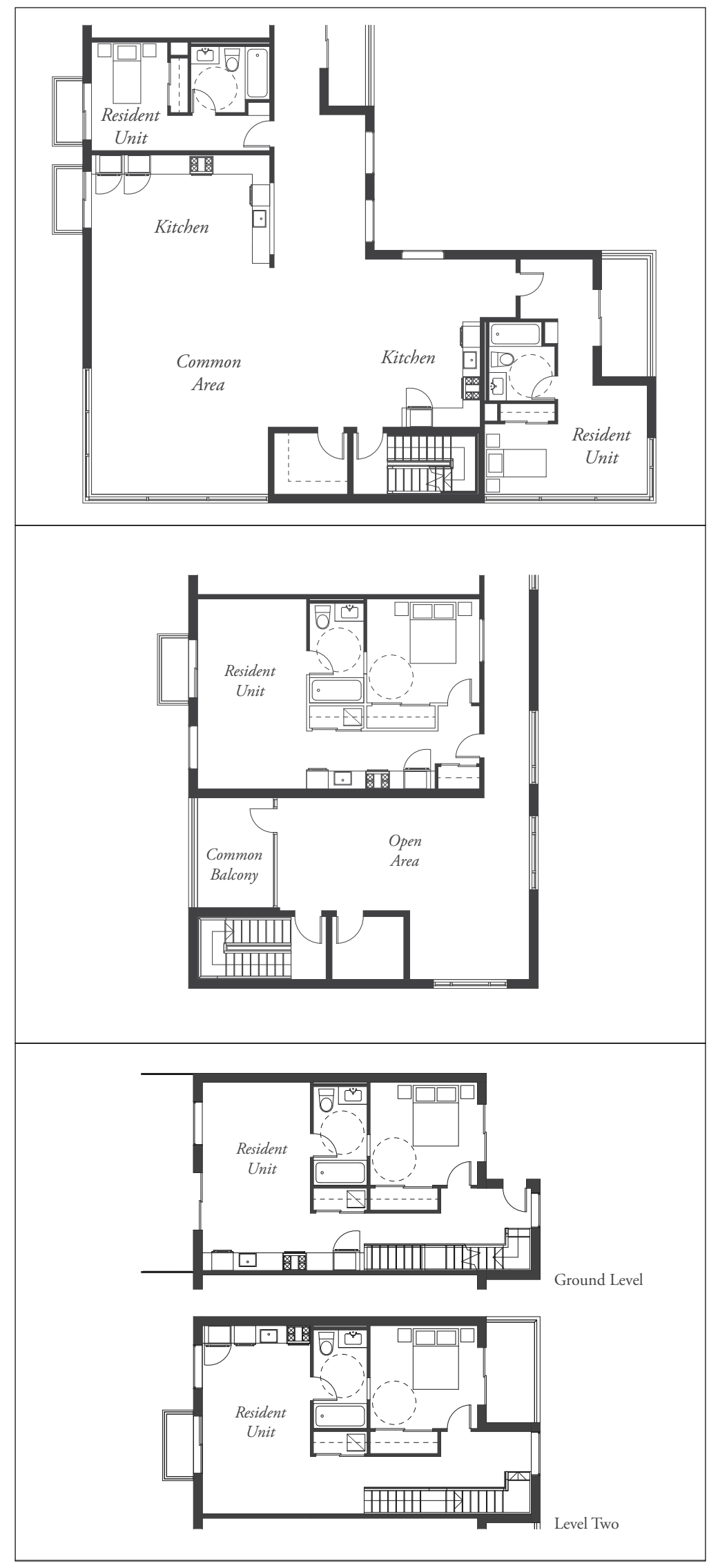

A

B

C 


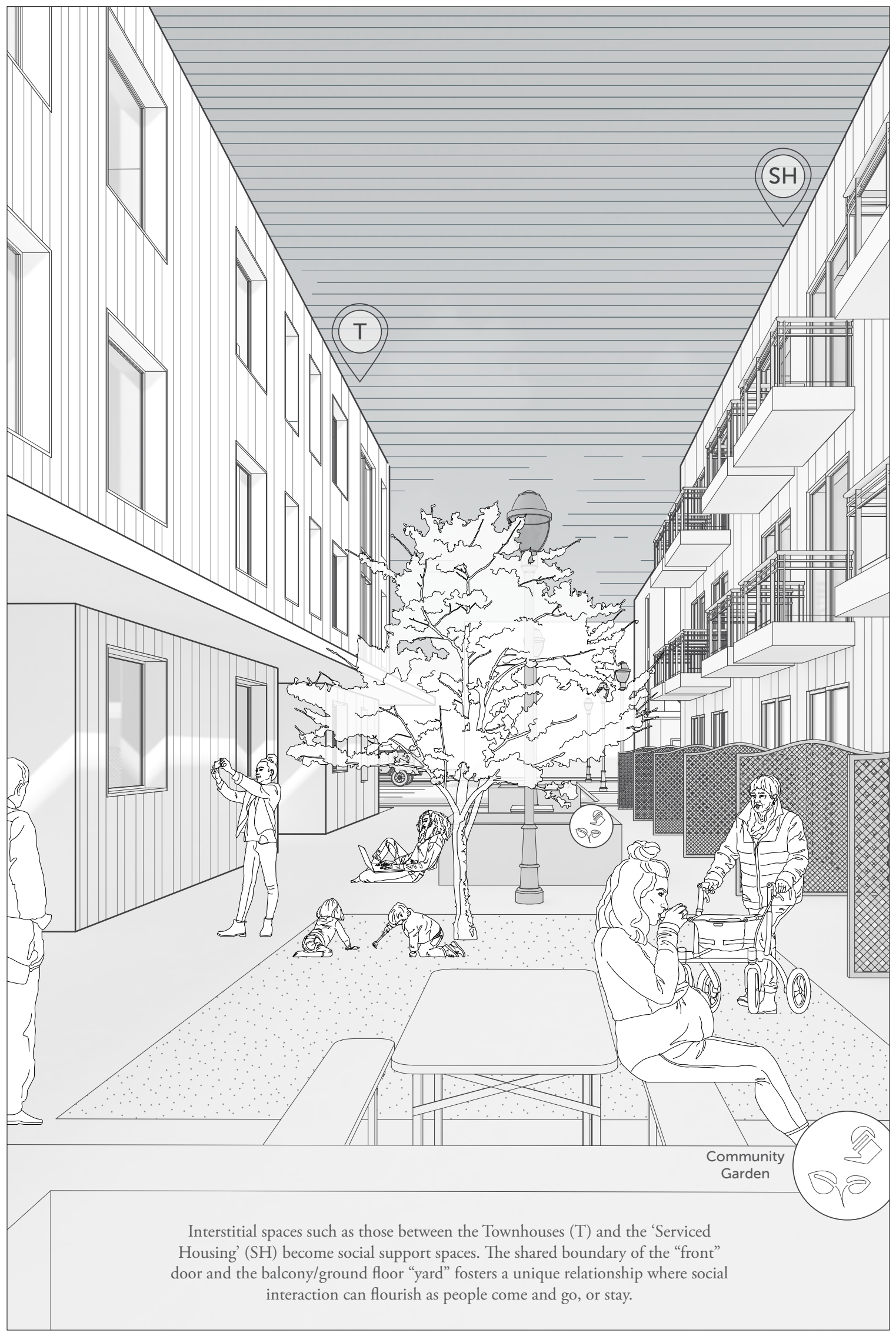

Fig. 49 / Part 1: The Housing Site. 3D view between townhouse block (T) and serviced housing (SH). 


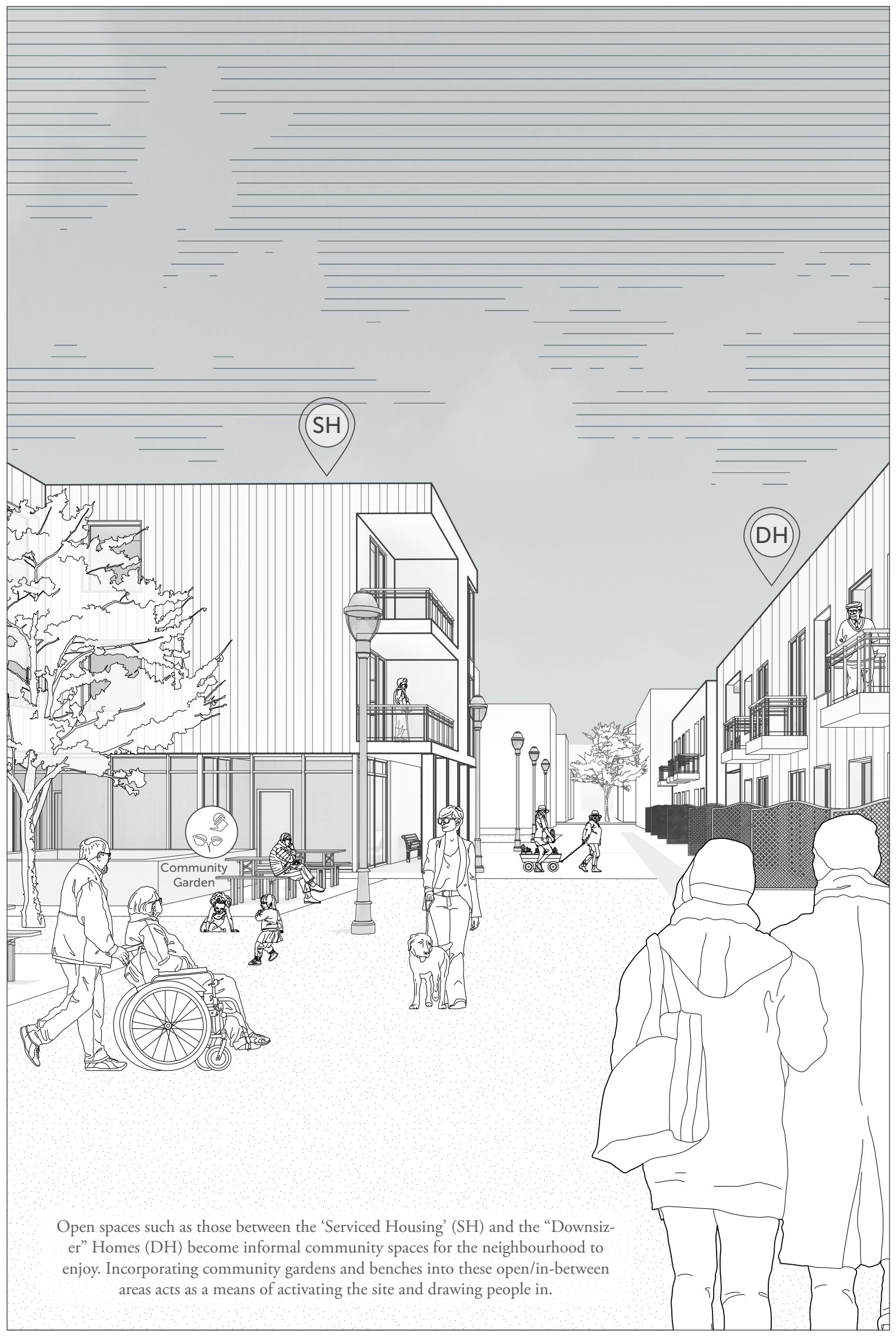

Fig. 50 / Part 1: The Housing Site. 3D view between serviced housing (SH) and "downsizer" homes (DH). 


\begin{abstract}
'In the context of aging in place and the isolation that accompanies some older adults' experience of aging, neighbourhood social capital may mediate the risk of displacement either to an institutional setting or to another distal neighbourhood." ${ }_{81}$
\end{abstract}

- Julia Janes, Institute for Life Course and Aging, University of Toronto 
This section, Part 2: 'Neighbourhood Connectivity' sets out a defined route within the neighbourhood (Figure 44). This route travels along the eastern side of 'The Housing Site' and extends toward Victoria Park Ave and into the commercial zones. This extension provides the opportunity to engage with the future LRT stop and the established malls: Golden Mile Plaza Shopping Mall, and Eglinton Square Shopping Centre, which are abundant in amenities/services that are beneficial to all residents. Making connections with existing services in the neighbourhood is a meaningful way to restore a sense of autonomy among senior residents who may be without access to a car or have reduced mobility.

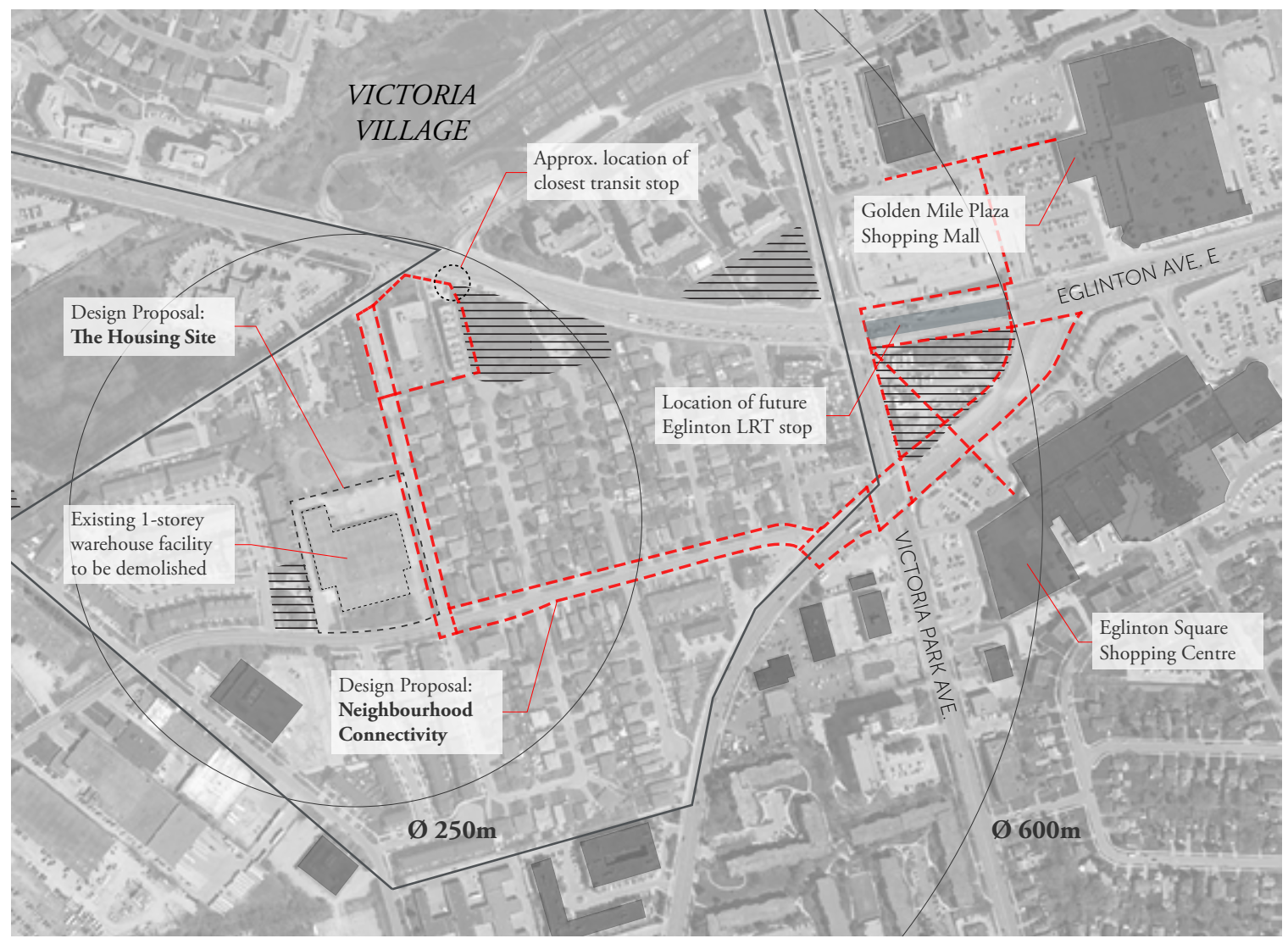

Fig. 51 / Design Proposal: Focus Area. Part 2: Neighbourhood Connectivity. 


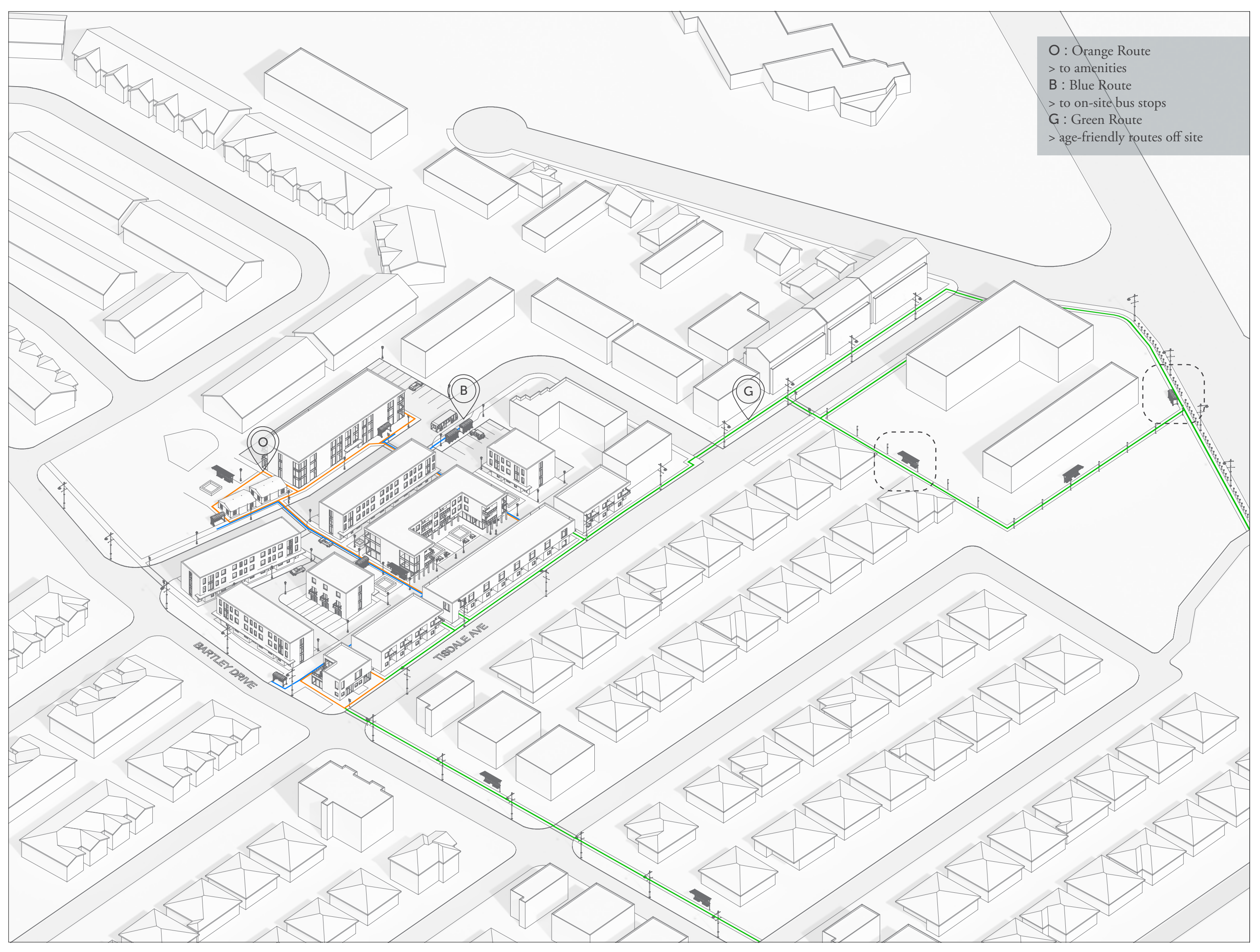




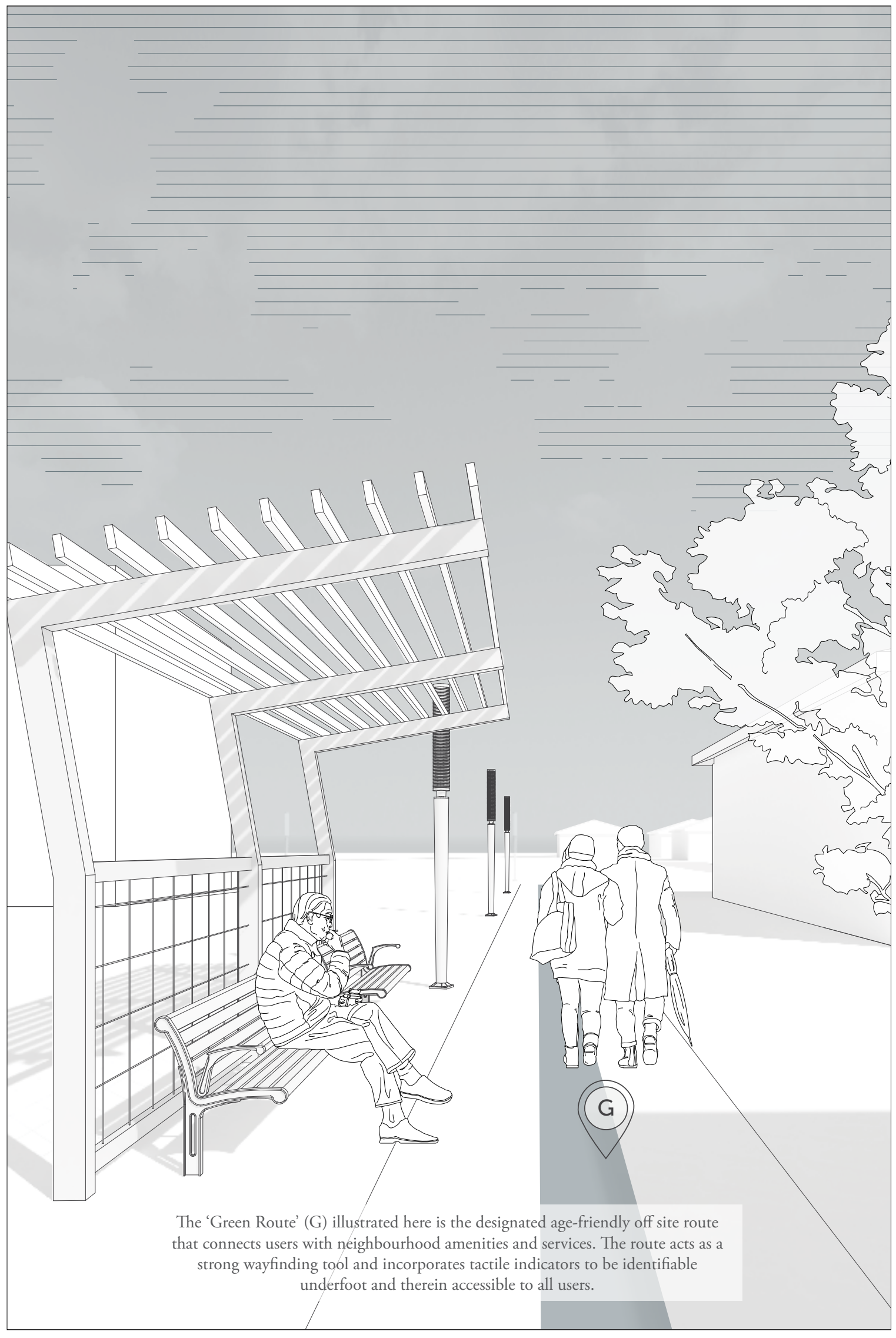

Fig. 53 / Part 2: Neighbourhood Connectivity. 3D view of defined neighbourhood route. 


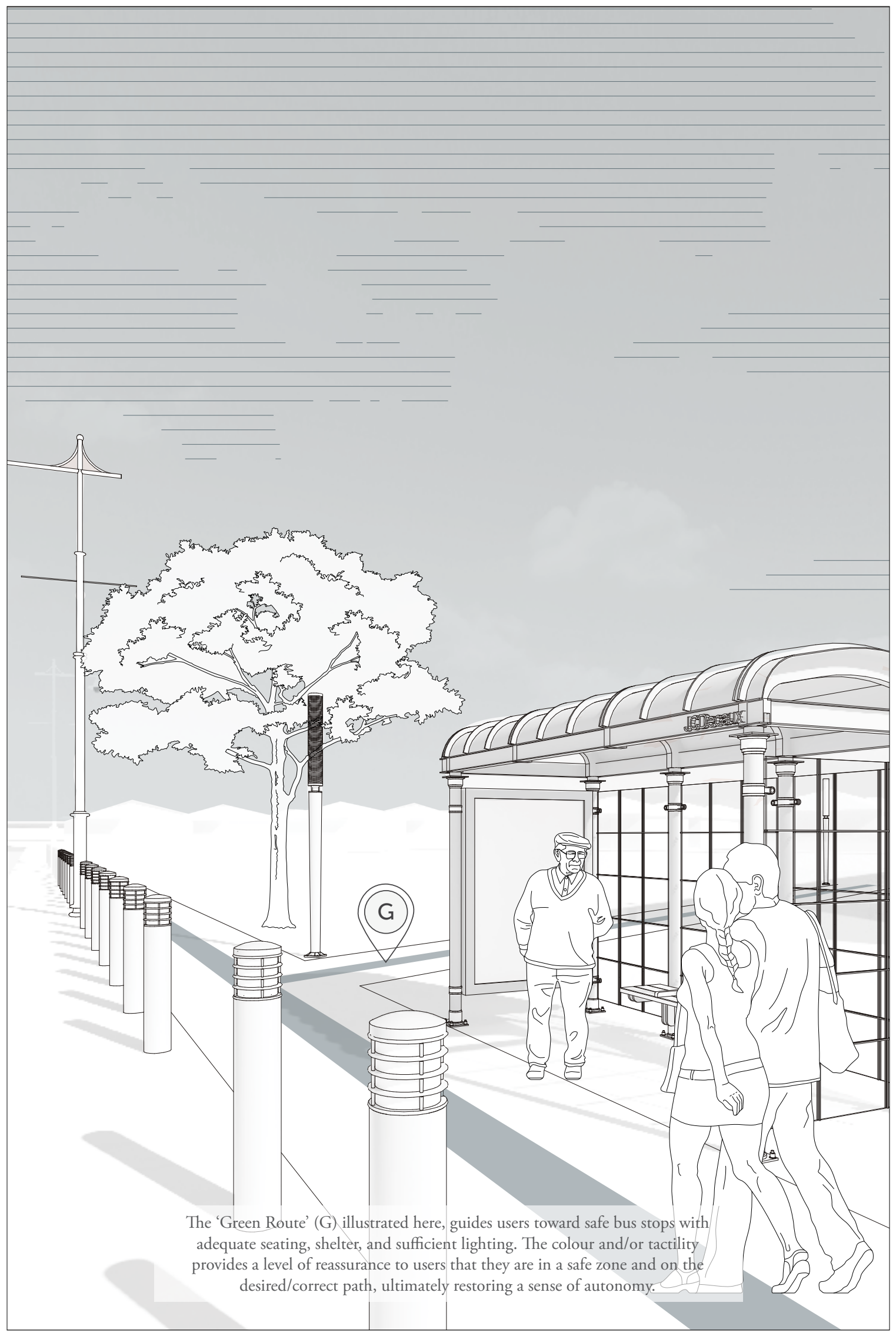




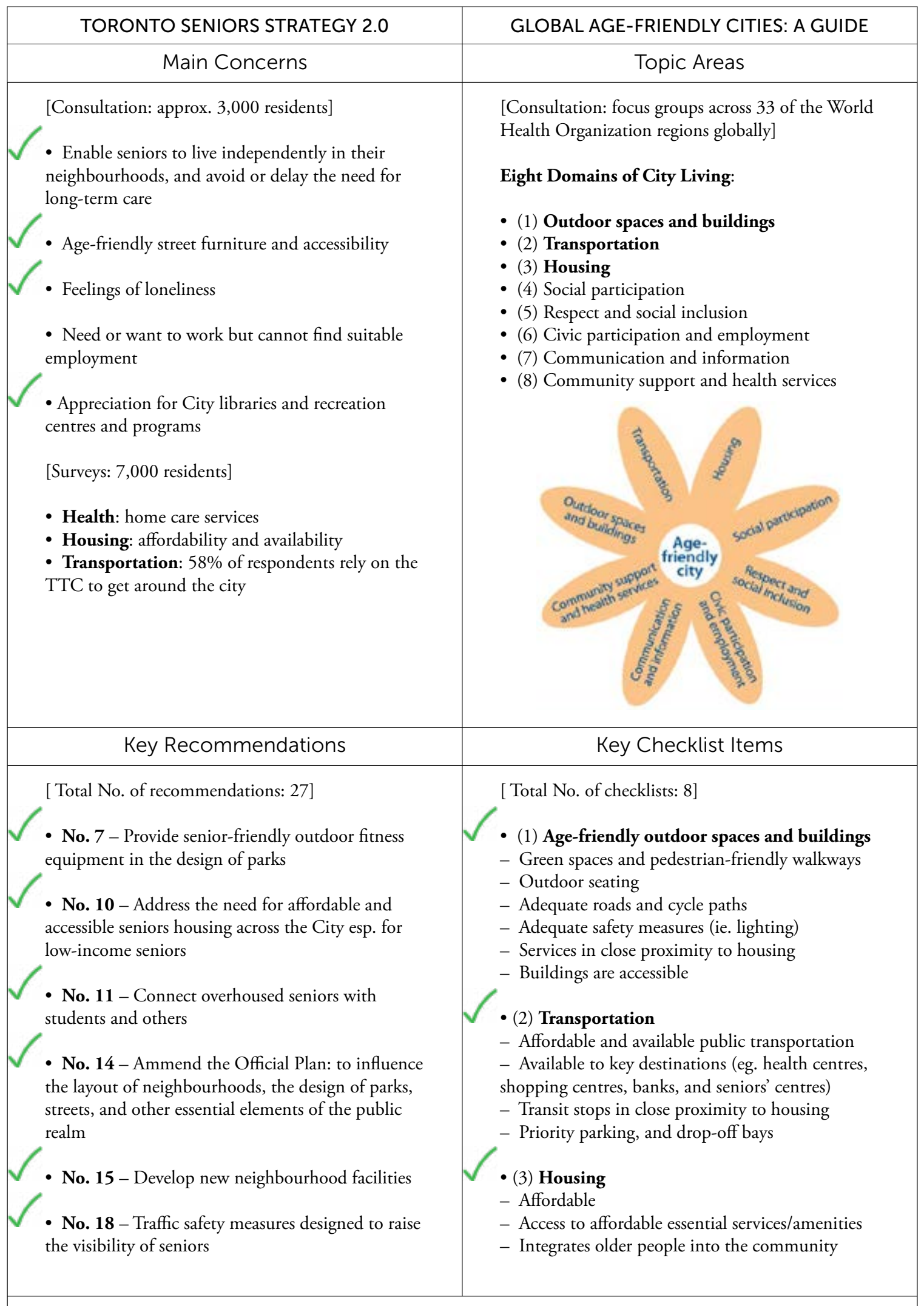

Key Themes: (1) Outdoor Spaces \& Buildings (2) Housing (3) Transportation 


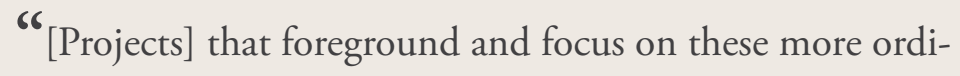
nary uses of existing spaces are more easily overlooked perhaps because they do not offer the promise of a new solution [...] They rely, instead, on the existing: identifying the value of what is already there and building on these..." 82
\end{abstract}

- Sophie Handler, An Alternative Age-Friendly Handbook 
The Age-Inclusive City is a hopeful proposal that as Toronto continues to age and the need for alternative living arrangements grows stronger, more neighbourhoods will take on projects that are inclusive of older residents. As a city of neighbourhoods, Toronto can only become truly age-inclusive when each and every neighbourhood provides options and opportunities for seniors to thrive in their built environment.

The World Health Organization highlights:

" $[\mathrm{H}]$ ealthy, older people are a resource for their families, their communities, and the economy. [...] Vibrant cities benefit a country's entire population - urban and rural. Because cities are the centre of cultural, social and political activity, they are a hothouse for new ideas, products and services that influence other communities and therefore the world." 83

It is for this very reason that the city of Toronto was selected for this proposal. As the capital of the province of Ontario, and Canada's largest city, Toronto is recognized on a global stage, and therein, so too are its actions and innovations. 


\section{Conclusion}

Through the analysis of different strategies, innovations, and precedents, it is clear that there is an overall desire among seniors to improve their physical environments at not only the scale of the house, but at the scale of the neighbourhood. Improving housing options and the public realm to be more inclusive of seniors' needs will be the path forward as we begin to see the baby boomer generation age and social norms change.

With this concluding statement, I would like to acknowledge that this thesis does not propose a one-size fits all approach, but rather an alternative approach to the neighbourhood block that is inclusive of our aging population. Institutional settings and aging at home (in all their varying forms) certainly hold a place in this world and require their own set of improvements to foster safe and comfortable environments for aging. However, as it stands today, these are the two most dominating options for seniors. This thesis is alternatively exploring the potential for a "Third Way." After all, we go through the rest of our lives with an abundance of options, why should that be any different just because we have aged?

Aging is certainly inevitable but moving to an institutional setting or living alone does not have to be. 


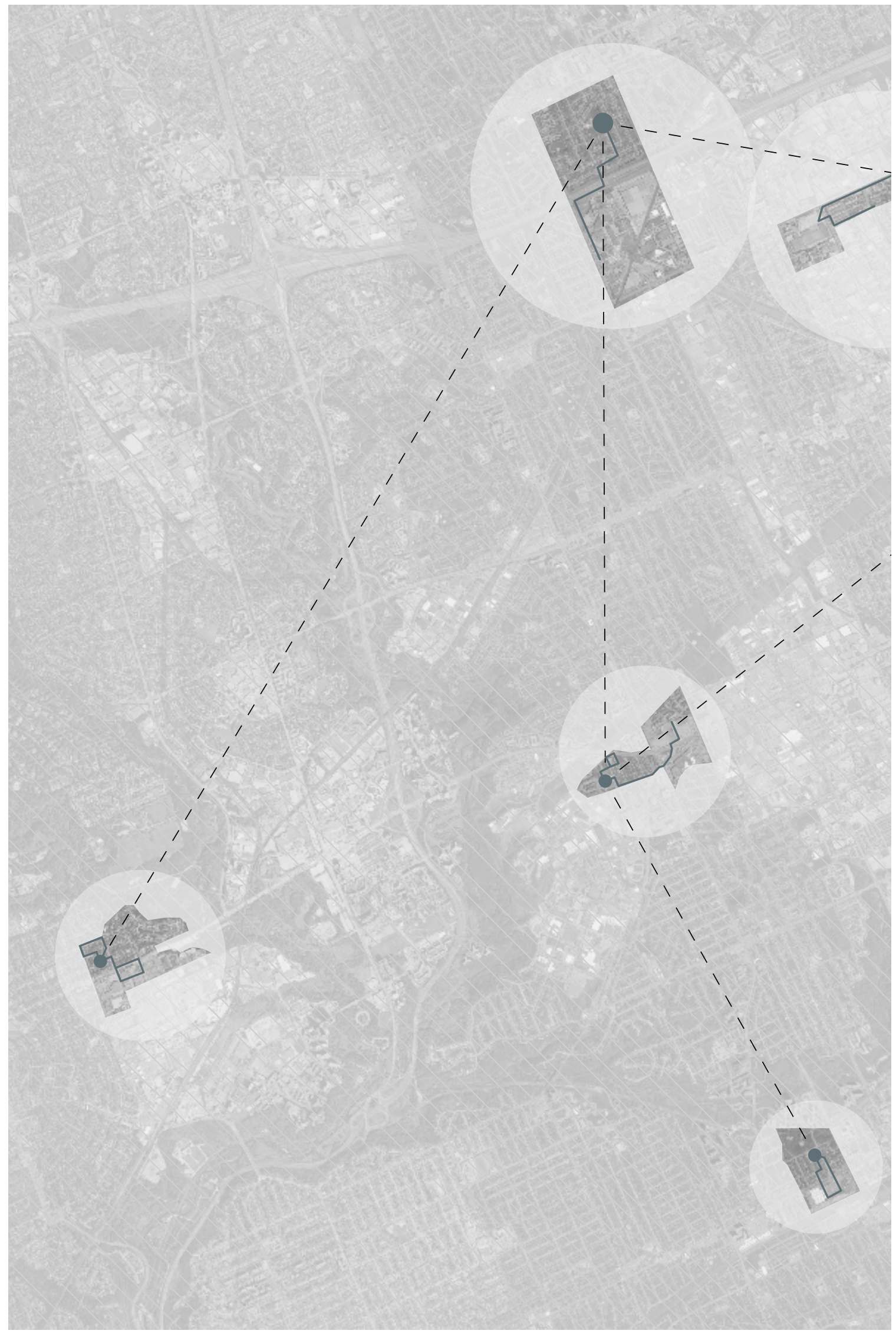

Fig. 56 / Toward an Age-Inclusive City: applying The Age-Inclusive Neighbourhood Model to neighbourhoods across Toronto. 


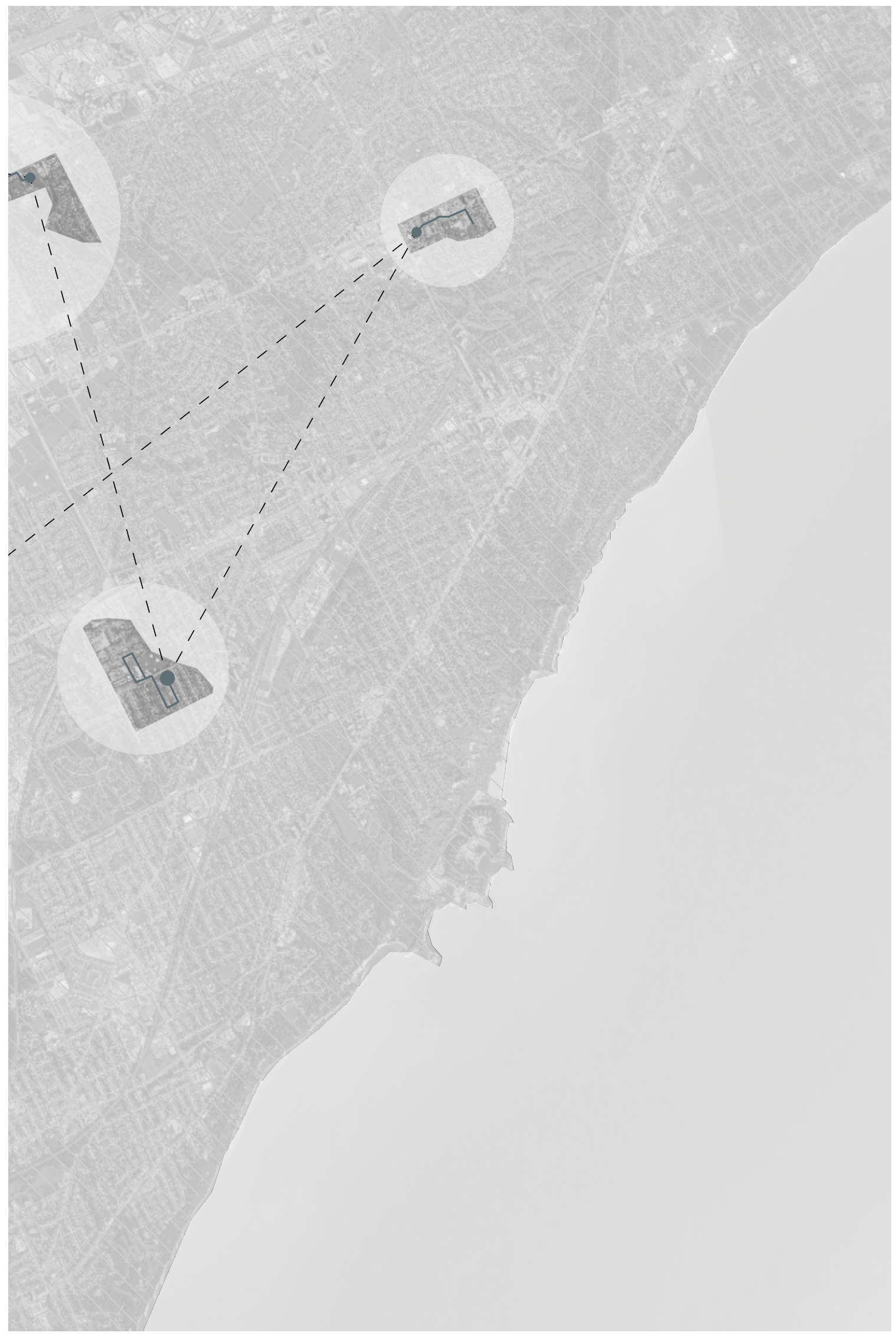

Fig. 57 / Toward an Age-Inclusive City: applying The Age-Inclusive Neighbourhood Model to neighbourhoods across Toronto. 


\section{Bibliography}

\section{PRINT}

Amabile, Michael et al. Cities Alive: Designing for ageing communities. London: Arup, 2019.

Blanchard, Janice M. "Aging in Community: The Communitarian Alternative to Aging in Place, Alone," Generations 37, No. 4 (2013).

Blanchard, Janice M., and William H. Thomas. "Moving Beyond Place: Aging in Community." Generations 33, No. 2 (2009).

Bucknell, Alice. "Aging in Place: For America's Older Adults, Access to Housing Is a Question of Race and Class." Harvard Graduate School of Design (2019).

City of Toronto. Toronto Seniors Strategy 2.0, 2018, 1-54.

City of Toronto. Toronto Strong Neighbourhoods Strategy, 1-44.

Davies, Robert. "Pandemic Effect: Long-Term Care Homes," Canadian Architect, August 2020, 22.

Dehaene, Michiel and Lieven De Cauter, eds. Heterotopia and the City: Public space in a postcivil society. London and New York: Routledge, 2008.

Federation of Canadian Municipalities. Seniors and Housing: The Challenge Ahead. (2015): 12.

Forsyth, Ann et al. "Improving housing and neighbourhoods for the vulnerable: older people, small households, urban design, and planning." URBAN DESIGN International 24, 171-186 (2019): 1-16.

Foucault, Michel, and Jay Miskowiec. Of Other Spaces. The Johns Hopkins University Press, 1986.

Handler, Sophie. An Alternative Age-Friendly Handbook. The University of Manchester Library, 2014.

McHugh, Patricia, and Alex Bozikovic. Toronto Architecture: A City Guide. Toronto: Penguin Random House, 2017. 

reveal tensions in public reaction to a photographic essay of eldercare staff and older adults." Journal of Aging Studies 48 (2019): 17-24.

Simpson, Deane. Young-Old: Urban Utopias of an Aging Society. Zürich: Lars Müller Publishers, 2015.

Verderber, Stephen. Sprawling Cities and Our Endangered Public Health. London and New York: Routledge, 2012.

World Health Organization. Global Age-friendly Cities: A Guide (2007).

World Health Organization. Global Age-Friendly Cities Project (2020).

WEB

Andrew-Gee, Eric and Laura Stone. "Understaffing turned seniors' homes into COVID-19 danger zones, health workers say. What can be done to fix that?" The Globe and Mail. August 10, 2020. https:// www.theglobeandmail.com/canada/article-understaffing-turned-seniors-homes-into-covid-19-danger-zones-health/. (accessed March 21, 2021).

"Bartley Towns in North York." Condos Deal. https://www.condosdeal.com/bartley-towns-in-north-york/. (accessed March 21, 2021).

Bentley, Chris. "Why More Seniors Are Forming Their Own 'Villages.” Bloomberg CityLab. September 17, 2015. https://www. bloomberg.com/news/articles/2015-09-17/to-age-in-place-more-seniors-are-forming-their-own-villages. (accessed March 21, 2021).

Botek, Anne-Marie. "Combatting the Epidemic of Loneliness in Seniors.” Aging Care. https:/www.agingcare.com/Articles/loneliness-in-the-elderly-151549.htm. (accessed March 21, 2021).

Bozikovic, Alex et al. "The 15-minute city aims to build more livable neighbourhoods. In Canada, only 23 per cent of urban dwellers live in this type of area." The Globe and Mail, November 23, 2020. https://www.theglobeandmail.com/canada/article-when-it-comes-toliveable-neighbourhoods-theres-a-wide-divide-in/. (accessed March 21, 2021) 
Bozikovic, Alex. "Yes, in my backyard: How urban planning must shift to meet our postpandemic challenges." The Globe and Mail, March 6, 2021. https://www.theglobeandmail.com/opinion/articleyes-in-my-backyard-how-urban-planning-must-shift-to-meet-our/. (accessed March 21, 2021).

Canadian Institute for Health Information. Pandemic Experience in the Long-Term Care Sector: How Does Canada Compare With Other Countries? Ottawa, ON: CIHI; 2020.

Canada Mortgage and Housing Corporation. Housing a Senior Population: The Economic and Social Benefits. March 31, 2018. https://www.cmhc-schl.gc.ca/en/developing-and-renovating/accessible-adaptable-housing/aging-in-place/economic-social-benefits-of-seniors-your-community. (accessed March 21, 2021).

City of Toronto. "104-110 Bartley Drive - Zoning By-law Amendment Application - Final Report.” June 15, 2018. https://www. toronto.ca/legdocs/mmis/2018/ny/bgrd/backgroundfile-117055.pdf. (accessed March 21, 2021).

City of Toronto. Neighbourhood Improvement Area Profiles. https:// www.toronto.ca/city-government/data-research-maps/neighbourhoods-communities/nia-profiles/. (accessed March 21, 2021).

City of Toronto. "78 Tisdale Avenue - Zoning Amendment and Draft Plan of Subdivision Applications - Final Report.” September 26, 2016. https:/www.toronto.ca/legdocs/mmis/2016/ny/bgrd/backgroundfile-96820.pdf. (accessed March 21, 2021).

"Deane Simpson." Architecture, Design and Conservation. https:// adk.elsevierpure.com/en/persons/deane-simpson\#:- :text=Deane $\% 20$ Simpson\%20is\%20an\%20architect,program\%20Urbanism\%20 and\%20Societal\%20Change. (accessed March 21, 2021).

"Designing Senior Housing for Safe Interaction: The Role of Architecture in Fighting COVID-19.” Mass Design Group. July 8, 2020. https://massdesigngroup.org/sites/default/files/multiple-file/2020-07/ Designing\%20Senior\%20Housing\%20for\%20Safe\%20Interaction. pdf. (accessed March 21, 2021).

Forsyth, Ann. http://annforsyth.net/. (accessed March 21, 2021). 

ternational Observatory on Social Housing. https://internationalsocialhousing.org/2017/05/29/learning-best-practices-in-housing-for-theelderly-from-the-dutch/. (accessed March 21, 2021).

Ireland, Nicole and Natalie Kalata. "As COVID-19 exposes long-term care crisis, efforts grow to keep more seniors at home." CBC News. February 03, 2021. https://www.cbc.ca/news/canada/toronto/covidontario-government-home-care-long-term-care-1.5897858. (accessed March 21, 2021).

Janes, Julia. "Mapping Aging in Place in a Changing Neighbourhood." Neighbourhood Change. University of Toronto, May 2008. http://neighbourhoodchange.ca/wp-content/uploads/2011/06/McDonald-2008-Aging-in-Place-neighbourhoods.pdf. (accessed March $21,2021)$.

Jones, Alexandra Mae. "Facing another retirement home lockdown, 90-year-old chooses medically assisted death." CTV News. November 19, 2020. https://www.ctvnews.ca/health/facing-another-retirement-home-lockdown-90-year-old-chooses-medically-assisted-death-1.5197140. (accessed January 11, 2021).

Kolson Hurley, Amanda. "Deane Simpson's "Young-Old."” Architect Magazine. September 23, 2015. https://www.architectmagazine. $\mathrm{com} /$ practice/deane-simpsons-young-old_o\#: - :text=In $\% 20$ his $\% 20$ new $\% 20$ book\%2C\%20Deane,life\%20phase\%2C\%20also \%20 known\%20as. (accessed January 11, 2021).

Loriggio, Paola. "Ontario long-term care residents describe devastating impact of isolation during COVID-19 pandemic." Global News. January 21, 2021. https://globalnews.ca/news/7591444/coronavirus-ontario-long-term-care-homes-seniors-isolation/. (accessed March 21, 2021).

McBride, Jason. "Houses of Horror." Toronto Life. November 11, 2020. https://torontolife.com/city/how-ontarios-long-term-carehomes-became-houses-of-horror/. (accessed March 21, 2021).

Morgenroth, Lisa and Michael Hanley. "On Campus and in the Community: How Higher Education Can Inform Seniors Housing Models." Gensler. 2015. https://www.gensler.com/uploads/document/425/file/senior-housing-higher-education-models.pdf. (accessed March 21, 2021). 
National Institute on Aging. Social Isolation, loneliness in older people pose health risks. April 23, 2019. https:/www.nia.nih.gov/news/ social-isolation-loneliness-older-people-pose-health-risks. (accessed March 21, 2021).

Robert Wood Johnson Foundation. The Green House Project. https:// www.rwjf.org/en/how-we-work/grants-explorer/featured-programs/ the-green-house-project.html (accessed March 21, 2021).

Shafaieh, Charles. "A radical transformation in building and designing for health is underway - but not everyone will benefit equally." Harvard Graduate School of Design (2020).

Sinha, Samir. "The post-pandemic future: We will stop warehousing older people in care homes." Toronto Life. August 19, 2020. https:// torontolife.com/city/the-post-pandemic-future-we-will-stop-warehousing-older-people-in-care-homes/. (accessed March 21, 2021).

"Social Complex in Alcabideche / Guedes Cruz Arquitectos." ArchDaily. https://www.archdaily.com/591843/social-complex-in-alcabideche-guedes-cruz-arquitectos (accessed March 21, 2021).

Statistics Canada. 2014. Baby-boomers accelerate Canada's aging population. Statistics Canada Catalogue no. 91-215-X. Ottawa. Version updated November 2015. Ottawa. https://www150.statcan.gc.ca/n1/ pub/91-215-x/2014000/part-partie2-eng.htm (accessed March 21, 2021).

Statistics Canada. 2011. Living arrangements of seniors. Census Program. Ottawa. Version updated July 2018. Ottawa. https://www12. statcan.gc.ca/census-recensement/2011/as-sa/98-312-x/98-312x2011003_4-eng.cfm (accessed March 21, 2021).

Statistics Canada. 2019. Population growth in Canada's urban areas fuelled by permanent and temporary immigration. The Daily. Ottawa. Version updated: March 2019. Ottawa. https://www150.statcan.gc. ca/n1/daily-quotidien/190328/dq190328b-eng.htm (accessed March 21, 2021).

Statistics Canada. 2020. Survey of Financial Security, 2019. The Daily. Version updated: December 2020. Ottawa. https://www150.statcan. gc.ca/n1/daily-quotidien/201222/dq201222b-eng.htm. (accessed March 21, 2021). 

Radio. March 31, 2010. https://www.npr.org/templates/story/story. php?storyId=125389925. (accessed March 21, 2021).

"Victoria Village - Neighbourhood Guide." Neighbourhood Guide. https://www.neighbourhoodguide.com/toronto/north-york/victoria-village/?wplpage $=2$. $($ accessed March 21, 2021)

Wilkes, Dave. "BILD: Canadians look at aging in place." Toronto Sun. February 05, 2021. https://torontosun.com/life/homes/bild-canadians-look-at-aging-in-place. (accessed March 21, 2021). 
Fig. 01-03: Multiple diagrams.

Canada Mortgage and Housing Corporation. Housing a Senior Population: The Economic and Social Benefits. March 31, 2018. https://www.cmhc-schl.gc.ca/en/developing-and-renovating/accessible-adaptable-housing/aging-in-place/economic-social-benefits-of-seniors-your-community. (accessed March 21, 2021).

Fig. 04: Graphic by Author.

Fig. 05: Graphic by Author.

Data from: "These are the GTA long-term care homes hardest-hit by COVID-19." CBC News. May 23, 2020. https://www.cbc.ca/news/ canada/toronto/gta-covid19-ltc-data-1.558111. (accessed March 21, 2021).

Fig. 06: Graphic by Author.

Data from: Yang, Jennifer. "Toronto's COVID-19 divide: The city's northwest corner has been 'failed by the system." Toronto Star. June 28, 2020. https://www.thestar.com/news/gta/2020/06/28/torontoscovid-19-divide-the-citys-northwest-corner-has-been-failed-by-thesystem.html. (accessed January 11, 2021).

Fig. 07: Graphic by Author.

Fig. 08: Graphic by Author.

Images from: Google Maps, 2020.

Fig. 09: Graphic by Author.

Images from: Google Maps, 2019.

Fig. 10: Graphic by Author.

Images from: Google Maps, 2018. 
Fig. 11: Annotated by Author.

"Long-Term Care Homes vs. Retirement Homes vs. Home Care in Ontario." Closing the Gap Healthcare. February 08, 2019. https:// www.closingthegap.ca/long-term-care-homes-vs-retirement-homes-vshome-care-in-ontario/. (accessed March 21, 2021).

Fig. 12: World Health Organization. Global Age-friendly Cities: A Guide (2007).

Fig. 13: Graphic by Author. Multiple sources, left to right:

City of Toronto. Toronto Seniors Strategy 2.0, 2018, 1-54.

World Health Organization. Global Age-friendly Cities: A Guide (2007).

Fig. 14: Graphic by Author.

Data from: City of Toronto. Neighbourhood Improvement Area Profiles. https://www.toronto.ca/city-government/data-research-maps/neighbourhoods-communities/nia-profiles/. (accessed March 21, 2021).

Fig. 15: Annotated by Author.

Image from: Google Maps, 2021.

Fig. 16: Graphic by Author.

Fig. 17: Graphic by Author.

Reference text: Forsyth, Ann et al. "Improving housing and neighbourhoods for the vulnerable: older people, small households, urban design, and planning." URBAN DESIGN International 24, 171-186 (2019): 1-16.

Fig. 18: "Social Complex in Alcabideche / Guedes Cruz Arquitectos." ArchDaily. https://www.archdaily.com/591843/social-complex-in-alcabideche-guedes-cruz-arquitectos (accessed March 21, 2021).

Fig. 19: Annotated by Author.

DVA Associates. "Hogeweyk." https://hogeweyk.dementiavillage. com/. (accessed March 21, 2021). 
Fig. 20: Multiple Images. From: https://www.thevillages.com/ (accessed March 21, 2021).

Fig. 21: https://www.thevillages.com/ (accessed March 21, 2021).

Fig. 22: Graphic by Author.

Fig. 23: Graphic by Author.

Image from: Google Maps, 2021.

Fig. 24-33: Annotated by Author.

Images from: Google Maps, 2020.

Fig. 34: City of Toronto. "104-110 Bartley Drive - Zoning Bylaw Amendment Application - Final Report.” June 15, 2018. https:/www.toronto.ca/legdocs/mmis/2018/ny/bgrd/backgroundfile-117055.pdf. (accessed March 21, 2021).

Fig. 35: City of Toronto. "104-110 Bartley Drive - Zoning Bylaw Amendment Application - Final Report.” June 15, 2018. https:/www.toronto.ca/legdocs/mmis/2018/ny/bgrd/backgroundfile-117055.pdf. (accessed March 21, 2021).

Fig. 36: Graphic by Author.

Fig. 37: Annotated by Author.

City of Toronto. "104-110 Bartley Drive - Zoning By-law Amendment Application - Final Report.” June 15, 2018. https://www. toronto.ca/legdocs/mmis/2018/ny/bgrd/backgroundfile-117055.pdf. (accessed March 21, 2021).

Fig. 38: Graphic by Author.

Fig. 39: Annotated by Author.

City of Toronto. "104-110 Bartley Drive - Zoning By-law Amendment Application - Final Report.” June 15, 2018. https://www. toronto.ca/legdocs/mmis/2018/ny/bgrd/backgroundfile-117055.pdf. (accessed March 21, 2021).

Fig. 40: Graphic by Author. 
Fig. 41-50: Graphics by Author.

Fig. 51: Graphic by Author.

Image from: Google Maps, 2021.

Fig. 52-54: Graphic by Author.

Fig. 55: Graphic by Author. Multiple sources, left to right:

City of Toronto. Toronto Seniors Strategy 2.0, 2018, 1-54.

World Health Organization. Global Age-friendly Cities: A Guide (2007).

Fig. 56-57: Graphics by Author. 


\section{APPENDICES}

A. Excerpts from: Global Age-Friendly Cities: A Guide

- Age-friendly outdoors spaces and buildings checklist

- Age-friendly transportation checklist

- Age-friendly housing checklist

B. Excerpts from: Toronto Seniors Strategy 2.0

Annotations by Author. 


\section{Age-friendly outdoor spaces and buildings checklist}

\section{Environment}

- The city is clean, with enforced regulations limiting noise levels and unpleasant or harmful odours in public places.

\section{Green spaces and walkways}

- There are well-maintained and safe green spaces, with adequate shelter, toilet facilities and seating that can be easily accessed.

- Pedestrian-friendly walkways are free from obstructions, have a smooth surface, have public toilets and can be easily accessed.

\section{Outdoor seating}

- Outdoor seating is available, particularly in parks, transport stops and public spaces, and spaced at regular intervals; the seating is well-maintained and patrolled to ensure safe access by all.

\section{Pavements}

- Pavements are well-maintained, smooth, level, non-slip and wide enough to accommodate wheelchairs with low curbs that taper off to the road.

- Pavements are clear of any obstructions (e.g. street vendors, parked cars, trees, dog droppings, snow) and pedestrians have priority of use.

\section{Roads}

- Roads have adequate non-slip, regularly spaced pedestrian crossings ensuring that it is safe for pedestrians to cross the road.

- Roads have well-designed and appropriately placed physical structures, such as traffic islands, overpasses or underpasses, to assist pedestrians to cross busy roads.

- Pedestrian crossing lights allow sufficient time for older people to cross the road and have visual and audio signals. 
Traffic

- There is strict enforcement of traffic rules and regulations, with drivers giving way to pedestrians.

\section{Cycle paths}

- There are separate cycle paths for cyclists.

\section{Safety}

- Public safety in all open spaces and buildings is a priority and is promoted by, for example, measures to reduce the risk from natural disasters, good street lighting, police patrols, enforcement of by-laws, and support for community and personal safety initiatives.

\section{Services}

- Services are clustered, located in close proximity to where older people live and can be easily accessed (e.g. are located on the ground floor of buildings).

- There are special customer service arrangements for older people, such as separate queues or service counters for older people.

\section{Buildings}

- Buildings are accessible and have the following features:

- elevators

- ramps

- adequate signage

- railings on stairs

- stairs that are not too high or steep

- non-slip flooring

- rest areas with comfortable chairs

- sufficient numbers of public toilets.

\section{Public toilets}

- Public toilets are clean, well-maintained, easily accessible for people with varying abilities, well-signed and placed in convenient locations. 


\section{Age-friendly transportation checklist}

\section{Affordability}

- Public transportation is affordable to all older people.

- Consistent and well-displayed transportation rates are charged.

\section{Reliability and frequency}

- Public transport is reliable and frequent (including services at night and at weekends).

\section{Travel destinations}

- Public transport is available for older people to reach key destinations such as hospitals, health centres, public parks, shopping centres, banks and seniors' centres.

- All areas are well-serviced with adequate, well-connected transport routes within the city (including the outer areas) and between neighbouring cities.

- Transport routes are well-connected between the various transport options.

\section{Age-friendly vehicles}

- Vehicles are accessible, with floors that lower, low steps, and wide and high seats.

\section{Specialized services}

- Sufficient specialized transport services are available for people with disabilities.

\section{Priority seating}

- Priority seating for older people is provided, and is respected by other passengers.

\section{Transport drivers}

- Drivers are courteous, obey traffic rules, stop at designated transport stops, wait for passengers to be seated before driving off, and park alongside the curb so that it is easier for older people to step off the vehicle.

\section{Safety and comfort}

- Public transport is safe from crime and is not overcrowded.

\section{Transport stops and stations}

- Designated transport stops are located in close proximity to where older people live, are provided with seating and with shelter from the weather, are clean and safe, and are adequately lit.

- Stations are accessible, with ramps, escalators, elevators, appropriate platforms, 


\section{Information}

- Information is provided to older people on how to use public transport and about the range of transport options available.

- Timetables are legible and easy to access.

- Timetables clearly indicate the routes of buses accessible to disabled people.

\section{Community transport}

- Community transport services, including volunteer drivers and shuttle services, are available to take older people to specific events and places.

\section{Taxis}

- Taxis are affordable, with discounts or subsidized taxi fares provided for older people with low incomes.

- Taxis are comfortable and accessible, with room for wheelchairs and/or walking frames.

- Taxi drivers are courteous and helpful.

\section{Roads}

- Roads are well-maintained, wide and well-lit, have appropriately designed and placed traffic calming devices, have traffic
- Roads are free of obstructions that might block a driver's vision.

- The rules of the road are strictly enforced and drivers are educated to follow the rules.

\section{Driving competence}

- Refresher driving courses are provided and promoted.

\section{Parking}

- Affordable parking is available.

- Priority parking bays are provided for older people close to buildings and transport stops.

- Priority parking bays for disabled people are provided close to buildings and transport stops, the use of which are monitored.

- Drop-off and pick-up bays close to buildings and transport stops are provided for handicapped and older people. 


\section{Age-friendly housing checklist}

Affordability

- Affordable housing is available for all older people.

\section{Essential services}

- Essential services are provided that are affordable to all.

\section{Design}

- Housing is made of appropriate materials and well-structured.

- There is sufficient space to enable older people to move around freely.

- Housing is appropriately equipped to meet environmental conditions (e.g. appropriate air-conditioning or heating).

- Housing is adapted for older people, with even surfaces, passages wide enough for wheelchairs, and appropriately designed bathrooms, toilets and kitchens.

\section{Modifications}

- Housing is modified for older people as needed.

- Housing modifications are affordable.

- Equipment for housing modifications is readily available.

- Financial assistance is provided for home modifications.

- There is a good understanding of how housing can be modified to meet the needs of older people.

\section{Maintenance}

- Maintenance services are affordable for older people.

- There are appropriately qualified and reliable service providers to undertake maintenance work.

- Public housing, rented accommodation and common areas are well-maintained. 
Ageing in place

- Housing is located close to services and facilities.

- Affordable services are provided to enable older people to remain at home, to "age in place".

- Older people are well-informed of the services available to help them age in place.

\section{Community integration}

- Housing design facilitates continued integration of older people into the community.

\section{Housing options}

- A range of appropriate and affordable housing options is available for older people, including frail and disabled older people, in the local area.

- Older people are well-informed of the available housing options.
- Sufficient and affordable housing dedicated to older people is provided in the local area.

- There is a range of appropriate services and appropriate amenities and activities in older people's housing facilities.

- Older people's housing is integrated in the surrounding community.

\section{Living environment}

- Housing is not overcrowded.

- Older people are comfortable in their housing environment.

- Housing is not located in areas prone to natural disasters.

- Older people feel safe in the environment they live in.

- Financial assistance is provided for housing security measures. 
Appendix B

\section{INTEGRATED CITY SENIORS HOUSING AND SERVICES ENTITY}

\section{RECOMMENDATION 1:}

The City of Toronto will initiate a process to develop a seniors housing and services entity at the City dedicated to taking a service system management approach to the needs of all seniors and integrating City services for seniors.

The overwhelming consensus at the Accountability Table resulting from the needs and concerns identified through the community engagement process is this: the way the City currently organizes its housing and services for seniors does not meet their needs now and this problem will be exacerbated over the next 10 to 15 years.

In consultation after consultation, Toronto seniors and caregivers spoke about the difficulty and frustration of navigating an increasingly complex and siloed government service system. This includes federal pension and income security programs, provincial primary healthcare, hospital and home and community care, municipal services and programs and those provided by the community-based not-for-profit sector (or 'for public benefit' sector). The City needs an organizational approach that better meets the needs of seniors and caregivers. At the municipal level there are over 40 services, programs and initiatives for seniors delivered across 14 City Divisions and Agencies.

A single division or entity at the City dedicated to integrating seniors housing and services will provide, for the first time, an identifiable entity for Toronto to receive and leverage funds from provincial and federal governments. This recommendation recognizes that the status quo is not an effective administrative $\$$ structure to meet the needs of our ageing population. A number of other WHO Age-Friendly cities have stand-alone seniors service departments. In January 2017, the province elevated the Ontario Seniors 
Appendix B

\section{RECOMMENDATION 3:}

The City of Toronto in partnership with Toronto Community Housing will seek provincial funding for additional Seniors Active Living Centres in Toronto.

In the 2017 Ontario Budget, the government announced funding to create up to 40 new Seniors Active Living Centres (SALCs), formerly known as initiatives that benefit seniors. It does not fund capital expenditures such as the purchase or building of facilities or renovations to existing buildings. Under the Seniors Active Living Centres Act, 2017, the province requires municipalities to provide a minimum
20 percent of the net annual cost of maintaining and operating individual SALC programs. These funds contribute to programs and services in existing facilities.

To date, eight of the new 40 SALCs that have been announced thus far are to be located with the City of Toronto and led by community-based organizations and agencies. 
Appendix B

\section{RECOMMENDATION 6:}

The City of Toronto will work with the Province of Ontario and community partners to develop a Toronto Caregivers Strategy with an emphasis on the needs of senior caregivers.

According to the Change Foundation, family caregivers represent almost 30 per cent of Ontarians who provide unpaid care to those who need assistance due to a health condition, disability, or challenges related to aging (A Profile of Family Caregivers in Ontario, 2016). Many of these caregivers are working full-time and/ or seniors. Caregiving is rewarding but it can also be emotionally, physically, and financially stressful. Many caregivers feel socially isolated and unsupported.
Consistent with Council direction to support caregivers [2017.CD17.9], the City and its partners can bring its resources to bear to better support these family caregivers with information, respite, transportation and financial supports, and improve access to other existing supports and services that may be available but unknown to caregivers. This will relieve caregiver stress, enhance caregiver resilience and expand social support and participation. 


\section{RECOMMENDATION 7:}

The City of Toronto will consider senior-friendly outdoor fitness equipment in the design and refurbishment of parks.

Cities around the world are responding to the changing needs and preferences of seniors and older adults by expanding the range of activities designed for them. The City of Toronto began installing public outdoor fitness equipment in parks several years ago with all ages in mind. Installing outdoor fitness equipment has been recognized as a global best practice to promote active aging and improved health and wellbeing outcomes, and seniors and older adults have embraced these facilities in Toronto. New outdoor fitness equipment will be considered in the design and refurbishment of parks throughout Toronto.

\section{RECOMMENDATION 8:}

The City of Toronto will work with Toronto Community Housing and FoodShare to establish healthy food access initiatives that are accessible to seniors living in social housing through Toronto Public Health.

The Mobile Good Food Market is a City partnership with FoodShare to bring fresh, healthy food to lowincome communities or communities with low access to healthy food options. Some market stops serve primarily seniors populations. In addition, the Bulk Food Buying Club is an initiative in collaboration with FoodReach that allows community members to purchase healthy, fresh food in bulk at good prices for local distribution. The Food Strategy is partnering with Toronto Community Housing to pilot this initiative to bring affordable, fresh healthy food to residents living in a mixed housing complex. 


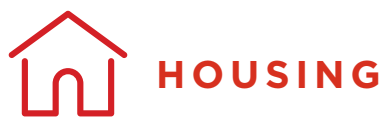

\section{RECOMMENDATION 9:}

The City of Toronto will develop Housing Opportunities Toronto: Housing Action Plan (2020-2030) to account for the evolving demographics and needs of older Torontonians over the next decade, including those in informal retirement communities, including apartment buildings or housing developments that house a high concentration of seniors

Toronto's Housing Action Plan (2020-2030), co-led by the Affordable Housing Office (AHO) and Shelter, Support and Housing Administration (SSHA), guides the City's housing and homelessness initiatives, policies, and programs from 2020 to 2030 . This [ plan will address the increasing need for affordable and accessible seniors housing across the City. It will consider the needs of the significant number of seniors living in older apartment buildings or housing developments that were not designed with seniors in mind and can perpetuate physical and social isolation. A one-stop seniors entity at the City will foster stronger and closer relationships with the five
Local Health Integration Networks that operate in Toronto. Additionally, proactively coordinating the City's services for seniors under one entity will support the work being done to improve services for seniors living in Toronto Community Housing through the implementation of Tenants First. The creation of a seniors housing and services entity at the City will help Toronto seniors and caregivers to knit together the complex terrain of municipal programs and services, provincial home and community care and other government-funded services for seniors in a similar way that the City has already done with the creation of its Children's Services Division. 


\section{RECOMMENDATION 10:}

The City of Toronto will address the specific and growing needs of older Torontonians by continuing to create new affordable housing and fund housing repairs and accessibility modifications for seniors by delivering federal-provincial-City funding and City incentives.

As of 2018, about one-third of households on the City's social housing waitlist are seniors. The City needs to scale up its efforts to create affordable housing for low-income seniors and provide some relief to the social housing waitlist. The Affordable Housing
Office will deliver and report on the impact of federal, provincial and City investments on the creation of new seniors rental homes and repairs/accessibility modifications for senior homeowners and renters.

\section{RECOMMENDATION 11:}

The City of Toronto will seek provincial funding under the Seniors Community Grant Program to pilot a HomeShare program in Toronto to connect overhoused seniors with students and others.

Some Toronto seniors find themselves overhoused. Some assistance with light household tasks and companionship would help them to more successfully age in place.

It is estimated that a significant number of seniors are overhoused living in single family dwellings with three or more bedrooms in the Greater Toronto and Hamilton
Area (GTHA). Trends like these have led to the coining of terms like "empty bedrooms". This program would facilitate matches between interested seniors and University graduate students seeking affordable housing. Successful matches could help to promote social connectedness, intergenerational and linguistic connections as well as promote financial independence and personal autonomy for seniors.

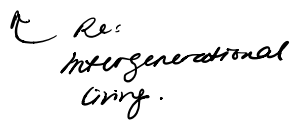


Appendix B

\section{RECOMMENDATION 14:}

The City of Toronto will amend the Official Plan to recognize the City's commitment to age-friendly principles.

The global age-friendly community movement, which was launched in Canada as a series of pilots just over a decade ago, has since been enthusiastically adopted in more than 850 communities across the country. Research by the Canadian Urban Institute (CUI) in 2016 found that although the age-friendly concept is an effective tool to engage with seniors, municipal commitments to becoming age-friendly are not yet reflected in land use plans and policies as a way to influence the layout of neighbourhoods or the design of parks, streets and other essential elements of the public realm.

The City of Toronto has the opportunity to become the first major city in Ontario to take this step.

Earlier this year, Council directed the Chief Planner \& Executive Director, City Planning to make an explicit acknowledgement of Council's commitment to being an age-friendly city in its new Official Plan when the review process begins in 2018 .

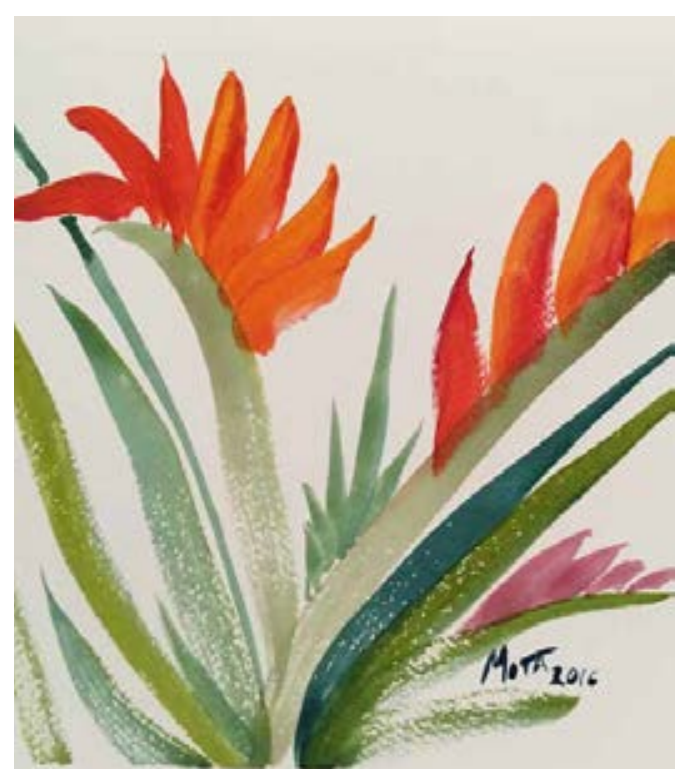

Art created by person living with dementia 
Appendix B

\section{RECOMMENDATION 15:}

The City of Toronto will negotiate the use of Section 37 benefits to develop new neighbourhood facilities, including those around apartment buildings or housing developments that house a high concentration of seniors, to meet the needs of seniors as appropriate.

As indicated in the recently updated Neighbourhood Profiles, the demographic and economic circumstances of neighbourhoods across the city vary considerably. Although every effort is made to ensure that affordable housing and civic resources such as schools, libraries and community centres are equitably distributed across the city, changing demand for City services tends to move faster than the process of creating or improving City facilities.

As the population of seniors continues to increase at different rates throughout Toronto, the use of Section 37 of the Ontario Planning Act presents an opportunity to augment or improve municipal assets directed to the needs of seniors through the development approvals process. Section 37 allows the City to negotiate with private developers for pay for some kind of community benefit in exchange for exceeding density limits in the zoning bylaw. There are currently many clusters of apartment buildings and housing developments that house a high concentration of seniors. Analyses will be undertaken to map high-density clusters against currently available municipal assets to identify geographic targets for Section 37 benefits. 
Appendix B

\section{RECOMMENDATION 18:}

As part Toronto's Vision Zero Road Safety Plan, the City will identify and install additional Seniors Safety Zones to promote the safety of seniors on City streets.

Seniors Safety Zones are part of Toronto's Vision Zero Road. They include traffic safety measures designed to raise the visibility of seniors - as well as giving them extended crossing times - to safely get across the street. Further investigations will be conducted to determine the need and feasibility for installing mid-block signals and/or traffic calming measures.
Initially, the priority for identifying potential Seniors Safety Zones was on those crossings where pedestrian fatalities and collision rates involving older adults are unusually high. Recommendation 18 would involve installing Seniors Safety Zones in neighbourhoods with a disproportionate number of seniors and with wider rights of way that result in higher vehicular speeds.

\section{RECOMMENDATION 19:}

The City of Toronto will construct new sidewalks on roads where they are missing to improve walkability, mobility and accessibility of city streets.

Constructing sidewalks where they are missing completes gaps in Toronto's walking network, and helps all residents and visitors connect to transit and neighbourhood and amenities. Sidewalks are the most basic form of infrastructure to ensure safe and comfortable walking conditions. Streets without sidewalks are a barrier to accessibility. Safe walking opportunities can reduce inequality by enabling individuals without motor vehicles, such as older adults, children, and many low-income families, to more easily access goods and services. 
"Good design for the most vulnerable is good design for everyone." MASS Design Group 